\title{
An inside-out perspective to valuation
}

\author{
Citation for published version (APA):
}

Ihl - Deviv'e, O. (2021). An inside-out perspective to valuation: from valuation inputs and institutional factors to valuation accuracy and precision. [Doctoral Thesis, Maastricht University]. ProefschriftMaken. https://doi.org/10.26481/dis.20210616oi

Document status and date:

Published: 01/01/2021

DOI:

10.26481/dis.20210616oi

Document Version:

Publisher's PDF, also known as Version of record

\section{Please check the document version of this publication:}

- A submitted manuscript is the version of the article upon submission and before peer-review. There can be important differences between the submitted version and the official published version of record.

People interested in the research are advised to contact the author for the final version of the publication, or visit the DOI to the publisher's website.

- The final author version and the galley proof are versions of the publication after peer review.

- The final published version features the final layout of the paper including the volume, issue and page numbers.

Link to publication

\footnotetext{
General rights rights.

- You may freely distribute the URL identifying the publication in the public portal. please follow below link for the End User Agreement:

www.umlib.nl/taverne-license

Take down policy

If you believe that this document breaches copyright please contact us at:

repository@maastrichtuniversity.nl

providing details and we will investigate your claim.
}

Copyright and moral rights for the publications made accessible in the public portal are retained by the authors and/or other copyright owners and it is a condition of accessing publications that users recognise and abide by the legal requirements associated with these

- Users may download and print one copy of any publication from the public portal for the purpose of private study or research.

- You may not further distribute the material or use it for any profit-making activity or commercial gain

If the publication is distributed under the terms of Article $25 \mathrm{fa}$ of the Dutch Copyright Act, indicated by the "Taverne" license above, 


\section{An inside-out perspective to valuation: from valuation inputs and institutional factors to valuation accuracy and precision}


(C) copyright Olga Ihl-Deviv'e, 2021

Printing: ProefschriftMaken || www.proefschriftmaken.nl ISBN: 978-94-6423-301-8

All rights reserved. No part of this publication may be reproduced, stored in a retrieval system or transmitted, in any form or by any means, electronic, mechanical, photocopying, recording or otherwise, without prior permission of the author or the copyright-owning journals for previous published chapters. 


\title{
An inside-out perspective to valuation: from valuation inputs and institutional factors to valuation accuracy and precision
}

\author{
Dissertation \\ to obtain the degree of Doctor at Maastricht University, \\ on the authority of the Rector Magnificus Prof.dr. Rianne M. Letschert \\ in accordance with the decision of the Board of Deans, \\ to be defended in public on \\ Wednesday $16^{\text {th }}$ of June 2021 at 16:00 hours.
}

by

Olga Ihl-Deviv'e 


\section{Supervisor}

Dr. Annelies Renders

\section{Assessment Committee}

Prof. Dr. Ann Vanstraelen (Chairperson)

Prof. Dr. Peter Sampers

Prof. Dr. Willem Buijink (Open Universiteit in Heerlen, Netherlands)

Prof. Dr. Wayne Landsman (University of North Carolina at Chapel Hill, United States) 


\section{Acknowledgements}

\section{"If you want to go fast, go alone. If you want to go far, go together." African proverb}

So many times did I picture myself writing my acknowledgments to then realize that this moment was "only" three dissertation chapters away. But not today, this time is different. And while I am predominantly filled with joy and happiness that I am finally writing the acknowledgements in my dissertation rather than in my head, I am also a little bit sad that this turbulent, educational, frustrating and rewarding $\mathrm{PhD}$ journey is coming to an end. Whatever PhD, personal or emotional stage I was in, I knew I could always count on quite some people to support me and give me that injection of positivity and good advice to keep me going. Hence, I would like to take this opportunity to express a couple of words of gratitude to people, who supported me along the way.

First and foremost, I would like to thank my supervisors, Annelies Renders and Mathijs van Peteghem. If there was an award for a "PhD student with the highest number of emails sent to supervisors", I would, with absolutely no doubt, be the big-time winner. I was debating whether I should refrain from mentioning the length of my emails, but that would not be the whole story. My supervisors were very lucky to have a PhD student who scores very high at both dimensions, the quantity and length of the emails sent. It is an incredible feeling to know that whether it is a "help", "I have a question", "what do you think?", "are you in the office?" to lately "zoom?" email, both of you would always find time for me to discuss my very urgent and important matters, despite your busy agendas. Thank you for your enormous support, encouragement, invaluable advice and remarkable patience.

Annelies, writing my master thesis on fair value accounting in the banking sector was one of the best decisions made so far. You have become my role model in so many respects, and there are so many things that I would like to thank you for. However, given my tendency to keep short stories long I will focus on the most important ones. I admire you for always keeping a cool head, seeing the bigger picture, decomposing the bigger problems into smaller achievable steps, while never losing sight of what is important. Whenever I would focus on higher level philosophical questions as to whether there is academic life for me after the $\mathrm{PhD}$, you managed to not only find the right motivational and encouraging words but also to redirect my energy towards a simple yet such a powerful strategy of taking one step at a time. Thank you for your unconditional support throughout my $\mathrm{PhD}$ process, and for helping me grow professionally and personally. I look forward to our research collaborations, coffee breaks, life talks and dance parties in the future. 
Mathijs, thank you for agreeing to supervise me, especially considering that my project was not quite within your research interests, at least not at the beginning. In the course of time, I could see that you also grew fond of warranted-multiple based valuation, and valuation and financial accounting in general ;-) But more than that, I could see how enthusiastic and genuinely interested you were when it came to my research ideas and projects. You always had an open ear for me to talk about research and what you could do to help me progress. Also, a big thank you for supporting me with various empirical and analyses-related matters, especially at times when I could not see a way out and was mentally preparing myself for a search of a new research question. Your analytical knowledge kit full of suggestions and considerations for different types of problems is truly impressive. I learnt a lot from you in many ways. Thank you for your admirable guidance and mentorship throughout my $\mathrm{PhD}$. I look forward to our coffee catch-ups and, of course, dance parties in the future.

I would also like to thank Wayne Landsman for providing me with an opportunity to visit the University of North Carolina at Chapel Hill. Those months were so insightful, challenging and enriching, and I am very grateful for this experience. Wayne, thank you for taking care of my well-being during the research visit (especially during the scary Dorian times), for your time and insightful discussions, and for your and Dena's very warm hospitality.

I also want to thank all members of my assessment committee, Ann Vanstraelen, Peter Sampers, Willem Buijink and Wayne Landsman for the evaluation of my dissertation and helpful comments and suggestions.

Next I would like to thank the "girls-only-office" crew. Britt, Raginee and Ulrike, I honestly don't know what I would do without you during my $\mathrm{PhD}$ journey, or to be precise without all those cookies and snacks, coffeelovers breaks, random sport activities in the office, and all the crazy and funny Snapchat moments with lots of laughter. Britta, thank you for introducing me to one of the greatest songs of all time, my life has definitely become way more wayhoooo since then, and for being there for me whenever I needed a timeout from work and a good chat about family or life in general. Thank you for pancake Wednesdays at Tribunal, our coffee and Snapchat breaks, and the good times in B2.23. Raginee, thank you for our research walks and talks, where we would discuss all sorts of things ranging from similarities of our families (grandmothers in particular) to how we will celebrate our first $\mathrm{A}^{+}$publication (or rather our strategies how to cope with all those setbacks on our way to that top publication). I hope I will see you at many conferences in the future, what a great (and, of course, productive) time we had at the seaside in Paphos! My friend, I also hope that you know that after our defenses, an intensive kicker course awaits us- I am not giving up on our kicker career yet! Ulrike, to be honest, it took me some time to get used to a colleague who would do some burpees and/or pushups in between meetings and calls, or who could stay concentrated for hours in a row. But it didn't take long until our legendary "Namaste 
my friend" video, hilarious but often also profound conversations, and fun times at doctoral consortiums and conferences (EAA PhD forum in Milan, the audit research session- just saying). Thank you for regularly checking up on me to see how I am doing, especially in the final stage of the $\mathrm{PhD}$ journey. You just knew too well how important those short cheer up messages were, when I was so close to permanently deleting the "diss_v10001_hopefully_final" file from my computer. Raginee and Ulrike, thank you for agreeing to be my paranymphs. Caren, even though strictly seen you are not part of the "girls-only-office" crew, our gang would not be complete without you. I appreciate that I could always come to you to talk about anything, your door was always open for me, irrespective of how busy you were. Thank you for your amazing and to the point advice for all kind of situations, for your kind and cheerful words whenever needed, and for visiting me in Aachen when I was not at my best.

I would further like to thank all my former and current colleagues of the Accounting and Information Management department of Maastricht University. Christoph, thank you for your monitoring walk-ins, which primarily served the purpose of motivating us to work hard (and secondarily to check if we had some nice cookies in the office). Thank you, Lars Hamers, for your positive vibes and the supply of good music, thanks to your "song of the week" emails we always stay tuned. Lei and Lu, thank you for the good times in B2.23, and the crash course on photoshopping and all the different selfie apps with their fascinating editing features- I definitely learnt a lot this evening. Katlijn, thank you for the great Eurovision evening, for your hospitality and for your office visits to check how my life was going. Patrick, thank you for the unforgettable lunch conversations, they certainly helped me to switch off from work for a bit (since my thoughts during lunches often revolved around the question of why the heck the topic was being discussed). Anant, thank you for your positive vibes in the department. A big thank you also goes to all other $\mathrm{PhD}$ students that accompanied me on my journey: Sophie, Nadine, Lena, Florian, Oscar, Simon, Harry, Lars Rieser, Paul, Yannik, Iver, and Benjamin. Thank you for the great lunches, pre-discussions, fun and delicious sushi evenings. A thank you also goes to all other members of the department, from whom I was able to learn a lot, be it during seminars, pre-discussions or, more importantly, department trips. Thank you, Ann, Frank, Alex, Roger, Harold, Rogier, Mark, Leon, Rick, Nick, Fynn, Banu, Isabella, Laury, Anke, Sacha, Sabine, Tanja, Miranda, Juliette and Elize.

There were of course many other great people that accompanied me on my $\mathrm{PhD}$ journey. A special thanks goes to the Limperg cohort- Mate, Alona and Razvan. Razvan, thank you for your very lively and rememberable explanation of the key message in Ball and Brown (1968). Every time I come across this reference, I have to think about your Ball $\&$ Brown moves on the dancefloor to show us the so famous price-earnings movements. Mate, thank you for organizing all those social after-class activities, which often started with "let's have an after-class drink" and ended up in midnight in-depth discussions about the meaning of life, and what it takes to be a good researcher. I look forward to 
our future conferences, I am sure quite some EAA attendees still remember our salsa battles on the dancefloor. Alona, thank you for your support and for sharing the pre$\mathrm{PhD}$ struggles with me, especially the econometrics course in Leuven. During that time, I learnt one of the most important lessons in life: it takes persistence, the right person by your side, and, of course YouTube and STATA forums, to succeed and overcome any challenge. Nina Karthaus, thank you for the great lunches and coffee breaks, and our recent "cheers to you and yes, you can do this" Whatsapp conversations to lift each other up whenever our almost final dissertations were driving us mad. Katja, thank you for the good times in Madrid and Chapel Hill. I love your honesty and "yes, I will tell you every detail" attitude, whatever it is that I want to know. Thank you for our insightful conversations and laughs, for your advice and kind and encouraging words. Especially in Chapel Hill, your positive words helped and encouraged me to look ahead with optimism, and to make it to the finish line of my research visit. Alexis and Boaz, thank you for the fun time in Chapel Hill. I am so grateful for all those free coffee chats in the VIP faculty lounge, our more or less successful "let's concentrate and not talk for at least an hour" work sessions, great dinners and "Might as Well" parties (with our attendance increasing the average age statistic of the party guests by at least seven years).

And then there is of course my family, and friends outside of the academic world. My dear friend Anna, very often I wonder how on Earth you managed to put up with me, especially when things didn't go as planned and I would turn our "work topics are tabu evenings" into a lecture on why not being accepted for a conference is really such a dramatic thing. I thank you from the bottom of my heart for your limitless understanding, patience and support, your warm-heartedness and positivity, and for always being there for me, no matter what. My dear mami, I still remember sitting on your lap and fascinatingly watch you do reconciliations, and intercompany profit eliminations (yes, I knew what these were at the age of four or five), and your big smile when debits and credits were equal. So here I am, writing one of my propositions on true happiness in life. Mama, thank you for always being there for me, for always finding the right moment and words to cheer me up but also to remind me of the costs and consequences that some of my decisions or approaches would entail. There are no words to describe my feelings when I saw your eyes lighten up whenever I had some good news to share, but also when I heard the sadness and the worry in your voice every time I would tell you that I wasn't sure if I was able to make it. Without your unconditional support and love, I would not have managed this journey. My dear brother, thank you for not giving up on trying to understand what it is exactly that I am doing in my dissertation, and more importantly, why this is important to society. Your questions on whether it was common to spend so many years on writing only one paper, and whether I already knew my defense date motivated me to keep going, most of the time. Thank you for always making me laugh, and for being one of my biggest fans. My dear husband, Sergej, thank you for always being by my side in good times and in bad. So often, I just had to mention couple of sentences, and you would immediately and correctly diagnose the seriousness of my problems to respond accordingly, that is either with a sushi dinner 
or a cold glass of wine (or two), all dependent on how bad it was. I truly admire your patience, empathy and your engineering driven problem-solving approach- no matter what the issue is (which did sometimes make me explode internally). So often, your very rational and objective root-cause analysis would help me see the bigger picture, and all the different paths to get from point A to point B. And you are absolutely right, even if some paths require a small detour on the way, they will still take me to where I want to be. Thank you for always believing in me, supporting me and my dreams, and never trying to hold me back from what I want in life.

Lastly, I would like to thank Nespresso for their amazing coffee and, more importantly, for their emergency next day coffee deliveries. A path to successful problem solving always starts with "but first, coffee" since even if caffeine can't solve the world's problems, it didn't cause any either. With the ambassador Nespresso membership status, publications and revisions, I am ready for ya.

Olga Ihl-Deviv'e

Aachen, May 2021 



\section{Table of contents}

Acknowledgements

Chapter 1 Introduction 1

1.1. The use of valuation 3

$\begin{array}{ll}\text { 1.2. Factors affecting valuation estimates } & 4\end{array}$

1.3. Who is my street peer? The relevance of using adjusted

1.4. Determinants and real effects of "Texas-wide" fairness

$\begin{array}{ll}\text { opinions: Evidence from tender offers } & 7\end{array}$

1.5. As good as it gets? The role of boutique financial advisers in

fairness opinions: Evidence from tender offers 9

$\begin{array}{ll}\text { 1.6. Outline of the dissertation } & 11\end{array}$

Chapter 2 Who is my street peer? The relevance of using adjusted accounting metrics for peer selection in multiple valuation $\quad 13$

$\begin{array}{ll}\text { ABSTRACT } & 14\end{array}$

2.1. Introduction $\quad 15$

2.2. Prior Literature and Research Question 18

2.3. Research Design 22

2.3.1. Sample Selection $\quad 22$

2.3.2. Empirical Model 24

2.3.3. Descriptive Statistics 25

2.4. GAAP versus IBES Peer Selection and Future EVS 28

2.4.1. Warranted Multiples 28

2.4.2. Predictive Ability and Valuation Accuracy of Street and GAAP Peers 29

2.4.3. Drivers of Differences in Selected Peers 35

2.5. GAAP versus Street Peers and Implications for Future Returns 37

2.6. Target Firm Complexity 42

2.6.1. Predictive Ability of Street Peers for Complex Target Firms 42

2.6.2. Complexity of Target Firms and Future Returns 45

2.7. Peer Comparability 46

2.8. Conclusion $\quad 47$

Appendix 2A: Illustration peer selection and peer-based implied valuation 
Chapter 3 Determinants and real effects of "Texas-wide" fairness opinions: Evidence from tender offers

3.1. Introduction $\quad 55$

3.2. The use of fairness opinions $\quad 58$

3.2.1. Institutional background 58

3.2.2. The role of the board of directors in issuing an FO 58

3.3. Theoretical predictions 60

3.3.1. Determinants of FO properties - wideness of price ranges 61

3.3.1.1. Knowledge and expertise of the board 61

3.3.1.2. Incentives of the board 62

3.3.2 The determinants of the FO properties - fairness of the FO 64

3.3.3. Shareholder class action lawsuits and the FO properties 65

3.4. Research design 66

3.4.1. Sample Selection 66

3.4.2. Empirical models 67

$\begin{array}{ll}\text { 3.5. Results } & 70\end{array}$

$\begin{array}{ll}\text { 3.5.1. Descriptive statistics } & 70\end{array}$

3.5.2. Wideness and fairness of the FO 74

3.5.3. Shareholder class action lawsuit initiation $\quad 76$

3.6. Additional analysis 77

3.7. Conclusion 79

Appendix 3A: Variable definitions with the corresponding datasources

Chapter 4 As good as it gets? The role of boutique financial advisers in fairness opinions: Evidence from tender offers $\quad 85$

ABSTRACT $\quad 86$

4.1. Introduction $\quad 87$

4.2. The use of fairness opinions 91

4.2.1. Institutional background 91

4.2.2. The role of financial advisers in issuing an FO 91

4.2.3. Boutique financial advisers 93

4.3. Theoretical predictions 94

4.3.1 Boutique advisers and fairness opinion precision $\quad 94$

4.3.2 Tender offer extensions 96

4.4. Research design 98

4.4.1. Sample Selection $\quad 98$

4.4.2. Empirical models 99

4.5. Results 103

4.5.1. Descriptive statistics 103

4.5.2. FO precision 106

4.5.3. Probability of a tender offer extension 108 
Appendix 4A: Variable definitions with the corresponding datasources

Chapter 5 Conclusion

5.2. Contributions and Future Research

References

Impact

Summary of the dissertation 



\section{Chapter 1}

\section{Introduction}



This dissertation explores the relation between the nature of valuation inputs, corporate governance and financial adviser attributes, and the precision and accuracy of valuation estimates. Valuing an asset, or more broadly, a firm as a whole and knowing what determines its value is a pre-requisite for intelligent decision-making (Damodaran, 2008). Valuation is the process of converting a forecast into an estimate of the value of the firm's assets or equity (Palepu et al., 2013). The relevance and indispensability of valuation becomes evident in the fact that valuations are not only conducted by external market participants, but also by internal parties within the firm for various business decisions. For example, small and young enterprises use valuations to attract funding from venture capital or private equity investors to grow and expand their operations (Damodaran, 2008). Once established, firms continue to rely on valuations for investment, financing, dividend payout and strategic decisions (Damodaran, 2008). Besides firms using valuations for various firm-specific needs and decisions, external market participants also conduct firm valuations, primarily for portfolio management and acquisition purposes.

\subsection{The use of valuation}

From the portfolio management angle, valuations are conducted by external parties to determine the "true" value of the firm. Firm valuations provide market participants with an estimate of the appropriate price to pay or receive when choosing new investments or managing existing stocks in a portfolio. The value of the firm is often related to its financial characteristics such as its growth prospects, risk profile and cash flows. Any deviation from this "true" value signals that a stock is potentially under- or overvalued and market participants can earn profits by adjusting their stock positions in portfolios (Damodaran, 2008). While some investors are sufficiently sophisticated and active to conduct valuations and manage their portfolios, others rely on information intermediaries such as sell- or buy-side analysts or portfolio managers for valuation and investment decisions. Security analysts, for instance, conduct independent research on the competitiveness and financial situation of a company and provide, among other things, earnings estimates, valuations (including target prices), and stock recommendations for the firms they cover. The added value of information intermediaries is that they provide relevant information to investors regarding the quality of various investment opportunities (Palepu et al., 2013).

Valuations are not only the centerpiece of investment and trading decisions, but they are also at the heart of acquisition analyses. Before making a bid, the acquiring firm needs to conduct valuations of potential targets, estimate their values, and select the target that fits best with the firm's strategy and generates the most synergies. On the target side, once the offer is made, the target firm needs to determine its fair value before evaluating the offer price and deciding to accept or reject the offer. Thereby it is of high importance to obtain accurate valuation estimates, which appropriately reflect the inherent value of 
the firm. Yet, it is often challenging to determine the fair price of a firm. Prior studies provide support that the information asymmetry between targets and acquirers is associated with mispricing as acquiring firms tend to overpay for targets (Moeller et al., 2004). In a takeover setting, it is equally essential to both target and acquiring firms to obtain an accurate valuation estimate of the target, and with it, the offer price.

To estimate the value of a firm, or an investment, a wide spectrum of valuation models exists. Valuation methods vary in their sophistication and their underlying assumptions about the derivation of firm fundamentals. In general, there are two main approaches to valuation. The first is the direct valuation approach, which derives a firm's value based on the present value of its expected future fundamental value, adjusted for risk and uncertainty. The most common direct valuation models include discounted cash flow analysis or discounted abnormal earnings, although the former is more widely used. The second approach is the relative valuation, which estimates a firm's value based on and relative to a peer group. The underlying premise is that the pricing of the peer group is applicable to the target firm (Palepu et al., 2013). While the relative valuation approach appears to be easier and more straightforward than the direct method, both techniques are well-established and widely used by market participants.

\subsection{Factors affecting valuation estimates}

Considering that direct and relative valuation approaches differ in their underlying assumptions about fundamentals that determine firm value, it follows naturally that they might yield different valuation estimates. However, it is often not only the valuation method as such that drives the differences in valuation estimates and their properties, but also other factors. Damodaran (2008) discusses the sources of potential biases and errors in valuations and identifies three main categories.

The first category deals with the valuation inputs perspective. Disregarding the choice of the valuation approach, whether direct or relative, the financial information that is used as valuation inputs into the methods is key and can severely affect the obtained valuation estimates. This follows the principle that a model's output is only as good as the inputs that go into it (Damodaran, 2008). The information sources vary from standardized and regulated financial statements to voluntary disclosures by the management or various financial reports disclosed by forecast tracking services such as $I / B / E / S$. All these represent different valuation inputs, which ultimately result in different firm valuation estimates.

Given the importance of financial analysts and the valuation information they disclose, the second category revolves around the role of institutional factors. Prior research, for instance, suggests that equity research analysts are more likely to issue buy rather than sell recommendations, meaning they are more likely to find firms to be undervalued 
than overvalued. ${ }^{1}$ In general, valuation estimates provided by financial analysts might be incorrect or biased for two main reasons. First, it might simply be the inherent valuation and forecasting difficulties embedded in firms that analysts cover. Second, analysts might face pressure from portfolio managers, some of whom might have large positions in the stock, and/or from their own firm's investment banking arms which have other profitable relationships with the firms in question (Damodaran, 2008). All in all, institutional factors can substantially affect, and shape valuation estimates provided by tracking services.

The third category refers to a broader strategic decisions and behaviors perspective. As financial analysts face pressure and incentives when issuing valuation estimates, so do managers when disclosing voluntary information or providing management discussions of performance in an annual report. For example, the biased recommendation of financial analysts as to whether a firm is over- or under-valued might motivate managers to issue incorrect or biased valuation estimates too. For example, managers might issue pessimistic management forecasts, and as a result, induce analysts to lower their earnings expectations to an achievable level (Baik and Jiang, 2006). Various external and institutional forces as well as personal incentives might incentivize managers to issue biased, and, thus, incorrect valuation estimates. This is exacerbated in case of acquisitions and takeovers since both parties, being the management and board of directors as well as financial advisers, might pursue their own objectives and incentives. One of such objectives might be to complete the deal, regardless of the fairness and attractiveness of the offer price. Both, financial advisers and board members can design and use valuations strategically to meet their desired objectives and to maximize their own wealth.

Considering the multifaceted nature of firm valuation and the factors affecting it, this dissertation investigates valuation from multiple perspectives. The dissertation incorporates the two main purposes of valuation, namely portfolio management and acquisition analysis, and investigates various factors that are expected to affect the accuracy and precision of valuation estimates. The first study is from the portfolio management perspective and addresses the valuation inputs angle. To be precise, I am interested whether the relative valuation approach improves if financial information provided by the tracking service $\mathrm{I} / \mathrm{B} / \mathrm{E} / \mathrm{S}$ is used as the primary valuation input, as opposed to the financials required by GAAP. Hence, I benchmark the two sets of valuation inputs in the relative valuation framework. The second and third study of this dissertation take the perspective of acquisitions and acquisition analysis. In both studies, the focus is on valuations provided by financial advisers in a fairness opinion as these are relevant not only to the board of directors but also to target shareholders when deciding on the proposed offer. Hereby, I focus on the precision of valuation information as it

1 By mid-2000, the percentage of buy recommendations had reached $74 \%$ of total recommendations outstanding while the percentage of sell recommendations had fallen to $2 \%$ (Barber et al., 2006). 
is one of the key dimensions that investors consider when assessing the credibility of a voluntary disclosure (Mercer, 2004). In the second study, I focus on the strategic decisions angle and examine to what extent the characteristics and incentives of a target board shape the precision of valuations in a fairness opinion. In addition, I investigate how shareholders perceive the usefulness and credibility of fairness opinion valuations, as captured by shareholder class action lawsuits. In the third study, I examine the drivers of the valuation precision and I focus on the role of reputation and expertise of fairness opinion providers, that is financial advisers. I investigate the relation between valuation precision and reputation of an adviser and a timely completion of a deal. I discuss each of these studies in more detail in the next sections.

\subsection{Who is my street peer? The relevance of using adjusted accounting metrics for peer selection in multiple valuation}

This study, which can be found in chapter two of this dissertation, examines the relevance of street earnings as a basis for peer selection in a multiple valuation framework. Adjusted accounting numbers - so-called street earnings improve multiple-based valuation through two channels. First, street earnings enhance the quality of the primary valuation inputs underlying a valuation model and, thus, form a better basis for valuation. Street earnings are essentially analyst-adjusted accounting numbers provided by the forecast tracking service $\mathrm{I} / \mathrm{B} / \mathrm{E} / \mathrm{S}$ and are shown to better reflect the true economic performance (e.g., Liu and Gao, 2016). Analysts filter out accounting distortions and incorporate "soft" information obtained via for instance conference calls, non-GAAP earnings information, and management forecasts (Doyle et al., 2013). Second, next to enhancing the quality of the primary valuation inputs, I argue that street earnings also improve peer-based (i.e., multiple) valuation methods via the identification of more comparable peers. If GAAP numbers do not accurately reflect the underlying business economics in a timely manner, peer selection and the corresponding multiple valuation are distorted. If street earnings are a more reliable indicator of true firm performance, then these numbers should serve as a better basis for selecting comparable benchmark firms which will then improve multiple valuation. I investigate these research questions using the warranted multiple approach developed by Bhojraj and Lee (2002) and focus on the Enterprise-Value-to-Sales (EVS) as the relevant pricing multiple. I calculate two predicted multiples per target firm, one based on peers identified using GAAP numbers, and one based on peers identified using street earnings.

Using a sample of 7,301 firm-year observations over the period 2003 to 2014, I first show that street earnings lead to a different set of selected peers compared to GAAP. Specifically, I find no (one) common peer for 14\% (15\%) of our target firm observations. However, this different peer selection does not automatically lead to a superior peerbased valuation, as on average, I do not find support for the relative superiority of street peers compared to GAAP peers. Yet, when significantly different peers are selected, then 
street-earnings based EVS explains significantly more variation of the future EVS of the target firm, compared to the predicted GAAP EVS. In a second step, I examine whether the difference between the predicted and actual EVS can signal potential mispricing, and hence is correlated with future returns. If street peers are more comparable to the target firm, then the predicted EVS based on these peers should more accurately reflect what the target firm's performance should be, compared to the predicted EVS based on GAAP peers. The return analyses show that the difference between the predicted street earnings-based and actual EVS is significantly associated with future returns, up to two years in the future. In contrast, the difference between the predicted GAAPbased and actual EVS is not associated with future returns. My analyses further show that street earnings form a better basis for constructing warranted multiples compared to GAAP numbers when target firms are more volatile, $R \& D$ intense, or internationally active. Lastly, I test the underlying assumption that the use of street earnings improves peer-based valuation performance through the identification of more comparable peers. My findings indeed indicate that the peers identified using street earnings are more comparable than the peers identified using GAAP numbers.

My findings shed light on the use of street earnings in multiple valuation. Multiple valuation is a quick and unsophisticated substitute for comprehensive valuations, allowing investors to benchmark firms to comparable peers. However, identification of comparable firms and the calculation of multiples are generally based on GAAP numbers, as these are readily available. In general, this is not problematic, as my analyses show that GAAP-based multiple valuation is on average relatively efficient when forecasting a target firm's future EVS using the warranted multiple approach. Yet, especially for complex firms, street earnings are likely to lead to a different peer selection and implied valuation. For these firms, my analyses suggest that street earnings form a better basis for peer selection and the calculation of predicted EVS. My findings provide a relatively easy way for sophisticated investors to improve investment strategies, by identifying circumstances under which street earnings add value.

\subsection{Determinants and real effects of "Texas-wide" fairness opinions: Evidence from tender offers}

This study, which can be found in chapter three of this dissertation, focuses on the properties of valuations disclosed in a fairness opinion (FO). A fairness opinion is obtained in mergers and acquisitions to help the board of the acquiring or target firm determine the appropriateness or "fairness" of the consideration to be paid or received. It contains various valuation analyses, which serve as the basis for financial advisers to assess whether the price paid or received is fair from a financial point of view to shareholders of the client firm (Liu, 2020). The informational value of an FO to shareholders depends heavily on the properties of these valuation analyses. Prior research shows that investors consider characteristics of a disclosure, such as its precision, when assessing its credibility 
and usefulness (e.g., Mercer, 2004). Hence, I examine two key properties of an FO: its precision and fairness. The precision of an FO, which is captured by the wideness of FO ranges, is supposed to provide assurance regarding the offer price and facilitate shareholders' decisions towards accepting the deal. It has received substantial criticism from media and regulators, as very wide ranges do not aid investors in evaluating the suggested offer price. Another key consideration to target shareholders is whether the offer price is fair according to the FO. I investigate the fairness of an FO by examining whether the offer price is at least equal to or below the overall price suggested in an FO. The goal of this study is to gain more insight into the determinants and consequences of the properties of fairness opinion valuation analyses.

Given the prominent role of the target's board of directors in a takeover setting, I analyze to what extent its characteristics and incentives are reflected in $\mathrm{FO}$ valuation analyses' properties. In a next step, I examine how these FO properties are perceived by target shareholders, as proxied by shareholder class action lawsuits. To investigate these questions, I focus on a setting in which FOs are likely to be important, namely tender offers, since their completion and success is highly dependent on target shareholders' tendering decisions. In this setting, it is pivotal for shareholders to receive an accurate assessment of the value of their shares and FO valuation analyses can help target shareholders in reaching an informed decision.

I hand-collected all U.S. tender offers and target $\mathrm{FO}$ valuation analyses between 2010 and 2018. The average incidence of FO-related lawsuits is 33 percent, corroborating the importance of FOs in tender offers. The results show that firm-specific knowledge and incentives of the board are strong predictors of the precision of valuation estimates provided in an FO. Specifically, I find a strong positive association between the independence of the board and the probability of issuing an imprecise FO. A longtenured board, on the other hand, is likely to issue a more precise FO as it possesses valuable firm-specific knowledge to value the target firm more precisely. Interestingly, I find that neither financial nor investment banking expertise of the board seems to matter for the FO precision. Lastly, the board's and the CEO's financial incentives to complete the tender offer are positively associated with the probability of issuing imprecise FOs. Turning to the fairness of the FO, I find that the higher the boards' equity stake, the lower the probability that an unfair FO is disclosed. The more equity directors own, the more sensitive these directors become to the offer price, as their payout is directly linked to the price. At the same time, the CEO's prospect of remaining employed at the merged company provides incentives to complete the tender offer, regardless of the fairness of the FO. The analyses further show that class action lawsuits specifically addressing FOs are positively correlated with imprecise and unfair FOs. Additional analyses also reveal that these properties are not only associated with the occurrence but also the amount of class action lawsuits. 
My findings contribute to the fairness opinion, corporate governance as well as litigation literature. First, FOs are still a largely unexplored phenomenon and prior studies provide conflicting evidence on FOs' effect on deal and shareholder wealth. My study aims to explain these contradicting prior studies' findings by focusing on underlying FO properties. I show that while targets issue an FO in all completed tender offers, onethird of them is exposed to FO-related class action lawsuits. This implies that it is not just the occurrence of an FO, but rather the underlying valuation analyses that should be examined. Second, this is the first study to incorporate the board's characteristics and incentives in the context of FOs. Prior research so far has been silent on the role of the target board's characteristics in the context of FO properties and how these can be used strategically to achieve the board's desired objectives. Lastly, this is the first study to analyze the association between FO properties and target shareholder class action lawsuits. Shareholder lawsuits are costly and delay the completion of the deal. Given that acquirers often chose a tender offer over a merger because of the faster completion times, it is crucial to understand which FO properties trigger shareholder lawsuits, thereby impeding fast completion of a tender offer.

\subsection{As good as it gets? The role of boutique financial advisers in fairness opinions: Evidence from tender offers}

This study, which can be found in chapter four of this dissertation, investigates the role of boutique advisers in the context of fairness opinions. Specifically, I am interested whether boutique advisers provide more precise FOs as compared to non-boutique advisers. Second, I investigate the association between the precision of a target-sought $\mathrm{FO}$ and boutique advisers and the probability of a timely deal completion.

Over the last years, the popularity of boutique financial advisers has been on the rise. Boutique advisers often specialize in certain industries, focus primarily on providing advisory services in mergers and acquisitions, and are generally viewed as independent (Chessell, 2015; Song, Wei and Zhou, 2013). These generally small but specialized investment banks are stealing M\&A market share from the larger well-established banks at increasing rates. In 2019, boutique financial advisers accounted for 32 percent and the top five bulge bracket banks for 34 percent of total M\&A advisory fees. ${ }^{2}$ The threat of a perceived (or actual) conflict of interest, and a desire to avoid it, have increased the demand by boards of directors for an independent and unbiased advice provided by boutique advisers. Yet, despite their growing popularity, the evidence regarding the benefits of hiring boutique advisers versus their competitors is still scarce (Song et al., 2013).

2 Retrieved from: https://www.refinitiv.com/content/dam/marketing/en_us/documents/gated/reports/refinitivboutique-fees-analysis.pdf 
Bulge bracket investment banks represent the traditional full-service brokerage houses that offer a wide range of services such as sales, trading, underwriting, research, and lending. In contrast, boutique advisers focus exclusively on providing M\&A advice. The differential nature and focus of boutique banks make it interesting to investigate whether they provide different FOs as compared to their counterparts. On the one hand, boutique advisers should provide more precise valuation ranges due to their industry specialization and M\&A expertise (Song et al., 2013). On the other hand, except for a few well-known boutique firms, boutique advisers in general tend to be less well known and are much more reliant on fees for advisory services because this is their only line of business. This might provide them with incentives to issue less precise FOs to ensure that the offer price falls within the valuation ranges so that the tender offer is completed, and their compensation is secured. In addition, we also explore whether the existence of prior ties with the acquirer affects the association between boutique advisers and the precision of their FOs. This might arise due to the potential conflict of interest faced by target boutique advisers. In a takeover setting, the primary concern of target advisers might shift to securing future business with the acquirer, with precise target valuations being of second order importance.

I hand-collected all U.S. tender offers and target FO valuation analyses between 2010 and 2018. The results show that 33 percent of target firms in tender offers hire a boutique investment bank, which supports the popularity of and demand for boutique financial advisers. I find that boutique advisers provide more precise FOs as compared to their counterparts, as suggested by their independence and M\&A expertise. The results further show that almost 40 percent of financial advisers hired by the target have prior ties with the acquirer. My results reveal that, in general, target advisers with prior ties with the acquirer tend to provide less precise FOs, yet the opposite is true for boutique advisers. These advisers provide more precise FOs if they have prior ties with the acquirer, likely to increase the likelihood that the acquirer rehires them in the future. This is in line with the "service excellence" idea as the provision of precise FOs is likely to improve boutique advisers' chances of being rehired by the acquirer in the future. With regard to the second research question, I find that the probability of a timely deal completion is positively associated with the precision of an FO, hinting at target shareholders' preference for more precise FO disclosures. I also find that target shareholders seem to tender their shares faster if the target hires a boutique adviser as compared to other non-boutique investment banks.

This paper contributes to the fairness opinion and financial adviser literature in several ways. First, this is the first paper to analyze how the type of a financial adviser is associated with the properties observed in an FO. While Chapter 3 of this dissertation suggests that the target board's characteristics and incentives are important determinants of the observed FO properties, this is the first study to explore the characteristics of an FO provider. Second, this is the first study to analyze how FO properties interact with tender offer extensions, which capture the speed of shareholders' tendering. Similar to 
class action lawsuits, extensions of a tender offer delay the completion of the deal and diminish the comparative advantage of faster completion times of tender offers over mergers. Thirdly, rather than exploring the target adviser's prior relationship with the target, I focus on prior ties with the acquirer since the latter has been largely unexplored, especially in the context of FOs.

\subsection{Outline of the dissertation}

The remainder of my dissertation is organized as follows. Chapter two presents the study on the relevance of street earnings as a basis for peer selection in a multiple valuation framework. Chapter three summarizes the findings on the determinants and consequences of the properties of fairness opinion valuation analyses, with the focus on the target board of directors. Chapter four covers the third study, which investigates the role of boutique advisers for the precision of a target-sought FO and the probability of a timely deal completion. Finally, chapter five concludes. 



\section{Chapter 2}

\section{Who is my street peer? \\ The relevance of using adjusted accounting metrics for peer selection in multiple valuation ${ }^{3,4}$}

3 This chapter is based on a working paper co-authored with Annelies Renders and Patrick Vorst.

4 We thank Han-Up Park (FARS discussant), Wayne Landsman, Cathy Shakespeare, Joachim Gassen, Ole-Kristian Hope, Bjorn Jorgensen, Frank Moers, Steven Young, as well as workshop participants at the 2020 FARS conference in Nashville, the EAA Doctoral Colloquium and Conference, and seminar participants at Lancaster University, Maastricht University, and the University of Amsterdam for their helpful comments. 


\begin{abstract}
This study benchmarks the use of street earnings versus GAAP numbers in a multiple valuation framework. Specifically, we examine whether multiple valuation using peers identified based on street earnings outperforms multiple valuation using peers identified based on GAAP numbers. To compare the performance of these peer valuations, we examine the predictive ability and valuation accuracy of peer-based multiple estimates. We rely on the warranted multiple approach developed by Bhojraj and Lee (2002), in which Enterprise-Value-to-Sales (EVS) ratios are predicted using a set of peer firms. Using a sample of U.S. listed firms over the period 2003 to 2014, we find that the use of street earnings leads to a completely different set of selected peers for $14 \%$ of the observations. When these different peers lead to a different implied valuation, the street earnings-based predicted EVS ratio has a higher predictive power and is more accurate than the GAAP-based predicted EVS ratio. We also provide evidence that the street earnings-based predicted EVS ratio better explains future stock returns and forms a useful benchmark in identifying target firm over- or underperformance. Cross-sectional analyses further show that street earnings' value predominantly materializes in complex firms. Our findings confirm the supremacy of street earnings vis-à-vis GAAP numbers and suggest that the warranted multiple valuation approach may help investors detect mispricing.
\end{abstract}




\subsection{Introduction}

This paper examines the relevance of using street earnings as a basis for peer selection in a multiple valuation framework. ${ }^{5}$ The role of financial information in valuing a target firm cannot be underestimated, as it helps investors in selecting and evaluating potential investments. The quality of the financial information is hence of crucial importance (Chen, Young and Zhuang, 2012). However, accounting numbers usually do not perfectly reflect the underlying business processes, for example because of accounting conservatism or a regulatory one-size-fits-all approach (Young, 2014). ${ }^{6}$ Investment strategies based on these numbers will then be biased, as these accounting distortions affect projected firm valuations and make it difficult to compare firms (Young and Zeng, 2015).

We argue that adjusted accounting numbers - so-called street earnings - form a better basis for valuation, as accounting distortions are filtered out and these numbers therefore better reflect true economic performance (Liu and Gao, 2016). Especially for valuation methods that rely on the identification of comparable peer firms, street earnings have the potential to improve valuation (Frankel and Roychodhury, 2005). However, despite the increasing prevalence of street earnings, evidence suggests that next to alternative metrics (un)sophisticated market participants also greatly rely on GAAP-based metrics. ${ }^{7}$ Hence, the goal of this paper is to investigate the superiority of street earnings for multiple valuation methods via improved peer selection.

Street earnings are essentially analyst-adjusted accounting numbers provided by the forecast tracking service I/B/E/S. ${ }^{8}$ Analysts improve the informativeness of accounting numbers in the following ways. First, analysts consider "soft" information obtained via for instance conference calls, non-GAAP earnings information and management forecasts (Doyle et al., 2013). ${ }^{9}$ This information may not be fully captured by the GAAP

5 Multiple valuation is a relatively straightforward valuation method which requires little sophistication on behalf of investors. Multiples of comparable firms are often used as a substitute for more sophisticated valuation methods, because they efficiently capture the essence of these sophisticated methods (Liu et al., 2002).

6 Curtis et al. (2014) identify the increased inability of GAAP numbers to capture a firm's increasingly complex business environment as one of the reasons why the provision of non-GAAP earnings by management is on the rise.

7 Papa and Peters (2016) show that $63.6 \%$ of survey respondents always or often use non-GAAP metrics, while $71.5 \%$ of all respondents always or often use GAAP measures. This result suggests that the regulators' concern about investors ignoring GAAP information and focusing solely on potentially misleading non-GAAP earnings may be overstated. The reasons why investors still greatly rely on GAAP earnings include that investors have concerns around the communication, consistency, comparability across periods and similar companies, and transparency of non-GAAP earnings (Papa and Peters, 2016).

$8 \mathrm{I} / \mathrm{B} / \mathrm{E} / \mathrm{S}$ issues adjusted performance metrics and accounting data called "street earnings". I/B/E/S bases its exclusion decisions on the items excluded by the majority of analysts, approximating analyst consensus (Black et al., 2017 ; $\mathrm{Gu}$ and Chen, 2004). Consistent with prior studies, we use I/B/E/S actuals as a proxy for analysts' consensus assessment of ex-post realized earnings (e.g., Black et al., 2017 ).

9 Note that the voluntary disclosure of non-GAAP information may in principle overcome the problem of uninformative GAAP numbers. However, the calculation of non-GAAP earnings is not standardized, and the discretion afforded in non-GAAP earnings may make identification of comparable firms more difficult. In addition, 
financial statements. Second, multiple analysts tend to follow the same firm, leading to a "check" on potential erroneous valuations or judgments (Alford and Berger, 1999). Third, analysts adjust potential biases in GAAP numbers for a relatively large set of firms, thereby facilitating investment by investors and allowing them to reap abnormal returns (Barber et al., 2001). Hence, analysts undo accounting distortions and render the accounting numbers more informative to investors.

Next to enhancing the quality of the financial information, we argue that analyst adjustments and the resulting street earnings also improve peer-based (i.e., multiple) valuation methods via the identification of comparable peers. Multiple valuation entails multiplying a value driver of a target firm (e.g., earnings or sales) by the corresponding multiple from a set of comparable benchmark firms (Bhojraj and Lee, 2002). The identification of comparable firms is key here. However, the multiples and peers are generally selected based on GAAP numbers (Papa and Peters, 2016). Hence, if GAAP numbers do not accurately reflect the underlying business economics in a timely manner, peer selection and the corresponding multiple valuation are distorted. If street earnings are a more reliable indicator of true firm performance, then these numbers should serve as a better basis for selecting comparable benchmark firms - which will then improve multiple valuation.

We investigate our research question using the warranted multiple approach developed by Bhojraj and Lee (2002). ${ }^{10}$ Given a valuation multiple, this approach identifies peer firms based on accounting data using a regression analysis. From these peers, a predicted multiple is calculated, which forms the basis for the target firm's implied valuation. We focus on the Enterprise-Value-to-Sales (EVS) as the relevant pricing multiple, as it is conceptually superior to alternative multiples when firms are differentially leveraged (Bhojraj and Lee, 2002). We calculate two predicted multiples per target firm, one based on peers identified using GAAP numbers, and one based on peers identified using street earnings.

Using a sample of 7,301 firm-year observations over the period 2003 to 2014, we first show that street earnings lead to a different set of selected peers compared to GAAP. Specifically, we find no common peer for $14 \%$ of our target firm observations. However, this different peer selection does not automatically lead to a superior peerbased valuation, as on average, we do not find support for the relative superiority of street peers compared to GAAP peers. This finding is driven by target firms for which

not all firms disclose non-GAAP information, leading to the omission of many potential peers. Finally, analysts are able to synthesize both non-GAAP and GAAP numbers and provide a comprehensive picture of the company, going beyond non-GAAP numbers and enhancing comparability even further (Liu and Gau, 2016).

10 This method has been shown to outperform other multiple valuation methods such as selecting peers that are closest to the target firm in size from the same industry (Bhojraj and Lee, 2002; Young and Zeng, 2015). Anecdotal evidence reveals that practitioners view the warranted multiple as a method which adjusts accounting ratios for fundamental drivers of risk, profitability and growth. For more discussion, see e.g. https://www.institutionalinvestor.com/article/ b14zpltbf803kb/warranted-multiples-offer-new-clues-to-future-equity-performance. 
the identified peers are different, but the predicted street earnings-based EVS does not differ substantially from the predicted GAAP-based EVS. When street earnings-based predicted EVS significantly differs from GAAP-based predicted EVS, the street-earnings based EVS explains significantly more variation of the future EVS of the target firm, compared to the predicted GAAP EVS. Moreover, the street earnings-based valuation yields more accurate EVS estimates than GAAP-based multiple valuation.

In a second step, we examine whether the difference between the predicted and actual EVS can signal potential mispricing, and hence is correlated with future returns. We expect that, if the difference between the predicted and actual EVS helps explain future stock returns, this association should be stronger for street earnings-based predicted EVS compared to GAAP-based predicted EVS. Specifically, if street peers are more comparable to the target firm, the predicted EVS based on these peers should more accurately reflect what the target firm's performance should be, compared to the predicted EVS based on GAAP peers. We use the difference between the predicted and actual EVS at the end of the year to make inferences about a target firm's over- or underperformance. The return analyses show that the difference between the predicted street earnings-based and actual EVS is significantly associated with future returns, up to two years in the future. In contrast, the difference between the predicted GAAP-based and actual EVS is not associated with future returns. These findings suggest that peer valuation based on street earnings helps identify over- or underperforming firms, allowing investors to reap abnormal buy-and-hold returns.

To further identify circumstances under which street earnings can improve peer-based valuation, we perform several cross-sectional analyses focusing on target firm complexity. These analyses show that street earnings form a better basis for constructing warranted multiples compared to GAAP numbers when target firms are more volatile, R\&D intense, or internationally active. These findings hold for both the predictive power of the street-earnings based predicted EVS, as well as the identification of mispricing. The value of using street earnings as a basis for peer selection in a warranted multiple framework seems to predominantly manifest itself when target firms are more complex and difficult to forecast.

Lastly, we test our underlying assumption that the use of street earnings improves peerbased valuation performance and identification of mispricing through the identification of more comparable peers. Similar to Liu and Gao (2016), we use De Franco et al.'s (2011) method to measure the comparability of earnings. Our results indeed show that the peers identified using street earnings are more comparable than the peers identified using GAAP numbers.

Our results shed light on the use of street earnings in multiple valuation. Multiple valuation is a quick and unsophisticated substitute for comprehensive valuations, allowing investors to benchmark firms to comparable peers. However, identification 
of comparable firms and the calculation of multiples are generally based on GAAP numbers, as these are readily available. In general, this is not problematic, as our analyses show that GAAP-based multiple valuation is on average relatively efficient. Both street earnings and GAAP numbers have a similar predictive ability when forecasting a target firm's future EVS using the warranted multiple approach. However, our results indicate that street earnings-based multiple valuation yields more accurate EVS estimates than its GAAP-based counterparty. We further show that especially for complex firms, street earnings are likely to lead to a different peer selection and implied valuation. For these firms, our analyses suggest that street earnings form a better basis for peer selection and the calculation of predicted EVS. Our findings provide a relatively easy way for sophisticated investors to improve investment strategies, by identifying circumstances under which street earnings add value.

The remainder of the paper is organized as follows: Section 2.2 describes the prior literature and outlines the research question. Section 2.3 discusses the research design and the sample. Section 2.4, 2.5 and 2.6 present the findings of our main analyses. Section 2.4 delineates the predictive ability and valuation accuracy of peers analyses, while section 2.5 summarizes findings regarding the mispricing and future stock returns. Section 2.6 outlines cross-sectional analyses on target firm complexity, section 2.7 discusses additional analyses on comparability of peers and section 2.8 concludes.

\subsection{Prior Literature and Research Question}

Firm valuation is a key driver of investment behavior. Popular direct valuation methods such as free-cash-flow-to-equity are generally quite sophisticated, requiring several assumptions, projections and present value calculations. An easier, straightforward "relative" valuation approach involves multiplying a value driver of a target firm (e.g., earnings) by the corresponding multiple from a set of comparable benchmark firms. In essence, a multiple valuation approach involves the following three steps: (1) identifying a value driver (e.g., earnings), (2) selecting comparable firms and calculating the average pricing multiple of the identified peer firms (e.g., price-to-earnings ratio), and (3) applying the average pricing multiple to the value driver of the firm being valued (Palepu et al., 2013). The multiple approach is a relatively unsophisticated valuation method, and bypasses some of the difficulties inherent in direct valuation methods, such as discounting and forecasting. However, the multiple still relies on the same valuation principles underlying the more sophisticated approaches, such as that value is an increasing function of future payoffs (Liu et al., 2002). Hence, multiples of comparable firms are often used because they efficiently capture the essence of the underlying valuation principles (Liu et al., 2002).

Corroborating the efficiency and ease of use of multiple valuation methods, Imam et al. (2008) show that - despite the availability of comprehensive valuation techniques - UK 
investment analysts continue to rely on unsophisticated valuation multiples. Moreover, Brown et al. (2015) show that sell-side financial analysts tend to focus on rather simple valuation models such as Price/Earnings-ratios and cash flow models, instead of the more sophisticated residual income and dividend discount models. In practice, the perceived technical difficulties in applying sophisticated direct valuation methods drive the complementary use of valuation multiples (Imam et al., 2008). In short, these studies suggest that valuation multiples are used by sophisticated market participants to complement comprehensive valuations and justify investment recommendations.

A crucial element of the multiple valuation method is the identification of comparable peer firms from which to calculate the average multiple. A different set of peers implies a different projected valuation, which can alter the investment recommendations of analysts and investment decisions by investors. Prior research has indeed highlighted the importance of economic comparability between the target firm and its selected peers for more accurate value estimates. For example, Alford (1992) shows that valuation errors decline when the industry delineation used to select comparable firms is narrowed to two or three-digit SIC codes. Consistent with the idea that firms in the same industry are exposed to similar economic shocks and accounting constraints, Liu et al. (2002) find that industry-level multiples perform better than multiples derived from the entire cross-section. Bhojraj and Lee (2002) build further on these studies and propose the use of a so-called warranted multiple approach in which peers are identified based on accounting variables that explain cross-sectional differences in observed pricing multiples. These and other studies all revolve around the issue of discovering ways to improve the identification of peers, so that "truly" comparable firms are selected to improve the accuracy of the target firm's value estimates.

The main obstacle in finding firms that share the same fundamental economic comparability is the quantity and quality of information, which boils down to firms' disclosure and reporting. Comparability of firms can be hindered for two reasons. First, the conservative and backward-looking nature of accounting standards can impair comparability across firms. Their one-size-fits-all approach may fail to capture the economic fundamentals of firms on a timely basis, which creates comparability problems in the context of pricing multiples (Young, 2014). For example, R\&D investments are investments in the long-term profitability of the firm but the requirement to expense these investments prohibits firms from recognizing the future benefits of $R \& D$ investments on their balance sheet. Consequently, the requirement to expense R\&D investments makes firms' balance sheets more similar, but not more comparable as it does not allow firms to signal the expected future benefits of their investments. Second, accrual accounting and the reliance on estimates allows managers to exercise considerable discretion, which can further reduce the comparability of GAAP earnings across similar firms. Different reporting practices and accounting choices applied to similar transactions can make similar firms appear to be different. Similarly, inappropriately applied accounting methods may cause economically different firms to appear similar in terms of their 
reported outcomes (Young and Zeng, 2015). In aggregate, a differential application of accounting rules may have otherwise similar firms appear different, which hampers the usability of multiple valuation methods. This is especially troublesome given that evidence shows that sophisticated investors still heavily rely on GAAP numbers (Papa and Peters, 2016).

Adjusted performance metrics, so-called "street earnings", may be a solution to this information problem. Street earnings are I/B/E/S earnings metrics which are released after the publication of financial statements and after the post-announcement conference calls took place. These street earnings mitigate the above-mentioned shortcomings in GAAP and incorporate relevant information not captured in the financial statements, for instance by capitalizing $R \& D$ on the balance sheet or excluding non-recurring items from the income statement. To compute street earnings, market specialists evaluate firms' reported earnings and adjust these based on the adjustments by analysts following the firm (Black et al., 2017b). ${ }^{11} \mathrm{I} / \mathrm{B} / \mathrm{E} / \mathrm{S}$ essentially determines the firm's period-specific street earnings definition based on how the majority of contributing analysts adjust accounting numbers for a particular firm-quarter (Black et al., 2017b). ${ }^{12}$ Similarly, we assume that on average street earnings (i.e., I/B/E/S actual earnings) reflect analysts' consensus opinion on the firm's realized earnings. ${ }^{13}$ As analysts' adjustments remove accounting distortions, street earnings may more accurately represent the underlying firm fundamentals.

Prior research supports the notion that street earnings provide a cleaner representation of a firm's "core" earnings. Bhattacharya et al. (2003) and Brown and Sivakumar (2003) provide evidence that street operating earnings are more persistent than GAAP operating income and that market participants perceive them as more relevant. In a similar vein, Liu and Gao (2016) show that street earnings better reflect core and continuing operations following analysts' expertise and professional judgment. Frankel and Lee (1998) use analysts' earnings forecasts to estimate a firm's fundamental value and document a high correlation with both contemporaneous and future stock returns. Moreover, revisions in analysts' earnings forecasts explain a substantially larger portion of contemporaneous

11 Analysts' majority definition might change based on disclosures in the earnings announcement and/or conference call, i.e., if an unexpected impairment occurs during the period, analysts may update their earnings definition (Black et al., 2017 ).

12 Black et al. $\left(2017^{\mathrm{b}}\right)$ emphasize that while street earnings are mainly determined by analysts, managers may also influence the calculation of street earnings through e.g. earnings presentations and the question-and-answer (Q\&A) sessions of the conference calls. $\mathrm{I} / \mathrm{B} / \mathrm{E} / \mathrm{S}$ then examines earnings press releases to determine if managers report a non-GAAP earnings number (Christensen, 2007). When analyst and non-GAAP numbers differ, I/B/E/S examines the reasons for these differences and may decide ex-post to include additional manager exclusions. Although investors may discount manager-provided non-GAAP earnings (Bentley et al., 2016), the I/B/E/S street earnings are generally assumed to be objectively determined (Black et al., 2017 ).

13 The process of determining which items to exclude is at the data provider's discretion and can be idiosyncratic in some circumstances (Abarbanell and Lehavy, 2007; Brown and Larocque, 2013). However, given that I/B/E/S centralizes the opinions of analysts following the firm, it is reasonable to assume that on average, street earnings approximate analyst consensus (Black et al., 2017 b). 
stock returns than earnings surprises based on reported earnings (Liu and Thomas, 2000). Lastly, in a multiple valuation framework, Frankel and Roychowdhury (2005) find that street earnings numbers are more relevant for valuation purposes than GAAP numbers. We consequently argue that street earnings form a superior basis for peer selection compared to GAAP numbers and hence should improve multiple valuation.

The potential added value of using street earnings in a multiple valuation framework may originate from two sources. First, street earnings are more informative as they remove accounting distortions from the financial statements (Black et al., 2017a). For example, while GAAP earnings contain non-recurring items, analysts typically exclude such items because they are usually not part of firms' normal operating activities (Liu and Gao, 2016). Street earnings may hence show a more accurate picture of the target firm's true performance, and consequently serve as a better basis for multiple valuation. Second, we argue that street earnings improve multiple valuation beyond the direct impact of information provided in street earnings themselves. Specifically, street earnings may further improve multiple valuation via the identification of more comparable peers. Liu and Gao (2016) empirically show that, following adjustments by analysts and I/B/E/S, street earnings are significantly more comparable than GAAP earnings. This enhanced comparability among firms should then facilitate benchmarking, thereby improving multiple valuation (Young and Zeng, 2015). Jointly considered, using street earnings as a basis for multiple valuation should yield improved valuation outcomes compared to multiple valuation based on GAAP earnings, because of a higher informativeness as well as a higher comparability.

The superiority of street earnings seems to be obvious given analysts' privileged relationships with firms and their extensive analyzing skills (Barber et al., 2001; Brown et al., 2015). Moreover, Liu and Gau (2016) provide evidence that street earnings are more comparable than GAAP and managers' reported non-GAAP earnings. However, several studies indicate that analysts' numbers used to determine street earnings might not be superior to other information sources because of analyst bias or inherent forecasting difficulties. For example, Gu et al. (2013) document significant pressure from institutional investors on financial analysts to issue optimistic stock recommendations. These biases may decrease the usefulness of street earnings for valuation purposes. Given that the costs of obtaining street earnings are non-trivial, it is important to investigate whether and when these adjusted numbers form a better basis for peer selection and multiple valuation compared to GAAP numbers.

Based on the preceding argumentation, we investigate the following three questions. First, we examine whether a peer-based valuation model based on street earnings yields improved valuation outcomes compared to peer valuation based on GAAP numbers. Second, we examine whether street-based peer valuation allows investors to identify over- and underperforming firms and make inferences about future performance. Third, 
we identify different circumstances under which peers selected based on street earnings should lead to the largest improvement in valuation and the identification of mispricing.

\subsection{Research Design}

\subsubsection{Sample Selection}

We obtain an initial sample of 117,135 firm-year observations of US listed firms from COMPUSTAT North America over the period 2000 to 2016. To facilitate estimation of a robust model, the same requirements as in Bhojraj and Lee (2002) need to be fulfilled for firms to be included in the sample. Hence, we exclude ADR firms and REITs as well as firms with prices below $\$ 3$ per share, sales below $\$ 100$ million or a negative book value of common equity. We only keep observations with non-missing price and accounting data needed to estimate the regressions and truncate the accounting variables at 1 and $99 \%$. Finally, we remove observations with a fiscal year-end that is not in December. Similar to Bhojraj and Lee (2002), long-term debt and R\&D expenses are assigned a value of zero in case of missing values.

For the remaining observations, operating profit, sales actuals and long-term growth rate forecasts are merged from the $\mathrm{I} / \mathrm{B} / \mathrm{E} / \mathrm{S}$ summary history database. Consistent with the requirements imposed on the COMPUSTAT sample, we require non-missing actuals of sales, operating profit and long-term growth rate forecasts, which reduces the sample 10,555 firm-year observations. For the peer selection in the later analyses, we require at least eight firms per industry-year combination. After truncating the industry-adjusted profit margins at 1 and $99 \%$ and excluding years with a low number of observations, the final sample consists of 7,301 firm-year observations from 1,782 unique firms over the period 2003 to 2014. Panel A of Table 1 presents the sample selection procedure, while Panel B presents the distribution of the sample over the years. 
TABLE 1: Sample Selection

\begin{tabular}{ll}
\hline Panel A: Selection process & \\
\hline Initial firm-year observations obtained from COMPUSTAT & $\mathbf{1 1 7 , 1 3 5}$ \\
Remaining observations after excluding ADRs and REITs & 113,960 \\
Remaining observations with sales of at least $\$ 100$ million, a share price of at least $\$ 3$, & 54,291 \\
and a positive book value of equity & \\
Remaining observations with at least 10 firms per industry & 54,021 \\
Remaining observations with non-missing accounting data & 45,135 \\
Remaining observations after truncating main accounting variables & 35,127 \\
Remaining observations with December fiscal year-end & 24,878 \\
Remaining observations with non-missing profit and sales actuals & 10,555 \\
Remaining observations after truncating industry-adjusted variables & 9,285 \\
Sample used for annual regressions & $\mathbf{9 , 2 8 5}$ \\
Remaining observations with at least 8 firms per industry-year to select peers & 7,848 \\
Remaining observations after deleting firms with identical market capitalization & 7,830 \\
Remaining observations after deleting years with a low number of observations & 7,301 \\
Sample used for warranted multiple estimation \& peer selection & $\mathbf{7 , 3 0 1}$ \\
Number of unique firms & 1,782
\end{tabular}

\begin{tabular}{lcc}
\hline Panel B: Sample by year & N & \% \\
\hline Year & 401 & 5.49 \\
2003 & 436 & 5.97 \\
2004 & 882 & 12.08 \\
2005 & 889 & 12.18 \\
2006 & 839 & 11.49 \\
2007 & 720 & 10.00 \\
2008 & 869 & 9.86 \\
2009 & 915 & 11.90 \\
2010 & 886 & 12.53 \\
2011 & 153 & 2.10 \\
2012 & 225 & 3.08 \\
2013 & 86 & 1.18 \\
2014 & 7,301 & $\mathbf{1 0 0 . 0 0}$ \\
\hline Total & & \\
\hline
\end{tabular}

This table presents the sample selection process (Panel A) and the distribution of the firm observations over the sample years (Panel B). 


\subsubsection{Empirical Model}

In a first step, we estimate two models which we run on a yearly basis in line with the warranted multiple approach proposed by Bhojraj and Lee (2002). ${ }^{14}$ The first model is based on the reported GAAP numbers, while the second model replaces two of the explanatory variables with the street earnings reported in $\mathrm{I} / \mathrm{B} / \mathrm{E} / \mathrm{S}$. Following this approach, we can compare GAAP and street earnings in predicting current and future EVS. ${ }^{15}$

The first model is based on GAAP earnings. The choice of variables is in line with prior valuation research that emphasizes the importance of growth, risk and profitability factors in a valuation setting (Bhojraj and Lee, 2002). Model (1) is summarized as follows:

$E V S_{i t}=\alpha_{t}+\beta_{1} I n d_{-} E V S_{i t}+\beta_{2} I n d_{-} P B_{i t}+\beta_{3} A d j_{-} P M_{-} G A A P_{i t}+\beta_{4} L O S S_{-} G A A P_{i t}+$ $\beta_{5} L O S S_{-} P M_{-} G A A P_{i t}+\beta_{6} A d j_{-} L T G_{-} F O R E C A S T_{i t}+\beta_{7} L E V_{i t}+\beta_{8} R N O A_{i t}+\beta_{9} R \& D_{i t}+\varepsilon_{i t}$

The variables used in the GAAP model include the following:

EVS: enterprise-value-to-sales ratio, computed as the market value of equity and the sum of total long-term debt and debt in current liabilities scaled by sales;

Ind_EVS: harmonic mean of EVS ratio for all firms with the same two-digit SIC $\operatorname{code}^{16}$;

Ind_PB: harmonic mean of price-to-book $(\mathrm{P} / \mathrm{B})$ ratio for all firms with the same two-digit SIC code;

Adj_PM_GAAP: industry-adjusted profit margin, computed as the difference between the firm's GAAP profit margin and the median industry GAAP profit margin, where profit margin is operating profit after depreciation divided by sales;

14 This method has been shown to outperform other, basic multiple valuation methods (Bhojraj and Lee, 2002; Young and Zeng, 2015).

15 We focus on EVS rather than the price-to-sales (PS) ratio because the EVS ratio is conceptually superior when firms are differentially leveraged (Bhojraj and Lee, 2002). Additionally, this ratio is particularly applicable to loss firms, which is important for firms operating in industries such as technology, telecommunication or pharmaceutical products (Bhojraj and Lee, 2002). Young and Zeng (2015) and Bhojraj and Lee (2002) show that once the warranted multiple approach is used, the choice of a value driver is not a significant factor affecting the results.

16 In line with prior research, we use the harmonic means of industry EVS and PB ratios (e.g., Baker and Ruback 1999; Bhojraj and Lee, 2002; Young and Zeng, 2015). Liu et al. (2002) show that the performance of valuation models improves when multiples are computed using the harmonic mean, relative to the mean or median ratio of the multiple for comparable firms. The harmonic mean is calculated on a year and industry basis, using the following formula:

$$
\text { Harmonic Mean }=\frac{N}{\frac{1}{x 1}+\frac{1}{x 2}+\frac{1}{x 3}+\cdots+\frac{1}{x n}}
$$

Where $\mathrm{N}$ is the number of firm-year observations per industry-year and $\mathrm{X}_{1-} \mathrm{X}_{\mathrm{N}}$ are the corresponding EVS ratios. 
LOSS_GAAP: indicator variable that is equal to one if the firm's GAAP profit margin is negative, and zero otherwise;

LOSS_PM_GAAP: this variable is computed as the interaction between $A d j$ PM_GAAP and LOSS_GAAP;

Adj_LTG_FORECAST: industry-adjusted long-term growth forecast as reported by $\mathrm{I} / \mathrm{B} / \mathrm{E} / \mathrm{S}$, computed as the difference between the analysts' consensus forecast of the firm's long-term growth rate and the industry average;

$L E V$ : book leverage, computed as total long-term debt scaled by the book value of common equity;

$R N O A$ : return on net operating assets, calculated as a firm's operating profit scaled by net operating assets;

$R \& D: \mathrm{R} \& \mathrm{D}$ expenses divided by sales.

The street model is based on the actuals reported by $\mathrm{I} / \mathrm{B} / \mathrm{E} / \mathrm{S}$. The model includes the same variables as Model (1), but replaces Adj_PM_GAAP, LOSS_GAAP, and LOSS PM_GAAP with the following variables:

Adj_PM_STREET: industry-adjusted profit margin, computed as the difference between the firm's profit margin as reported by $\mathrm{I} / \mathrm{B} / \mathrm{E} / \mathrm{S}$ and the median industry profit margin (based on $\mathrm{I} / \mathrm{B} / \mathrm{E} / \mathrm{S}$ actuals of operating profit and sales);

LOSS_STREET: indicator variable that is equal to one if the firm's profit margin as reported by $\mathrm{I} / \mathrm{B} / \mathrm{E} / \mathrm{S}$ is negative, and zero otherwise;

LOSS_PM_STREET: this variable is computed as the interaction between Adj_ PM_STREET and LOSS_STREET.

\subsubsection{Descriptive Statistics}

Summary statistics of the variables used in the GAAP and street model are reported in Table 2, Panel A. The median observation has an EVS ratio of 1.8, leverage of 51 percent and a return on net operating assets of 20 percent. The median industry-adjusted profit margins using GAAP and street earnings are both zero. The descriptives of the industryadjusted profit margins are comparable to prior studies and are expected to have means and medians close to zero (Bhojraj and Lee 2002). The mean and median EVS values in our sample are slightly higher than the mean and median EVS values (1.20 and 0.94, respectively) reported by Bhojraj and Lee (2002). This is consistent with prior studies documenting an increase over time in the accounting-based multiples such as EVS and PB (e.g., Frankel and Lee, 1991; Bhojraj and Lee, 2002). 
Table 2, Panel B, presents the correlation matrix. Panel B shows that all the variables except for $L E V, R N O A$ and LOSS_PM_STREET are significantly correlated with EVS. The industry EVS ratio (Ind_EVS) has the highest correlation, followed by Adj_PM_ STREET. This suggests that EVS is positively correlated with street earnings-based profit margins. GAAP's industry adjusted profit margin $\left(A d j \_P M_{-} G A A P\right)$ is also positively correlated with $E V S$, although the correlation coefficient is somewhat lower. The other two variables that are strongly and positively correlated with $E V S$ are $R \& D$ and $A d j_{-}$ $L T G \_F O R E C A S T$, which is line with prior research showing that higher growth firms have higher EVS ratios (Bhojraj and Lee, 2002).

TABLE 2: Descriptive Statistics

\begin{tabular}{lcccccccc}
\hline \multicolumn{1}{l}{ Panel A: Descriptive Statistics } & \multicolumn{1}{c}{ N } & Mean & Min & Q1 & Median & Q3 & Max & Std. Dev. \\
\hline & 7,301 & 2.309 & 0.167 & 1.047 & 1.789 & 2.930 & 13.652 & 1.895 \\
\hline EVS & 7,301 & 1.409 & 0.400 & 0.945 & 1.299 & 1.749 & 3.979 & 0.634 \\
Ind_EVS & 7,301 & 1.887 & 0.848 & 1.583 & 1.866 & 2.179 & 4.752 & 0.436 \\
Ind_PB & 7,301 & 0.009 & -0.276 & -0.039 & 0.000 & 0.055 & 0.260 & 0.084 \\
Adj_PM_GAAP & 7,301 & 0.009 & -0.358 & -0.041 & 0.000 & 0.058 & 0.308 & 0.089 \\
Adj_PM_STREET & 7,301 & 2.353 & -15.575 & -3.125 & 0.000 & 4.250 & 135.500 & 12.764 \\
Adj_LTG_FORECAST & 7,301 & 0.048 & 0.000 & 0.000 & 0.000 & 0.000 & 1.000 & 0.215 \\
LOSS_GAAP & 7,301 & -0.007 & -0.276 & 0.000 & 0.000 & 0.000 & 0.000 & 0.033 \\
LOSS_PM_GAAP & 7,301 & 0.039 & 0.000 & 0.000 & 0.000 & 0.000 & 1.000 & 0.195 \\
LOSS_STREET & 7,301 & -0.006 & -0.358 & 0.000 & 0.000 & 0.000 & 0.000 & 0.034 \\
LOSS_PM_STREET & 7,301 & 0.771 & 0.000 & 0.212 & 0.509 & 0.972 & 7.958 & 0.947 \\
LEV & 7,301 & 26.328 & -90.041 & 10.170 & 19.910 & 34.434 & 209.125 & 26.838 \\
RNOA & 7,301 & 0.034 & 0.000 & 0.000 & 0.000 & 0.031 & 1.185 & 0.071 \\
R\&D & & & & & & & &
\end{tabular}


TABLE 2: Descriptive Statistics (continued)

\begin{tabular}{|c|c|c|c|c|c|c|c|c|c|c|c|}
\hline \multicolumn{12}{|c|}{ Panel B: Pearson Correlation Coefficients } \\
\hline & (1) & (2) & (3) & (4) & (5) & (6) & (7) & (8) & (9) & (10) & (11) \\
\hline (1) EVS & 1 & & & & & & & & & & \\
\hline \multirow[t]{2}{*}{ (2) Ind_EVS } & 0.452 & 1 & & & & & & & & & \\
\hline & $(0.00)$ & & & & & & & & & & \\
\hline \multirow[t]{2}{*}{ (3) Ind_PB } & 0.206 & 0.233 & 1 & & & & & & & & \\
\hline & $(0.00)$ & $(0.00)$ & & & & & & & & & \\
\hline \multirow[t]{2}{*}{ (4) Adj_PM_GAAP } & 0.356 & -0.002 & 0.002 & 1 & & & & & & & \\
\hline & $(0.00)$ & $(0.86)$ & $(0.84)$ & & & & & & & & \\
\hline \multirow[t]{2}{*}{ (5) Adj_PM_STREET } & 0.406 & -0.020 & 0.033 & 0.900 & 1 & & & & & & \\
\hline & $(0.00)$ & $(0.09)$ & $(0.00)$ & $(0.00)$ & & & & & & & \\
\hline \multirow[t]{2}{*}{ (6) LOSS_PM_GAAP } & -0.052 & -0.008 & -0.017 & 0.435 & 0.359 & 1 & & & & & \\
\hline & $(0.00)$ & $(0.49)$ & $(0.16)$ & $(0.00)$ & $(0.00)$ & & & & & & \\
\hline \multirow[t]{2}{*}{ (7) LOSS_PM_STREET } & -0.017 & -0.011 & -0.006 & 0.353 & 0.412 & 0.757 & 1 & & & & \\
\hline & $(0.15)$ & $(0.34)$ & $(0.61)$ & $(0.00)$ & $(0.00)$ & $(0.00)$ & & & & & \\
\hline \multicolumn{12}{|l|}{ (8)Adj_LTG_ } \\
\hline \multirow[t]{2}{*}{ FORECAST } & 0.138 & 0.046 & 0.031 & -0.064 & -0.063 & -0.109 & -0.115 & 1 & & & \\
\hline & $(0.00)$ & $(0.00)$ & $(0.00)$ & $(0.00)$ & $(0.00)$ & $(0.00)$ & $(0.00)$ & & & & \\
\hline \multirow[t]{2}{*}{ (9) LEV } & 0.005 & 0.087 & -0.118 & -0.068 & -0.073 & 0.015 & 0.010 & 0.008 & 1 & & \\
\hline & $(0.69)$ & $(0.00)$ & $(0.00)$ & $(0.00)$ & $(0.00)$ & $(0.20)$ & $(0.41)$ & $(0.51)$ & & & \\
\hline \multirow[t]{2}{*}{ (10) RNOA } & -0.015 & -0.093 & 0.143 & 0.379 & 0.343 & 0.260 & 0.222 & -0.094 & -0.076 & 1 & \\
\hline & $(0.21)$ & $(0.00)$ & $(0.00)$ & $(0.00)$ & $(0.00)$ & $(0.00)$ & $(0.00)$ & $(0.00)$ & $(0.00)$ & & \\
\hline \multirow[t]{2}{*}{ (11) R\&D } & 0.320 & -0.017 & 0.243 & -0.011 & 0.093 & -0.225 & -0.116 & 0.088 & -0.144 & -0.040 & 1 \\
\hline & $(0.00)$ & $(0.16)$ & $(0.00)$ & $(0.36)$ & $(0.00)$ & $(0.00)$ & $(0.00)$ & $(0.00)$ & $(0.00)$ & $(0.00)$ & \\
\hline
\end{tabular}

This table presents descriptive statistics of the variables used in the yearly regression analyses. Panel A provides summary statistics and Panel B shows the correlations among the variables. Variable definitions: $E V S=$ (market value of equity + long-term debt + debt in current liabilities)/net sales; $\mathrm{PB}=$ market value of equity/total common equity; Ind_EVS = harmonic mean of the EVS ratio for firms in the industry (based on 2-digit SIC codes) estimated per year; Ind_PB = harmonic mean of the PB ratio for firms in the industry (based on 2-digit SIC codes) estimated per year; Adj_PM_GAAP = target GAAP profit margin - GAAP median industry profit margin, where profit margin is operating profit after depreciation/net sales; Adj_PM_STREET = target I/B/E/S actual profit margin - I/B/E/S median actual industry profit margin; LOSS_GAAP = 1 if target GAAP profit margin is negative, and 0 otherwise; LOSS_PM_GAAP $=$ Adj_PM_ GAAP * LOSS_GAAP; LOSS_STREET $=1$ if target I/B/E/S actual profit margin is negative, and 0 otherwise; LOSS_ PM_STREET $=$ Adj_PM _STREET $*$ LOSS_ANL; Adj_LTG_FORECAST $=\mathrm{I} / \mathrm{B} / \mathrm{E} / \mathrm{S}$ median long-term EPS growth forecast - median I/B/E/S industry forecast; LEV = total long-term debt/total stockholders' equity; $R N O A=$ operating income after depreciation/(net property, plant and equipment + total current assets - total current liabilities) $* 100$; $R \& D$ = industry-adjusted $\mathrm{R} \& \mathrm{D}$, computed in two steps: (1) compute the average R\&D level for each industry-year; (2) compute the level of abnormal $R \& D$ as a normalized deviation from the industry average level: ( $R \& D$ - industry median $\mathrm{R} \& \mathrm{D})$ /industry standard deviation of $\mathrm{R} \& \mathrm{D}$. 


\subsection{GAAP versus IBES Peer Selection and Future EVS}

\subsubsection{Warranted Multiples}

Based on our argumentation above, we posit that street numbers substantially affect peer selection via their impact on the warranted multiple. We therefore generate two predicted EVS multiples for each firm-year observation using the warranted multiple approach (Bhojraj and Lee, 2002). This predicted multiple is a prediction of a firm's current year EVS ratio and is the basis for selecting comparable firms to forecast a target firm's future EVS ratios.

For each firm-year observation, four peers from the same two-digit SIC industry are selected. The first set of four peers is selected based on the predicted GAAP EVS ratio, while the second set of four peers is selected based on the predicted street EVS ratio. We focus on peers from the same industry as prior research shows that industry-matched peers are superior in terms of valuation accuracy compared to peers selected from the COMPUSTAT universe (Foster, 1986; Alford, 1992). To estimate the current-year predicted EVS ratio, which then forms the basis for our peer selection, we require a minimum of eight firms per industry-year to ensure that enough potential peers are available. The key variables are defined as follows:

EVS_PRED_GAAP: predicted EVS based on GAAP valuation inputs. This variable is computed using the estimated regression coefficients from the prior year's regression using the GAAP version of Model (1) and accounting and market-based variables from the current year;

EVS_PRED_STREET: predicted EVS based on street earnings valuation inputs. This variable is computed using the estimated regression coefficients from the prior year's regression using the street version of Model (1) and accounting and market-based variables from the current year;

HARM_GAAP: harmonic mean of the actual EVS ratio of the four firms in the industry with the closest GAAP predicted EVS;

HARM_STREET: harmonic mean of the actual EVS ratio of the four firms in the industry with the closest street predicted EVS.

Before selecting peers, it is important to examine the extent to which the predicted EVS ratios, which are used to select peers, are different. A $t$-test on the difference between street and GAAP predicted EVS ratios suggests that the mean of the paired differences is negative $(-0.0176)$ and the difference is significant at $1 \%$ ( $\mathrm{p}$-value $<0.001)$. This suggests that on average street predicted EVS ratios are lower than the corresponding GAAP predicted EVS ratios. 
The next step is to examine the extent to which the peers selected based on GAAP and street earnings differ from each other. The results indicate that for $86 \%$ of the sample at least one common peer is identified, out of four peers. For $14 \%$ of the sample, no common peers are identified. The average overlap of peers in our sample is $65 \%$. This implies that out of four peers based on street earnings, on average 1.4 (2.6) of the peers are different (same) as the GAAP-based peers. These results imply that for a non-trivial percentage of firm-year observations, the set of peers is completely different once street instead of GAAP earnings are used.

\subsubsection{Predictive Ability and Valuation Accuracy of Street and GAAP Peers}

To evaluate whether street earnings are associated with better peer-based valuation performance, we examine two valuation performance dimensions. In line with prior research, the first dimension captures the ability of peers to predict current and future EVS ratios. The second dimension measures the valuation accuracy of peer-based valuation (e.g., Bhojraj and Lee, 2002; Young and Zeng, 2015).

Turning to the predictive ability of peers, we run two models for every firm-year observation to test whether street peers are more predictive of the target firm's current and future EVS. The first model includes the harmonic mean of the street peers as the independent variable and current and future (one-, two-, and three-year ahead) EVS values as the dependent variable. The second model includes the harmonic mean of the GAAP peers as the independent variable. We then compare the adjusted R-squared values of the two models using a Vuong test to determine which model has a significantly larger adjusted R-squared value (Brown and Sivakumar, 2003; Bradshaw and Sloan, 2002). The results are presented in Table 3. 
TABLE 3: Predictive Power of Street and GAAP Harmonic Mean of Peers for Current and Future EVS Ratios

\begin{tabular}{|c|c|c|c|c|c|}
\hline Panel A: Full Sample & & & & & \\
\hline & $\mathbf{N}$ & Intercept & HARM_STREET & HARM_GAAP & Adj. $R^{2}$ \\
\hline \multicolumn{6}{|l|}{$E V S_{i, t}$} \\
\hline STREET model & 7,301 & $\begin{array}{c}0.385 \\
(<.0001)\end{array}$ & $\begin{array}{c}0.980 \\
(<.0001)\end{array}$ & & 44.37 \\
\hline GAAP model & 7,301 & $\begin{array}{c}0.370 \\
(<.0001)\end{array}$ & & $\begin{array}{c}0.995 \\
(<.0001)\end{array}$ & 43.49 \\
\hline $\begin{array}{l}\text { Vuong } Z \text {-statistic } \\
\text { (p-value) }\end{array}$ & & & & & $\begin{array}{c}1.083 \\
(0.279)\end{array}$ \\
\hline \multicolumn{6}{|l|}{$E V S_{i, t+1}$} \\
\hline STREET model & 4,839 & $\begin{array}{c}0.582 \\
(<.0001)\end{array}$ & $\begin{array}{c}0.825 \\
(<.0001)\end{array}$ & & 36.77 \\
\hline GAAP model & 4,839 & $\begin{array}{c}0.559 \\
(<.0001)\end{array}$ & & $\begin{array}{c}0.846 \\
(<.0001)\end{array}$ & 35.71 \\
\hline $\begin{array}{l}\text { Vuong } Z \text {-statistic } \\
\text { (p-value) }\end{array}$ & & & & & $\begin{array}{l}1.213 \\
(0.225)\end{array}$ \\
\hline \multicolumn{6}{|l|}{$E V S_{i, t+2}$} \\
\hline STREET model & 3,903 & $\begin{array}{c}0.689 \\
(<.0001)\end{array}$ & $\begin{array}{c}0.757 \\
(<.0001)\end{array}$ & & 32.37 \\
\hline GAAP model & 3,903 & $\begin{array}{c}0.677 \\
(<.0001)\end{array}$ & & $\begin{array}{c}0.768 \\
(<.0001)\end{array}$ & 30.79 \\
\hline $\begin{array}{l}\text { Vuong } Z \text {-statistic } \\
\text { (p-value) }\end{array}$ & & & & & $\begin{array}{l}1.601 \\
(0.109)\end{array}$ \\
\hline \multicolumn{6}{|l|}{$E V S_{i, t+3}$} \\
\hline STREET model & 3,156 & $\begin{array}{c}0.769 \\
(<.0001)\end{array}$ & $\begin{array}{c}0.700 \\
(<.0001)\end{array}$ & & 29.54 \\
\hline GAAP model & 3,156 & $\begin{array}{c}0.732 \\
(<.0001)\end{array}$ & & $\begin{array}{c}0.726 \\
(<.0001)\end{array}$ & 29.29 \\
\hline $\begin{array}{l}\text { Vuong } Z \text {-statistic } \\
\text { (p-value) }\end{array}$ & & & & & $\begin{array}{c}0.276 \\
(0.783)\end{array}$ \\
\hline $\begin{array}{l}\text { Average Adj. R } \\
\text { STREET model }\end{array}$ & & & & & 35.76 \\
\hline $\begin{array}{l}\text { Average Adj. R } \\
\text { GAAP model }\end{array}$ & & & & & 34.82 \\
\hline
\end{tabular}


TABLE 3: Predictive Power of Street and GAAP Harmonic Mean of Peers for Current and Future EVS Ratios (continued)

\begin{tabular}{|c|c|c|c|c|c|}
\hline & $\mathbf{N}$ & Intercept & HARM_STREET & HARM_GAAP & Adj. $R^{2}$ \\
\hline \multicolumn{6}{|l|}{$E V S_{t}$} \\
\hline STREET model & 1,825 & $\begin{array}{c}0.999 \\
(<.0001)\end{array}$ & $\begin{array}{c}0.779 \\
(<.0001)\end{array}$ & & 28.04 \\
\hline GAAP model & 1,825 & $\begin{array}{c}1.063 \\
(<.0001)\end{array}$ & & $\begin{array}{c}0.776 \\
(<.0001)\end{array}$ & 25.10 \\
\hline $\begin{array}{l}\text { Vuong } Z \text {-statistic } \\
\text { (p-value) }\end{array}$ & & & & & $\begin{array}{l}1.496 \\
(0.135)\end{array}$ \\
\hline \multicolumn{6}{|l|}{$E V S_{t+1}$} \\
\hline STREET model & 1,148 & $\begin{array}{c}1.192 \\
(<.0001)\end{array}$ & $\begin{array}{c}0.621 \\
(<.0001)\end{array}$ & & 22.18 \\
\hline GAAP model & 1,148 & $\begin{array}{c}1.271 \\
(<.0001)\end{array}$ & & $\begin{array}{c}0.615 \\
(<.0001)\end{array}$ & 17.94 \\
\hline $\begin{array}{l}\text { Vuong } Z \text {-statistic } \\
\text { (p-value) }\end{array}$ & & & & & $\begin{array}{l}2.044 \\
(0.041)\end{array}$ \\
\hline \multicolumn{6}{|l|}{$E V S_{t+2}$} \\
\hline STREET model & 898 & $\begin{array}{c}1.325 \\
(<.0001)\end{array}$ & $\begin{array}{c}0.576 \\
(<.0001)\end{array}$ & & 18.72 \\
\hline GAAP model & 898 & $\begin{array}{c}1.420 \\
(<.0001)\end{array}$ & & $\begin{array}{c}0.555 \\
(<.0001)\end{array}$ & 13.86 \\
\hline $\begin{array}{l}\text { Vuong } Z \text {-statistic } \\
\text { (p-value) }\end{array}$ & & & & & $\begin{array}{l}2.105 \\
(0.035)\end{array}$ \\
\hline \multicolumn{6}{|l|}{$E V S_{t+3}$} \\
\hline STREET model & 728 & $\begin{array}{c}1.523 \\
(<.0001)\end{array}$ & $\begin{array}{c}0.488 \\
(<.0001)\end{array}$ & & 14.02 \\
\hline GAAP model & 728 & $\begin{array}{c}1.479 \\
(<.0001)\end{array}$ & & $\begin{array}{c}0.516 \\
(<.0001)\end{array}$ & 12.73 \\
\hline $\begin{array}{l}\text { Vuong } Z \text {-statistic } \\
\text { (p-value) }\end{array}$ & & & & & $\begin{array}{c}0.665 \\
(0.506) \\
-\end{array}$ \\
\hline $\begin{array}{l}\text { Average Adj. R } \\
\text { STREET model }\end{array}$ & & & & & 20.74 \\
\hline $\begin{array}{l}\text { Average Adj. R } \\
\text { GAAP model }\end{array}$ & & & & & 17.41 \\
\hline
\end{tabular}

This table provides estimated coefficients from the following prediction models:

$$
E V S i_{i, t+k}=\alpha_{t}+\sum_{J=1}^{1} \text { explanatory variable }+\mu i_{t}
$$

Where $\mathrm{k}=0,1,2,3$ are current, one-, two-, and three-year ahead EVS ratios. HARM_GAAP = harmonic mean of the actual EVS ratio of the four firms within the industry with the closest predicted GAAP EVS; HARM_STREET= harmonic mean of the actual EVS ratio of the four firms within the industry with the closest predicted street EVS. In Panel A the full sample is used, whereas in Panel B the sample consists of observations in the top quartile of the variable ABS_DIFF_HARMMPEERS. It captures the absolute difference in the harmonic mean of the peers based on the two different warranted multiples (HARM_STREET - HARM_GAAP). All other variables are defined below Table 2. 
An important first finding is that the harmonic mean of the peers by itself explains a substantial portion of the variation in the EVS ratios. The results in Table 3, Panel A indicate that the harmonic mean of the street peers explains on average $35.76 \%$ of the variation in the current and future EVS values, while this is $34.82 \%$ for the GAAP peers. The predictive ability of street peers increases slightly with the length of the forecast period. For the current year, these peers explain $0.88 \%$ more variation, for the year $t+1$ they explain $1.06 \%$, and for year $\mathrm{t}+2$ they explain $1.58 \%$ more of the variation in the EVS ratio - though the differences in the explanatory power between the two sets of peers are not statistically significant.

However, it is important to note that even if the identified peers are different, the harmonic mean might not substantially differ between street and GAAP peers. Appendix $2 \mathrm{~A}$ illustrates how, despite having a different set of peers, the harmonic means are not significantly different when street or GAAP peers are used. We therefore not only consider the number of different peers, but also the absolute difference in the harmonic means of the peers to capture a significantly different set of peers.

To further explore this issue, we focus on firms where street and GAAP peers have a fundamentally different harmonic mean. For every firm-year observation, we create a variable $A B S \_D I F F \_H A R M P E E R S$, which captures the absolute difference in the harmonic mean of street peers and that of the GAAP peers. The full sample is then divided in quartiles based on this absolute difference with the top quartile reflecting the highest differences in the harmonic mean of peers.

Results for the top-quartile subsample are presented in Table 3, Panel B and indicate that the street peers explain on average $20.74 \%$, while the GAAP peers explain only $17.41 \%$ of the variation in current and future EVS ratios. When significantly different peers are selected, i.e., peers which lead to a different harmonic mean of the EVS ratio, the gap in the explanatory power between the two sets of peers increases. In line with the full sample, the predictive ability of the street peers increases slightly with the length of the forecast period. For the current year, street peers explain $2.94 \%$ more variation, for the year $t+1$ they explain $4.24 \%$ and for year $t+2$ they explain $4.86 \%$ more of the variation in the EVS ratio, compared to GAAP peers. The differences in the explanatory power between the two sets of peers are statistically significant at $5 \%$ for the one- and two-year ahead EVS ratios. ${ }^{17}$

Taken together, the results indicate that on average street peers do not outperform GAAP peers, unless significantly different peers are selected. The larger the difference in

17 Untabulated results indicate that the higher the difference in the mean of peers (e.g., top decile), the higher the gap in the explanatory power between the two sets of peers. In the top decile, the street peers explain on average $15 \%$ and the GAAP peers $9 \%$ of the variation in current and future EVS ratios. For the current year, street peers explain $3.21 \%$, for the year $\mathrm{t}+1$ they explain $6.89 \%$ and for the year $\mathrm{t}+2$ they explain $10.72 \%$ more of the variation in the EVS ratio. 
the harmonic mean of the selected peers, the better street peers explain the target firm's current, one- and two-year ahead EVS ratios.

Besides investigating the predictive ability of peers to forecast future EVS multiples, it is also important to consider the accuracy of these peer-based EVS predictions. Therefore, the second dimension captures absolute valuation errors of both street- and GAAP-based peer valuations. STREET_AVE captures valuation errors produced by street-based multiple valuation and GAAP_AVE captures those produced by GAAP peers. We then compare the differences in the valuation errors between the two sets of peers to identify which set of peers yields more accurate EVS estimates. The results are presented in Table 4.

TABLE 4: Valuation Accuracy of Street and GAAP Harmonic Mean of Peers for Current and Future EVS Ratios

\begin{tabular}{|c|c|c|c|}
\hline \multicolumn{4}{|c|}{ Panel A: Full Sample } \\
\hline & $\mathbf{N}$ & Mean & Median \\
\hline \multicolumn{4}{|l|}{$E V S_{i, t}$} \\
\hline STREET_AVE & 7,301 & 0.379 & 0.285 \\
\hline GAAP_AVE & 7,301 & 0.385 & 0.288 \\
\hline Difference & & $-0.006^{*}$ & -0.003 \\
\hline (p-value) & & $(0.080)$ & $(0.112)$ \\
\hline \multicolumn{4}{|l|}{$E V S_{i, t+1}$} \\
\hline STREET_AVE & 4,683 & 0.355 & 0.277 \\
\hline GAAP_AVE & 4,683 & 0.367 & 0.282 \\
\hline Difference & & $-0.012^{* * *}$ & $-0.005^{*}$ \\
\hline (p-value) & & $(0.002)$ & $(0.075)$ \\
\hline \multicolumn{4}{|l|}{$E V S_{i, t+2}$} \\
\hline STREET_AVE & 3,675 & 0.353 & 0.274 \\
\hline GAAP_AVE & 3,675 & 0.364 & 0.279 \\
\hline Difference & & $-0.011^{* * *}$ & -0.005 \\
\hline (p-value) & & $(0.010)$ & $(0.171)$ \\
\hline \multicolumn{4}{|l|}{$\boldsymbol{E V} \boldsymbol{S}_{i, t+3}$} \\
\hline STREET_AVE & 2,908 & 0.352 & 0.272 \\
\hline GAAP_AVE & 2,908 & 0.373 & 0.280 \\
\hline Difference & & $-0.021^{* * *}$ & $-0.008^{* * *}$ \\
\hline (p-value) & & $(<.0001)$ & $(0.005)$ \\
\hline
\end{tabular}




\begin{tabular}{|c|c|c|c|}
\hline \multicolumn{4}{|c|}{ Panel B: Top Quartile Difference } \\
\hline & $\mathbf{N}$ & Mean & Median \\
\hline \multicolumn{4}{|l|}{$E V S_{i, t}$} \\
\hline STREET_AVE & 1,825 & 0.418 & 0.302 \\
\hline GAAP_AVE & 1,825 & 0.441 & 0.329 \\
\hline Difference & & $-0.023^{* *}$ & $-0.027^{* * *}$ \\
\hline (p-value) & & $(0.047)$ & $(0.005)$ \\
\hline \multicolumn{4}{|l|}{$\boldsymbol{E} \boldsymbol{V} \boldsymbol{S}_{i, t+1}$} \\
\hline STREET_AVE & 1,130 & 0.356 & 0.272 \\
\hline GAAP_AVE & 1,130 & 0.384 & 0.299 \\
\hline Difference & & $-0.028^{* * *}$ & $-0.027^{* *}$ \\
\hline (p-value) & & $(0.002)$ & $(0.032)$ \\
\hline \multicolumn{4}{|l|}{$E V S_{i, t+2}$} \\
\hline STREET_AVE & 863 & 0.355 & 0.283 \\
\hline GAAP_AVE & 863 & 0.370 & 0.287 \\
\hline Difference & & -0.015 & -0.004 \\
\hline (p-value) & & $(0.212)$ & $(0.498)$ \\
\hline \multicolumn{4}{|l|}{$E V S_{i, t+3}$} \\
\hline STREET_AVE & 706 & 0.332 & 0.254 \\
\hline GAAP_AVE & 706 & 0.352 & 0.268 \\
\hline Difference & & $-0.020^{*}$ & -0.014 \\
\hline (p-value) & & $(0.055)$ & $(0.319)$ \\
\hline
\end{tabular}

This table presents tests of valuation accuracy for street and GAAP peers, which is captured by absolute valuation errors. Absolute valuation errors capture the difference between actual and peer-based implied EVS. STREET_AVE $i_{i, t+k}=$ $\left(E V S i_{i, t+k^{-}}\right.$HARM_STREETi $\left.i_{i, t+k}\right) / E V S i_{i, t+k^{k}}$ Similarly, GAAP_AVEi $i_{i, t+k}=\left(E V S i_{i, t+k^{-}}\right.$HARM_GAAPi $\left.i_{i, t+k}\right) / E V S i_{i, t+k^{\prime}}$, where $\mathrm{k}=0,1,2,3$ are current, one, two, and three-year ahead actual EVS and peer-based implied EVS ratios. Difference captures the mean (median) difference between STREET_AVEi $i_{i, t+k}$ and GAAP_AVEi ${ }_{i, t+k}$. Negative differences suggest that GAAP peers provide less accurate EVS estimates than street peers, while positive differences suggest that street peers exhibit higher valuation errors, and thus less accurate EVS estimates than GAAP peers. In Panel A the full sample is used, whereas in Panel B the sample consists of observations in the top quartile of the variable ABS_DIFF_HARMMPEERS. Please refer to Table 3 for definition of HARM_STREET, HARM_GAAP and ABS_DIFF_HARMMPEERS variables. The pairwise differences between STREET_AVEi $i_{i, t+k}$ and $G A A P_{-} A V E i_{i, t+k}$ are tested using a paired t-test (for mean differences) and a paired Wilcoxon signed rank test (for median differences). ${ }^{*},{ }^{* *}$, and ${ }^{* * *}$ represent significance at the 10 percent, 5 percent, and 1 percent levels, respectively.

Panel A of Table 4 depicts differences in the valuation errors for the full sample, while Panel B represents the top-quartile subsample with highest differences in the harmonic mean of the peers. The results in panel A suggest that mean absolute valuation errors decline when street-based peer valuation is used, with the decline being economically significant for all forecasting windows. When street-based peer valuation is used, the decline in mean absolute valuation errors is $1.6 \%$ and $5.6 \%$ for the current and threeyear ahead EVS multiple, respectively. Panel B of Table 4 provides similar and slightly stronger results. The use of street earnings in peer selection is associated with a decline 
in mean absolute valuation errors of $5.2 \%$ and $5.7 \%$ for current and three-year ahead EVS multiples, respectively.

Taken together, the results indicate that street peers are associated with more accurate multiples-based valuation estimates through improved peer selection. Especially when peers are selected that also lead to a different harmonic mean, street-based peers yield more accurate valuation estimates than GAAP peers. In addition, when different peers are selected, street peers are more predictive of the target firm's one- and two-year ahead EVS ratios.

\subsubsection{Drivers of Differences in Selected Peers}

Given that on average street peers do not outperform GAAP peers, it is important to understand for which firms analysts and their street earnings add value. Hence, besides examining which set of peers better explains the target firm's current and future EVS ratios, it is also important to investigate whether we can find variables that explain the differences in the selected peers. We therefore examine the association between several firm and industry-specific characteristics and the likelihood of finding significantly different peers using a probit model.

The dependent variable of the model is an indicator variable equal to one if the absolute difference in the harmonic means between street and GAAP peers is in the top quartile, and zero otherwise. We include a set of firm-specific variables which are likely to affect forecast accuracy and the ability of GAAP numbers to capture the underlying business economics. These measures proxy for firm complexity. For more complex firms, accounting standards are less likely to capture firms' economic fundamentals on a timely basis. Analysts' firm and industry-specific information advantage is likely to have a larger effect on the difference in the selected peers in complex and opaque firms (e.g., Duru and Reeb, 2002; Lehavy et al., 2011). As explanatory variables, we include R\&D and advertising expenditures, merger and acquisition activities, intangible assets, goodwill and foreign income. We also include the level of inventory build-up following Hutton et al. (2012), as firms with unusual operating situations such as abnormal inventory are particulary difficult to forecast. Further we include industry complexity and opaqueness, industry dispersion, and industry size. We refer to Table 5 for a detailed explanation of the variable definitions. 
TABLE 5: Drivers of Systematic Differences in Selected Peers

\begin{tabular}{|c|c|c|c|}
\hline & Coefficient & p-value & Marginal effects \\
\hline INTERCEPT & -1.877 & $<.0001$ & \\
\hline$R \approx D$ & 0.162 & $<.0001$ & 0.043 \\
\hline$A D V$ & 2.216 & 0.009 & 0.586 \\
\hline$I N T$ & 0.046 & 0.677 & 0.012 \\
\hline$M \mho A$ & 0.109 & 0.027 & 0.029 \\
\hline FOREIGN_INC & 0.493 & 0.082 & 0.130 \\
\hline$I N V_{-} B U I L D$ & 0.055 & 0.006 & 0.014 \\
\hline GOODWILL & 0.085 & 0.531 & 0.023 \\
\hline INDUSTR_DISPR & 0.362 & $<.0001$ & 0.096 \\
\hline$I N D U S T R \_I N D$ & 0.278 & $<.0001$ & 0.073 \\
\hline N_INDYEAR & 0.012 & 0.262 & 0.003 \\
\hline Number of observations & & 7,097 & \\
\hline Industry FE & & YES & \\
\hline Year FE & & YES & \\
\hline Pseudo R-square & & 16.45 & \\
\hline
\end{tabular}

This table presents the results of a probit model on the drivers of systematic differences in the selected peers. The dependent variable is an indicator variable equal to one if the target firm's absolute difference in the EVS mean of peers is in the top quartile and zero otherwise. $R \mathcal{\sigma} D=$ industry-adjusted $R \& D$, computed in two steps: (1) compute the average R\&D level for each industry-year; (2) compute the level of abnormal $\mathrm{R} \& \mathrm{D}$ as a normalized deviation from the industry average level: ( $R \& D$ - industry median $\mathrm{R} \& \mathrm{D})$ /industry standard deviation of $\mathrm{R} \& \mathrm{D} ; A D V=$ advertising expense divided by net sales; $I N T=$ net intangible assets scaled by total assets; $M \mathcal{S} A=$ indicator variable equal to one if a firm has merger and acquisition-related (M\&A) costs, and zero otherwise; FOREIGN_INC= foreign income divided by sales; INV_BUILD = computed in three steps: (1) compute for each firm-year day's inventory, where day's inventory is equal to (inventory/cost of goods sold) $\times 365 ; 2$ ) compute the average day's inventory for each industry-year; (3) compute the level of abnormal inventory as a normalized deviation from the industry average day's inventory: (days inventory - industry median days inventory)/industry standard deviation of days inventory; GOODWILL= indicator variable equal to one if a firm has goodwill, and zero otherwise; INDUSTR_IND= indicator variable equal to one if a firm belongs to one of the more complex and opaque industries, and zero otherwise, where more complex industries include the following sectors: computer software; electronic equipment; pharmaceutical products and drugs; chemicals; petroleum and natural gas; health services; utilities; communications; business services; hardware computers; measuring and control equipment; financial trading; restaurants, hotels and motels; precious metals; non-metallic and industrial metal mining; INDUSTR_DISPR= industry dispersion, calculated as the interquartile range of the EVS of all firms for a given industry-combination; $N \_I N D Y E A R=$ number of firms per industry-year available for the peer selection. Standard errors are clustered by firm.

Table 5 presents the results of the probit model and the accompanying marginal effects. All predictors, except for intangibles and goodwill, are significant at $10 \%$. All firm and industry-specific characteristics are positively related to the likelihood of having different peers. The strongest predictor for having significantly different peers is the intensity of advertising expenditures. A one-percent increase in advertising expenditures is associated with a $58.6 \%$ higher likelihood of having different peers. The second strongest predictor for having different peers is foreign income exposure. A one-percent increase in foreign income is associated with a $13 \%$ higher likelihood of having different peers. The third strongest predictor for having different peers is industry dispersion, 
which emphasizes the role of industry characteristics in peer-based valuation (Alford, 1992). R\&D expenditures and M\&A related costs are also strong predictors for having different peers. This is in line with our expectations since GAAP, with its required expensing of R\&D investments, is unable to fully capture the economic fundamentals of an R\&D-intense firm on a timely basis (Healy et al., 2002). For firms operating in one of the more complex industries, the likelihood of having different peers is $7 \%$ higher than for firms operating in less complex industries. These results support the industry-specific knowledge and expertise of analysts.

Overall, these results suggest that for firms with more complex operations and firms operating in more complex industries, analysts' expertise and information advantage are more likely to result in a different set of peers and a better prediction of current and future EVS ratios.

\subsection{GAAP versus Street Peers and Implications for Future Returns}

Peer-based valuation is widely used by investors when making investment decisions. Doukas et al. (2010) argue that peer-based valuation affects investor beliefs and thus stock prices, as it provides relevant information about other stocks and the economy. Moreover, peer-based valuation allows investors to categorize securities as "underpriced" or "overpriced" and make inferences about future performance. The underlying assumption is that investors have imperfect information about expected returns or cash flows and therefore learn about it using relative industry performance information (Doukas et al., 2010).

One would expect that analyst coverage and the large extent of information disclosure would allow professional investors to identify mispricing, bringing the market into equilibrium. However, anecdotical evidence suggests that these sophisticated investors still strongly rely on GAAP numbers when conducting valuation analyses (Papa and Peters, 2016). Given our prior arguments on GAAP numbers being a flawed basis for valuation analyses, an implication is that mispricing is still likely to exist. Prior research indeed suggests that the market does not fully incorporate accounting and analyst information into stock prices and consequently has flawed expectations (Piotroski and So, 2012). We hence posit that street earnings-based multiple valuation can help address mispricing in the market.

The essence of peer-based multiple valuation is to identify peers that are similar to the target firm, and then take the average multiple of these peers as an indication of what the multiple of the target firm should be. The predicted EVS reflects what the target firm's performance should be, as it is the mean predicted EVS of its comparable peers. Similar to Doukas et al. (2010), we expect any gap between the actual EVS of the target firm and the predicted EVS to be reflective of over- or under-performance, as the target 
firm's multiple is not in line with that of its peers. ${ }^{18}$ The difference between the predicted and actual EVS may then help in identifying potential mispricing and should correlate with future returns. ${ }^{19}$ In our setting, we have two different predicted EVS ratios: One using street peers and one using peers identified based on GAAP numbers. Following our reasoning and findings, we expect that if the difference between the predicted and actual EVS helps explain future stock returns, this association should predominantly (or even only) exist for street earnings-based predicted EVS. To test this conjecture, we use the difference between the predicted and actual EVS at the end of the year (DIFFEVS) to make inferences about a target firm's over- or under-performance, where DIFFEVS is calculated separately for the street earnings-based predicted multiple and the GAAPbased predicted multiple. ${ }^{20}$ Next, we run the following model:

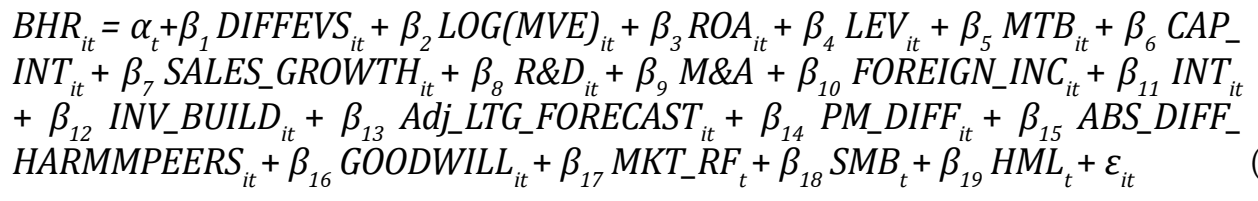

The dependent variable represents the buy-and-hold-returns for different holding periods, ranging from 12,24 to 36 months - so $t$ up to $t+3$. We refer to Table 6 for a detailed explanation of the variable definitions.

We run model (2) separately for the street earnings and GAAP scenarios. To disentangle the role of the differential peer selection from the direct impact of analyst adjustments as such, we control for $\mathrm{I} / \mathrm{B} / \mathrm{E} / \mathrm{S}$ adjustments that are used as key input variables in the peer selection process. Specifically, we include the difference between $\mathrm{I} / \mathrm{B} / \mathrm{E} / \mathrm{S}$ and GAAP profit margins (PM_DIFF) in the model to capture the aggregate impact analyst adjustments. ${ }^{21}$ We further adjust the buy-and-hold returns for risk using the FamaFrench three-factors. Industry and year fixed effects are included in the model and standard errors are clustered at the firm level. ${ }^{22}$ The results are presented in Table 6.

18 Using the ratio of the firm's actual value relative to its industry-based predicted value to capture mispricing, Doukas, Kim and Pantzalis (2010) find that the peer-based implied mispricing is related to future abnormal returns. Hence, any gap between our predicted multiple and the firm's actual EVS should be associated with future returns.

19 Note that a negative difference between the predicted and actual EVS implies that the target firm exceeded the peerbased expectations, which should be associated with higher returns in the future (e.g., actual EVS of 12 whereas the implied EVS is 10). In contrast, a positive difference reveals that the target firm under-performed and fell short of its peer-based expectations, which is expected to be associated with lower future returns (e.g., an actual EVS of 10, whereas the predicted EVS is 12 ).

20 The results reported in Table 6 are based on a sample where DIFFEVS_STREET is not equal to DIFFEVS_GAAP to capture differential peer-based valuation. Our inferences remain unaffected when using the full sample.

21 To filter out the effect of analyst adjustments and ensure that our results are driven by the peer selection, we use total I/B/E/S adjustments in untabulated analyses. We replace PM_DIFF with the scaled difference in EPS, which is measured as $\left(\mathrm{EPS}_{\mathrm{I} / \mathrm{B} / \mathrm{E} / \mathrm{S}}-\mathrm{EPS}_{\mathrm{GAAP}}\right) / \mathrm{EPS}_{\mathrm{GAAP}}$ Our inferences are unaffected.

22 Our inferences remain unaffected if we cluster standard errors by industry and year. 
TABLE 6: Buy-and-Hold Returns

\begin{tabular}{|c|c|c|c|}
\hline \multicolumn{4}{|l|}{ Panel A: STREET Model } \\
\hline & $\begin{array}{l}\text { 12-month } \\
\text { BHR }\end{array}$ & $\begin{array}{c}\text { 24-month } \\
\text { BHR }\end{array}$ & $\begin{array}{c}\text { 36-month } \\
\text { BHR }\end{array}$ \\
\hline DIFFEVS_STREET & $\begin{array}{c}-0.013^{* *} \\
(-2.20)\end{array}$ & $\begin{array}{c}-0.021^{*} \\
(-1.83)\end{array}$ & $\begin{array}{l}-0.020 \\
(-1.13)\end{array}$ \\
\hline$L O G(M V E)$ & $\begin{array}{l}-0.010^{*} \\
(-1.94)\end{array}$ & $\begin{array}{c}-0.039^{* * *} \\
(-3.68)\end{array}$ & $\begin{array}{c}-0.046^{* * *} \\
(-3.27)\end{array}$ \\
\hline$R O A$ & $\begin{array}{l}0.132 \\
(1.01)\end{array}$ & $\begin{array}{l}0.063 \\
(0.28)\end{array}$ & $\begin{array}{l}-0.082 \\
(-0.26)\end{array}$ \\
\hline$L E V$ & $\begin{array}{c}0.024^{* *} \\
(2.23)\end{array}$ & $\begin{array}{c}0.045^{* *} \\
(2.30)\end{array}$ & $\begin{array}{l}0.043 \\
(1.58)\end{array}$ \\
\hline$M T B$ & $\begin{array}{c}-0.009^{* *} \\
(-2.24)\end{array}$ & $\begin{array}{l}-0.010 \\
(-1.26)\end{array}$ & $\begin{array}{l}0.002 \\
(0.18)\end{array}$ \\
\hline CAP_INT & $\begin{array}{l}-0.010 \\
(-0.92)\end{array}$ & $\begin{array}{l}-0.019 \\
(-1.09)\end{array}$ & $\begin{array}{l}-0.007 \\
(-0.29)\end{array}$ \\
\hline SALES_GROWTH & $\begin{array}{l}-0.008 \\
(-0.33)\end{array}$ & $\begin{array}{l}-0.018 \\
(-0.62)\end{array}$ & $\begin{array}{l}-0.034 \\
(-1.02)\end{array}$ \\
\hline$R \& D$ & $\begin{array}{l}0.004 \\
(0.58)\end{array}$ & $\begin{array}{l}0.019 \\
(1.50)\end{array}$ & $\begin{array}{c}0.040^{* *} \\
(2.24)\end{array}$ \\
\hline$M \mho A$ & $\begin{array}{l}0.008 \\
(0.46)\end{array}$ & $\begin{array}{l}0.029 \\
(0.89)\end{array}$ & $\begin{array}{l}0.001 \\
(0.03)\end{array}$ \\
\hline FOREIGN_INC & $\begin{array}{l}0.117 \\
(1.04)\end{array}$ & $\begin{array}{l}0.053 \\
(0.28)\end{array}$ & $\begin{array}{l}-0.145 \\
(-0.53)\end{array}$ \\
\hline$I N T$ & $\begin{array}{c}-0.110^{* * *} \\
(-2.88)\end{array}$ & $\begin{array}{l}-0.091 \\
(-1.23)\end{array}$ & $\begin{array}{l}0.026 \\
(0.25)\end{array}$ \\
\hline GOODWILL & $\begin{array}{l}0.004 \\
(0.13)\end{array}$ & $\begin{array}{l}0.069 \\
(1.29)\end{array}$ & $\begin{array}{l}0.119^{*} \\
(1.75)\end{array}$ \\
\hline$I N V_{-} B U I L D$ & $\begin{array}{l}-0.001 \\
(-0.09)\end{array}$ & $\begin{array}{r}-0.002 \\
(0.17)\end{array}$ & $\begin{array}{l}-0.003 \\
(-0.19)\end{array}$ \\
\hline $\begin{array}{l}\text { Adj_LTG_ } \\
F O R E C A S T\end{array}$ & $\begin{array}{c}-0.002^{* *} \\
(-2.14)\end{array}$ & $\begin{array}{c}-0.005^{* *} \\
(-3.87)\end{array}$ & $\begin{array}{c}-0.007^{* * *} \\
(-4.64)\end{array}$ \\
\hline PM_DIFF & $\begin{array}{l}0.223 \\
(1.06)\end{array}$ & $\begin{array}{l}0.268 \\
(0.85)\end{array}$ & $\begin{array}{l}0.130 \\
(0.33)\end{array}$ \\
\hline $\begin{array}{l}A B S_{-} D I F F_{-} \\
H A R M M P E E R S\end{array}$ & $\begin{array}{l}0.008 \\
(0.67)\end{array}$ & $\begin{array}{l}0.006 \\
(0.28)\end{array}$ & $\begin{array}{l}-0.019 \\
(-0.70)\end{array}$ \\
\hline$M K T \_R F$ & $\begin{array}{c}-0.023^{* * *} \\
(-7.71)\end{array}$ & $\begin{array}{c}-0.046^{* * *} \\
(-10.40)\end{array}$ & $\begin{array}{c}-0.023^{* * *} \\
(-7.56)\end{array}$ \\
\hline$S M B$ & $\begin{array}{c}0.043^{* * *} \\
(6.64)\end{array}$ & $\begin{array}{c}0.070^{* * *} \\
(7.75)\end{array}$ & $\begin{array}{c}0.020^{* * *} \\
(5.44)\end{array}$ \\
\hline$H M L$ & $\begin{array}{c}0.014^{* * *} \\
(4.84)\end{array}$ & $\begin{array}{c}0.010^{* *} \\
(2.20)\end{array}$ & $\begin{array}{c}-0.007^{*} \\
(-1.79)\end{array}$ \\
\hline Industry and year fixed effects & Yes & Yes & Yes \\
\hline $\mathrm{N}$ & 3,751 & 3,575 & 3,399 \\
\hline Adjusted $\mathrm{R}^{2}$ & $30.05 \%$ & $30.87 \%$ & $21.61 \%$ \\
\hline
\end{tabular}


TABLE 6: Buy-and-Hold Returns (continued)

\begin{tabular}{|c|c|c|c|}
\hline \multicolumn{4}{|l|}{ Panel B: GAAP Model } \\
\hline & $\begin{array}{c}\text { 12-month } \\
\text { BHR }\end{array}$ & $\begin{array}{c}\text { 24-month } \\
\text { BHR }\end{array}$ & $\begin{array}{c}\text { 36-month } \\
\text { BHR }\end{array}$ \\
\hline DIFFEVS_GAAP & $\begin{array}{l}-0.004 \\
(-0.67)\end{array}$ & $\begin{array}{l}-0.011 \\
(-0.95)\end{array}$ & $\begin{array}{l}-0.017 \\
(-0.98)\end{array}$ \\
\hline$L O G(M V E)$ & $\begin{array}{c}-0.010^{* *} \\
(-1.98)\end{array}$ & $\begin{array}{c}-0.040^{* * *} \\
(-3.71)\end{array}$ & $\begin{array}{c}-0.046^{* * *} \\
(-3.27)\end{array}$ \\
\hline$R O A$ & $\begin{array}{l}0.126 \\
(0.97)\end{array}$ & $\begin{array}{l}0.055 \\
(0.24)\end{array}$ & $\begin{array}{l}-0.088 \\
(-0.28)\end{array}$ \\
\hline$L E V$ & $\begin{array}{c}0.022^{* *} \\
(2.04)\end{array}$ & $\begin{array}{c}0.042^{* *} \\
(2.20)\end{array}$ & $\begin{array}{l}0.043 \\
(1.57)\end{array}$ \\
\hline$M T B$ & $\begin{array}{l}-0.006 \\
(-1.64)\end{array}$ & $\begin{array}{l}-0.007 \\
(-0.89)\end{array}$ & $\begin{array}{l}0.003 \\
(0.27)\end{array}$ \\
\hline CAP_INT & $\begin{array}{l}-0.001 \\
(-0.13)\end{array}$ & $\begin{array}{l}-0.010 \\
(-0.80)\end{array}$ & $\begin{array}{l}-0.005 \\
(-0.18)\end{array}$ \\
\hline SALES_GROWTH & $\begin{array}{l}-0.005 \\
(-0.21)\end{array}$ & $\begin{array}{l}-0.010 \\
(-0.59)\end{array}$ & $\begin{array}{l}-0.032 \\
(-0.95)\end{array}$ \\
\hline$R \& D$ & $\begin{array}{l}0.004 \\
(0.55)\end{array}$ & $\begin{array}{l}0.019 \\
(1.51)\end{array}$ & $\begin{array}{c}0.041^{* *} \\
(2.28)\end{array}$ \\
\hline$M \& A$ & $\begin{array}{l}0.008 \\
(0.47)\end{array}$ & $\begin{array}{l}0.030 \\
(0.90)\end{array}$ & $\begin{array}{l}0.001 \\
(0.02)\end{array}$ \\
\hline FOREIGN_INC & $\begin{array}{l}0.110 \\
(0.98)\end{array}$ & $\begin{array}{l}0.041 \\
(0.22)\end{array}$ & $\begin{array}{l}-0.155 \\
(-0.57)\end{array}$ \\
\hline$I N T$ & $\begin{array}{c}-0.113^{* * *} \\
(-2.94)\end{array}$ & $\begin{array}{l}-0.095 \\
(-1.29)\end{array}$ & $\begin{array}{l}0.023 \\
(0.22)\end{array}$ \\
\hline GOODWILL & $\begin{array}{l}0.006 \\
(0.18)\end{array}$ & $\begin{array}{l}0.071 \\
(1.32)\end{array}$ & $\begin{array}{l}0.119^{*} \\
(1.76)\end{array}$ \\
\hline$I N V_{-} B U I L D$ & $\begin{array}{l}-0.001 \\
(-0.16)\end{array}$ & $\begin{array}{l}-0.003 \\
(-0.23)\end{array}$ & $\begin{array}{l}-0.003 \\
(-0.21)\end{array}$ \\
\hline $\begin{array}{l}\text { Adj_LTG_ } \\
F O R E C A S T\end{array}$ & $\begin{array}{c}-0.002^{* *} \\
(-2.16)\end{array}$ & $\begin{array}{c}-0.005^{* * *} \\
(-3.88)\end{array}$ & $\begin{array}{c}-0.007^{* * *} \\
(-4.63)\end{array}$ \\
\hline PM_DIFF & $\begin{array}{l}0.179 \\
(0.86)\end{array}$ & $\begin{array}{l}0.187 \\
(0.59)\end{array}$ & $\begin{array}{l}0.042 \\
(0.11)\end{array}$ \\
\hline $\begin{array}{l}A B S_{-} D I F F_{-} \\
H A R M M P E E R S\end{array}$ & $\begin{array}{l}0.003 \\
(0.23)\end{array}$ & $\begin{array}{l}0.000 \\
(0.02)\end{array}$ & $\begin{array}{l}-0.023 \\
(-0.82)\end{array}$ \\
\hline$M K T \_R F$ & $\begin{array}{c}-0.023^{* * *} \\
(-7.69)\end{array}$ & $\begin{array}{c}-0.046^{* * *} \\
(-10.45)\end{array}$ & $\begin{array}{c}-0.023^{* * *} \\
(-7.52)\end{array}$ \\
\hline$S M B$ & $\begin{array}{c}0.043^{* * *} \\
(6.59)\end{array}$ & $\begin{array}{c}0.070^{* * *} \\
(7.78)\end{array}$ & $\begin{array}{c}0.020^{* * *} \\
(5.43)\end{array}$ \\
\hline$H M L$ & $\begin{array}{c}0.014^{* * *} \\
(4.82)\end{array}$ & $\begin{array}{c}0.010^{* *} \\
(2.18)\end{array}$ & $\begin{array}{c}-0.007^{*} \\
(-1.81)\end{array}$ \\
\hline Industry and year fixed effects & Yes & Yes & Yes \\
\hline $\mathrm{N}$ & 3,751 & 3,575 & 3,399 \\
\hline Adjusted $\mathrm{R}^{2}$ & $29.98 \%$ & $30.81 \%$ & $21.59 \%$ \\
\hline
\end{tabular}

This table reports buy-and-hold returns (BHR) for different holding periods using the following model:

$$
B H R_{i, t}=\alpha_{t}+\sum_{J=1}^{19} \text { explanatory variable }+\mu i_{t}
$$

Where $\mathrm{t}=12,24$ and 36 month holding periods. The holding period returns are calculated as $\mathrm{BHR}_{\mathrm{i}, \mathrm{t}}=$ $\left[\prod_{t=1}^{T}\left(1+R_{i, t}\right)-1\right]$, where $\mathrm{R}_{\mathrm{i}, \mathrm{t}}$ is the CRSP monthly return on stock $i$. In Panel A DIFFEVS_STREET $T_{i t}$ measured as HARM_STREET-EVS ${ }_{i t}$ is used, while in Panel $\mathrm{B}$ the variable is replaced by DIFFEVS_GAAP ${ }_{i t}=H_{A R M}$ GAAP-EVS The control variables in both models include: $L O G(M V E)_{i t}=$ the natural logarithm of market value of equity; $R O A_{i t}=$ net 
income scaled by total assets; $L E V_{i t}=$ total long-term debt scaled by the book value of common equity; $M T B_{i t}=$ marketto-book ratio; CAP_INT $T_{i t}=$ total assets scaled by sales; $S A L E S \_G R O W T H_{i t}=\left(\right.$ Sales $_{\mathrm{t}}-$ Sales $\left._{\mathrm{t}-1}\right) / S_{\text {ales }}$; $R \& D_{i t}=$ industryadjusted R\&D, computed in two steps: (1) compute the average R\&D level for each industry-year; (2) compute the level of abnormal $\mathrm{R} \& \mathrm{D}$ as a normalized deviation from the industry average level: (R\&D-industry median $\mathrm{R} \& \mathrm{D}) /$ industry standard deviation of $\mathrm{R} \& \mathrm{D} ; M \& A=$ indicator variable equal to one if a firm has merger and acquisition-related (M\&A) costs, and zero otherwise; FOREIGN_INC $C_{i t}=$ foreign income divided by sales; $I N T_{i t}=$ net intangible assets scaled by total assets; GOODWILL= indicator variable equal to one if a firm has goodwill, and zero otherwise; INV_BUILD = computed in three steps: (1) compute for each firm-year day's inventory, where day's inventory is equal to (inventory/cost of goods sold) $\times 365$; 2) compute the average day's inventory for each industry-year; (3) compute the level of abnormal inventory as a normalized deviation from the industry average day's inventory: (days inventory - industry median days inventory)/ industry standard deviation of days inventory; $A d j \_L T G_{-} F O R E C A S T_{i t}=$ industry-adjusted I/B/E/S long-term growth forecasts; $P M_{-} D I F F_{i t}=\mathrm{I} / \mathrm{B} / \mathrm{E} / \mathrm{S}$ profit margin-GAAP profit margin; ABS_DIFF_HARMMPEERS $=$ HARM_STREET$H A R M_{-} G A A P ; M K T_{-} R F_{t}=$ value-weighted market index return- risk free rate, obtained from Kenneth French's website; $S M B_{t}=$ excess returns of small-cap companies over large-cap companies, obtained from Kenneth French's website; $H M L=$ excess returns of value stocks (high book-to-price ratio) over growth stocks (low book-to-price ratio), obtained from Kenneth French's website. Coefficient estimates and t-statistics are presented within the columns. Standard errors are clustered by firm. * **, and ${ }^{* * *}$ represent significance at the 10 percent, 5 percent, and 1 percent levels, respectively.

Panel A of Table 6 presents the results for the street earnings-based multiple valuation model, while Panel B presents the findings for the GAAP-based multiple valuation model. The results in Table 6 reveal that DIFFEVS_STREET helps to explain one- and two-year ahead buy-and-hold returns, whereas DIFFEVS_GAAP is not associated with future returns. Panel A shows that, for a 12-month holding period, target firms that exceed their peer-based expectations by one point have $1.3 \%$ higher buy-and-hold returns ( $p$-value $=0.028$ ). Similarly, for the 24-month holding period, target firms exceeding their peer-based expectations have $2.1 \%$ higher buy-and-hold returns ( $\mathrm{p}$-value=0.068). In contrast, the results presented in Panel B fail to provide evidence of an association between the predicted GAAP EVS and future target firm returns.

In line with our expectations, significant results only exist for the street-based predicted EVS. Phrased differently, the market does not appear to fully integrate the information provided in street earnings into stock prices. Over-performing target firms (i.e., negative difference between predicted and actual EVS) realize higher future returns, whereas under-performing firms (i.e., a positive difference between predicted and actual EVS) realize lower future holding returns. These results suggest that the predicted street EVS forms a measure of what the target firm's EVS should be. If the target firm's EVS is below the predicted EVS, the firm is underperforming, which is indicative of negative future returns. If the target firm's EVS is above the predicted EVS, the target firm is exceeding its peers-based expectations, which is indicative of higher future returns. 


\subsection{Target Firm Complexity}

\subsubsection{Predictive Ability of Street Peers for Complex Target Firms}

The probit analysis in Section 2.4.3 suggests that for complex firms or firms operating in a complex industry, the street peers are more likely to differ from the GAAP peers. Hence, we perform cross-sectional analyses using three different proxies to capture the complexity of a target firm. First, we use the volatility of operating income measured on a rolling basis over a three-year period $(V O L)$. Previous research shows that volatility is a very relevant dimension in predicting earnings. Dichev and Tang (2009) show that even analysts find it difficult to fully understand and incorporate the implications of earnings volatility. Second, we use the level of foreign income (FOREIGN_INC) as international diversification represents a unique dimension of the forecasting and valuation difficulty (Duru and Reeb, 2002). Lastly, we use the level of industry-adjusted R\&D (R\&D). $R \& D$ activities are highly risky investments and the economic benefits that firms receive from $R \& D$ activities tend to be very difficult to predict. Prior research shows that investors do not fully understand the cash-flow implications of R\&D investments (Chan et al., 2001). In addition, GAAP accounting for R\&D leads to accounting data that is less informative about the future economic benefits, so the need for analysts is greater for R\&D-intensive firms.

We investigate the predictive ability of street versus GAAP peers on complex firms, which are identified as firms with above-median values on our complexity characteristics. The results are reported in Panels A and B of Table 7. 
TABLE 7: Complexity of Target Firms

\begin{tabular}{|c|c|c|c|}
\hline \multicolumn{4}{|c|}{ Panel A: Complex Target Firms - Above Median Subsample } \\
\hline & VOL & FOREIGN_INC & $R \& D$ \\
\hline & Adj. $R^{2}$ & Adj. $\mathbf{R}^{2}$ & Adj. $\mathbf{R}^{2}$ \\
\hline \multicolumn{4}{|l|}{$E V S_{t}$} \\
\hline HARM_STREET & 44.92 & 44.44 & 42.05 \\
\hline HARM_GAAP & 43.33 & 42.10 & 40.96 \\
\hline $\begin{array}{l}\text { Vuong } Z \text {-statistic } \\
\text { (p-value) }\end{array}$ & $\begin{array}{c}1.312 \\
(0.190)\end{array}$ & $\begin{array}{c}1.564 \\
(0.118)\end{array}$ & $\begin{array}{l}1.066 \\
(0.287)\end{array}$ \\
\hline $\mathrm{N}$ & 3,562 & 1,991 & 4,424 \\
\hline \multicolumn{4}{|l|}{$E V S_{t+1}$} \\
\hline HARM_STREET & 36.31 & 37.50 & 34.24 \\
\hline HARM_GAAP & 33.97 & 32.43 & 32.94 \\
\hline $\begin{array}{l}\text { Vuong } Z \text {-statistic } \\
\text { (p-value) }\end{array}$ & $\begin{array}{c}2.074 \\
(0.038)\end{array}$ & $\begin{array}{l}3.235 \\
(0.001)\end{array}$ & $\begin{array}{c}1.256 \\
(0.209)\end{array}$ \\
\hline $\mathrm{N}$ & 2,465 & 1,417 & 2,962 \\
\hline \multicolumn{4}{|l|}{$E V S_{t+2}$} \\
\hline HARM_STREET & 31.31 & 29.51 & 30.17 \\
\hline$H A R M \_G A A P$ & 29.01 & 27.08 & 28.07 \\
\hline $\begin{array}{l}\text { Vuong } Z \text {-statistic } \\
\text { (p-value) }\end{array}$ & $\begin{array}{l}1.703 \\
(0.089)\end{array}$ & $\begin{array}{c}1.584 \\
(0.113)\end{array}$ & $\begin{array}{c}1.795 \\
(0.073)\end{array}$ \\
\hline $\mathrm{N}$ & 2,023 & 1,202 & 2,373 \\
\hline \multicolumn{4}{|l|}{$E V S_{t+3}$} \\
\hline HARM_STREET & 27.07 & 30.08 & 28.04 \\
\hline$H A R M \_G A A P$ & 26.86 & 26.58 & 26.89 \\
\hline $\begin{array}{l}\text { Vuong } Z \text {-statistic } \\
\text { (p-value) }\end{array}$ & $\begin{array}{c}0.188 \\
(0.851)\end{array}$ & $\begin{array}{c}2.269 \\
(0.023)\end{array}$ & $\begin{array}{c}1.107 \\
(0.268)\end{array}$ \\
\hline $\mathrm{N}$ & 1,687 & 1,000 & 1,860 \\
\hline
\end{tabular}


TABLE 7: Complexity of Target Firms (continued)

\begin{tabular}{|c|c|c|c|}
\hline \multicolumn{4}{|c|}{ Panel B: Complex Target Firms - Below Median Subsample } \\
\hline & VOL & FOREIGN_INC & $R \& D$ \\
\hline & Adj. $R^{2}$ & Adj. $\mathbf{R}^{2}$ & $\operatorname{Adj} . R^{2}$ \\
\hline \multicolumn{4}{|l|}{$E V S_{t}$} \\
\hline HARM_STREET & 43.30 & 44.15 & 45.52 \\
\hline HARM_GAAP & 43.00 & 43.74 & 45.21 \\
\hline $\begin{array}{l}\text { Vuong } Z \text {-statistic } \\
\text { (p-value) }\end{array}$ & $\begin{array}{c}0.282 \\
(0.778)\end{array}$ & $\begin{array}{c}0.420 \\
(0.674)\end{array}$ & $\begin{array}{l}0.250 \\
(0.803)\end{array}$ \\
\hline $\mathrm{N}$ & 3,562 & 5,310 & 2,877 \\
\hline \multicolumn{4}{|l|}{$E V S_{t+1}$} \\
\hline HARM_STREET & 37.39 & 36.24 & 39.83 \\
\hline$H A R M \_G A A P$ & 36.96 & 36.71 & 39.03 \\
\hline $\begin{array}{l}\text { Vuong } Z \text {-statistic } \\
\text { (p-value) }\end{array}$ & $\begin{array}{c}0.314 \\
(0.754)\end{array}$ & $\begin{array}{l}-0.434 \\
(0.664)\end{array}$ & $\begin{array}{c}0.470 \\
(0.638)\end{array}$ \\
\hline$\underline{N} \ldots \ldots$ & 2,264 & 3,422 & 1,877 \\
\hline \multicolumn{4}{|l|}{$E V S_{t+2}$} \\
\hline HARM_STREET & 33.28 & 33.24 & 35.46 \\
\hline$H A R M \_G A A P$ & 31.96 & 31.93 & 34.89 \\
\hline $\begin{array}{l}\text { Vuong } Z \text {-statistic } \\
\text { (p-value) }\end{array}$ & $\begin{array}{c}0.935 \\
(0.350)\end{array}$ & $\begin{array}{c}1.018 \\
(0.309)\end{array}$ & $\begin{array}{c}0.302 \\
(0.763)\end{array}$ \\
\hline $\mathrm{N}$ & 1,802 & 2,701 & 1,530 \\
\hline \multicolumn{4}{|l|}{$E V S_{t+3}$} \\
\hline HARM_STREET & 32.83 & 28.75 & 31.67 \\
\hline HARM_GAAP & 32.31 & 29.98 & 33.68 \\
\hline $\begin{array}{l}\text { Vuong } Z \text {-statistic } \\
\text { (p-value) }\end{array}$ & $\begin{array}{c}0.317 \\
(0.751)\end{array}$ & $\begin{array}{l}-1.134 \\
(0.266)\end{array}$ & $\begin{array}{l}-1.024 \\
(0.306)\end{array}$ \\
\hline $\mathrm{N}$ & 1,409 & 2,156 & 1,296 \\
\hline
\end{tabular}


TABLE 7: Complexity of Target Firms (continued)

\begin{tabular}{|c|c|c|c|c|c|c|}
\hline \multicolumn{7}{|c|}{ Panel C: Complex Target Firms and Buy-and-Hold Returns } \\
\hline & $\begin{array}{c}(1) \\
H I G H \\
V O L\end{array}$ & $\begin{array}{c}(2) \\
\text { HIGH } \\
\text { FOREIGN } \\
\text { INC }\end{array}$ & $\begin{array}{c}\text { (3) } \\
H I G H \\
\text { RodD }\end{array}$ & $\begin{array}{c}(4) \\
L O W \\
V O L\end{array}$ & $\begin{array}{c}\text { (5) } \\
\text { LOW } \\
\text { FOREIGN_ } \\
\text { INC }\end{array}$ & $\begin{array}{c}(\sigma) \\
L O W \\
R \circlearrowleft D\end{array}$ \\
\hline \multicolumn{7}{|l|}{ 12-month BHR } \\
\hline DIFFEVS_STREET & $\begin{array}{c}-0.017^{* *} \\
(-2.50)\end{array}$ & $\begin{array}{c}-0.015^{*} \\
(-1.75)\end{array}$ & $\begin{array}{c}-0.011^{*} \\
(-1.84)\end{array}$ & $\begin{array}{l}0.001 \\
(0.13)\end{array}$ & $\begin{array}{l}-0.009 \\
(-1.15)\end{array}$ & $\begin{array}{l}0.011 \\
(0.64)\end{array}$ \\
\hline $\mathrm{N}$ & 2,302 & 2,249 & 3,228 & 1,998 & 2,120 & 1,141 \\
\hline Adjusted $\mathrm{R}^{2}$ & $35.86 \%$ & $34.40 \%$ & $28.76 \%$ & $26.53 \%$ & $27.72 \%$ & $36.94 \%$ \\
\hline \multicolumn{7}{|l|}{ 24-month BHR } \\
\hline DIFFEVS_STREET & $\begin{array}{c}-0.036^{* * *} \\
(-2.89)\end{array}$ & $\begin{array}{c}-0.027^{*} \\
(-1.78)\end{array}$ & $\begin{array}{c}-0.020^{*} \\
(-1.79)\end{array}$ & $\begin{array}{l}0.016 \\
(0.86)\end{array}$ & $\begin{array}{l}-0.018 \\
(-1.27)\end{array}$ & $\begin{array}{l}0.008 \\
(0.29)\end{array}$ \\
\hline $\mathrm{N}$ & 2,224 & 2,162 & 3,071 & 1,879 & 2,007 & 1,098 \\
\hline Adjusted $\mathrm{R}^{2}$ & $35.98 \%$ & $35.14 \%$ & $28.52 \%$ & $27.77 \%$ & $27.46 \%$ & $39.04 \%$ \\
\hline \multicolumn{7}{|l|}{ 36-month BHR } \\
\hline DIFFEVS_STREET & $\begin{array}{c}-0.033^{*} \\
(-1.74)\end{array}$ & $\begin{array}{l}-0.014 \\
(-0.64)\end{array}$ & $\begin{array}{l}-0.022 \\
(-1.31)\end{array}$ & $\begin{array}{l}0.026 \\
(0.91)\end{array}$ & $\begin{array}{l}-0.022 \\
(-1.04)\end{array}$ & $\begin{array}{l}0.033 \\
(0.99)\end{array}$ \\
\hline $\mathrm{N}$ & 2,114 & 2,054 & 2,915 & 1,787 & 1,908 & 1,047 \\
\hline Adjusted $\mathrm{R}^{2}$ & $27.81 \%$ & $24.93 \%$ & $22.28 \%$ & $19.71 \%$ & $21.56 \%$ & $23.49 \%$ \\
\hline
\end{tabular}

Panel A and B provide estimated coefficients from the estimation model as in Table 3, except that DIFFEVS_STREET is used as an independent variable. For every proxy, we use observations that are either above or below the corresponding median. DIFFEVS_STREET $T_{i t}$ is measured as HARM_STREET $-E V S_{i t}$ VOL $=$ three-year rolling standard deviation of operating income after depreciation; FOREIGN_INC = foreign income divided by sales; $R \& D_{i t}=$ industry-adjusted R\&D, computed in two steps: (1) compute the average R\&D level for each industry-year; (2) compute the level of abnormal $\mathrm{R} \& \mathrm{D}$ as a normalized deviation from the industry average level: (R\&D-industry median $\mathrm{R} \& \mathrm{D})$ /industry standard deviation of R\&D. All other variables are defined below Table 3. Panel C reports buy-and-hold returns for different holding periods using the same estimation model as in Table 6 . All variables are defined below Table 6. For every proxy of complexity, we use observations that are either above (columns 1-3) or below (columns 4-6) the corresponding median. For the sake of brevity, only the main variable of interest, DIFFEVS_STREET, is reported. We truncate VOL at 1 and $99 \%$. Coefficient estimates and t-statistics are presented within the columns. Standard errors are clustered by firm. *, **, and ${ }^{* * *}$ represent significance at the 10 percent, 5 percent, and 1 percent levels, respectively.

In line with our expectations, the results show that for complex firms, street peers are better able to capture future EVS ratios. More specifically, for volatile and internationally diversified firms, street peers significantly outperform GAAP peers, as measured by the Vuong test. In these circumstances, analysts' fundamental adjustments to the accounting numbers are particularly important. Turning to less complex firms in Panel B, we find no effect of street earnings outperformance. In sum, these analyses show that street earnings' added value is predominantly concentrated among more complex firms.

\subsubsection{Complexity of Target Firms and Future Returns}

Considering the results in Table 6, which suggest that the street-based EVS of comparable peers helps in identifying over- or under-performance, we next examine whether the mispricing implications are stronger for complex target firms. For these firms, the street peer-based information might be even more important than for less complex firms, due to the inherent forecasting difficulty of complex firms. Hence, we expect the value of 
using street-based peer valuation to materialize mostly for complex firms. We therefore regress future stock returns on the difference between the predicted street EVS and the actual EVS (DIFFEVS_STREET), dividing the sample using the same complexity proxies as in panels A and B of Table 7. Complex firms are identified as those firms with above-median values on our complexity characteristics. Conversely, less complex firms are identified as firms with below-median values on the chosen complexity characteristics.

The results are reported in Table 7, Panel C. Columns (1) to (3) present the results for complex firms and columnn (4) to (6) those for less complex target firms. In line with our expectations, the relationship between the different peers and future returns is only significant for complex target firms and holds most strongly for volatile firms $(V O L)$. Panel $\mathrm{C}$ shows that, for a 24-month holding period, volatile target firms that exceed their peer-based expectations by one point have 3.6\% higher buy-and-hold returns $(\mathrm{p}$-value $=0.004)$. Similarly, for the 36-month holding period, volatile target firms that over-perform have $3.3 \%$ higher buy-and-hold returns (p-value $=0.083$ ). For diversified (FOREIGN_INCOME) and R\&D intense $(R \& D)$ firms, the peer-based implied mispricing is also associated with future returns. For a 24-month holding period, diversified target firms that exceed their peer-based expectations by one point have $2.7 \%$ higher buy-and-hold returns (p-value $=0.076$ ). For less complex target firms, the coefficient on DIFFEVS_STREET is insignificant for all three complexity proxies and holding periods. In sum, the value of using street peers in predicting EVS especially holds for complex and difficult-to-forecast target firms.

\subsection{Peer Comparability}

The key assumption underlying our analyses is that the use of street earnings improves peer-based valuation performance via the identification of more comparable peers, as the shortcomings originating in accounting rules are mitigated. This assumption has been validated by prior research, which shows that street earnings are inherently more comparable than GAAP numbers (Liu and Gao, 2016). However, given that the enhanced comparability of street earnings-based peers is a crucial assumption in the interpretation of our results, we aim to empirically validate this proposition. ${ }^{23}$

Similar to Liu and Gao (2016), we use De Franco et al.'s (2011) method to measure the comparability of earnings. This method measures accounting comparability based on the similarity of the mapping between earnings and stock returns. ${ }^{24}$ We generate two firm-year comparability scores, namely STREET_SCORE and GAAP_SCORE.

23 In untabulated analyses, we explore alternative sources of comparability such as growth. These analyses show that peers identified using street earnings are more similar to the target firm in terms of sales growth, compared to the GAAP-based peers.

24 Despite potential drawbacks, the measure has been commonly used in the literature and has been validated in many settings (e.g., Kim et al., 2013). 
STREET_SCORE captures average comparability between the target firm and its street peers. Similarly, GAAP_SCORE represents the average comparability between the target firm and its GAAP peers. Since comparability scores are defined as negative values, a more negative comparability score indicates a higher comparability between the peers and the target firm. We evaluate the differences in the comparability between different sets of peers by employing pair-sample tests of the equality of mean (median) comparability scores. A negative difference between GAAP_SCORE and STREET_SCORE indicates that street peers are more comparable to the target firm than the corresponding GAAP peers. Table 8 presents the comparability scores of street- and GAAP-based peers.

TABLE 8: Comparability of Street and GAAP Peers

\begin{tabular}{lcc}
\hline & Mean & Median \\
\hline STREET_SCORE & -2.277 & -1.174 \\
GAAP_SCORE & -2.312 & -1.216 \\
Difference & $-0.035^{* * *}$ & $-0.042^{* *}$ \\
(p-value) & $(0.008)$ & $(0.022)$ \\
\hline
\end{tabular}

This table presents comparability scores for a target firm and its street- and GAAP-based peers. STREET_SCORE captures the average comparability score between the target firm and its street peers. Similarly, GAAP_SCORE captures the average comparability between the target firm and its GAAP peers. Comparability scores closer to zero indicate greater comparability. A negative difference indicates that street peers are more comparable to the target firm than the corresponding set of GAAP peers. A positive difference indicates that street peers are less comparable to the target firm than GAAP peers. The pairwise differences between GAAP_SCORE and STREET_SCORE are tested using a paired t-test (for mean differences) and a paired Wilcoxon signed rank test (for median differences). *, ${ }^{* *}$, and ${ }^{* * *}$ represent significance at the 10 percent, 5 percent, and 1 percent levels, respectively. For detailed explanations on the computation of comparability scores, please refer to Liu and Gao (2016).

The results in Table 8 indicate that peers selected based on street earnings are more comparable to the target firm than peers selected based on GAAP earnings $(-2.277$ vs. -2.312). The mean difference in comparability scores is -0.035 (p-value 0.008 ), which represents a $1.5 \%$ improvement in comparability between the target firm and its selected peers once street earnings instead of GAAP earnings are used. The results provide support for our assumption that street earnings improve multiple valuation through the identification of more comparable peers.

\subsection{Conclusion}

Multiple approaches exist for valuing potential investments, some of which forecast the value of a firm directly, while others use relative valuation, which involves multiplying a value driver of a target firm (e.g., earnings) by the corresponding multiple from a set of comparable benchmark firms. The latter approach is relatively unsophisticated, easy to implement, and is used by investors and analysts around the world (e.g., Brown et al., 2015; Imam et al., 2008). The performance of a relative valuation approach crucially 
hinges on the identification of comparable benchmark firms, as a different set of peer firms will imply a different valuation. Here an important information problem arises: The selection of peer firms is based on observable data, which is generally obtained from the financial statements. This implicitly assumes that the accounting standards provide a comprehensive and accurate picture of the underlying firm fundamentals. However, the rising complexity of firms and their environment nowadays reduces the ability of GAAP numbers to provide an accurate depiction of firm business processes (Young, 2014). Using GAAP numbers as the basis for selecting peer firms may as a consequence not result in the selection of economically similar peers.

This paper examines a potential solution to this information problem, being the use of street earnings as a basis for peer selection. Street earnings are GAAP earnings adjusted for accounting shortcomings, such as e.g., the capitalization of leases. Street earnings may hence be more reflective of "true" firm performance. Moreover, street earnings may further improve multiple valuation via the identification of more comparable peers, as it facilitates benchmarking different firms (Frankel and Roychowdhury, 2005). We consequently expect the identification of peers based on street earnings to outperform peer identification based on GAAP earnings in a multiple valuation setting.

We obtain data on U.S. listed firms from 2003 to 2014. We identify four peers using GAAP earnings and four peers using street earnings to form the basis of multiple valuation. The results show that for $14 \%$ of the sample firms, no common peers are identified. These statistics show that the use of street earnings impacts the identification of peer firms. Surprisingly, this different peer selection does not improve valuation, as on average, both street and GAAP peers perform equally well when forecasting a target firm's future EVS using the warranted multiple approach. However, investigating a subset of firms where the different peers do lead to a significantly different valuation, the results show that street peers outperform GAAP peers in predicting future EVS. We show further that street earnings-based valuation yields more accurate EVS estimates than GAAP-based multiple valuation. In a next step, we show that the difference between predicted street EVS and the actual EVS helps explain future stock returns, suggesting that street-earnings based peer valuation help identify target firm over- and underperformance and consequently mispricing. Further analyses show that the superiority of street earnings-based peers materializes specifically when target firms are more volatile, $\mathrm{R} \& \mathrm{D}$ intense and have a high level of foreign income.

Our findings contribute to the relative valuation literature, in particular the research stream on the relevance of peer selection in obtaining accurate value estimates. We show that GAAP-based multiple valuation is on average relatively efficient, as both street earnings- and GAAP-based peers perform equally well when forecasting a target firm's future EVS multiple using the warranted multiple approach. Street earnings' added value seems to materialize mostly for complex firms, which adds to the growing body of research contributes on the role and potential superiority of analysts. Moreover, 
street earnings-based multiple valuation allows investors to recognize over- and underperforming firms and realize higher buy-and-hold returns.

The findings of our study are subject to several limitations. One limitation is that we only focus on firms followed by analysts, reducing the pool of potential peers. The most representative peers may be firms not followed by analysts, which would work against our findings. However, the proportion of firms not followed by analysts is considerably low, with $8 \%$ of firms in S\&P 500 and 22\% of non-S\&P 500 firms not being followed by analysts. The most visible and important peer firms are likely included in our data. A second limitation originates in analyst characteristics. The current design does not take into account personal attributes of the analysts, such as analyst incentives (Baik et al., 2009; De Franco et al., 2015) or affiliation. These personal factors may significantly impact analyst adjustments, which will then feed back into the selection of similar peers. The further exploration of these caveats is left to future research. 


\section{Appendix 2A: Illustration peer selection and peer-based implied valuation}

In 2005, for the target company Consol Energy Inc (IBES ticker CNX) four I/B/E/S (FNDC, PEAB, ARLP and ANRI) and four GAAP (JRCC, ACI, ANRI and FLR) industry peers are selected. The target firm's yearly predicted street EVS is 3.77 and the corresponding predicted GAAP EVS is 2.93 , while the actual EVS is 1.90 . The overview below shows that three different peers are selected once analyst information is used as opposed to GAAP and the common peer is ANRI. Even though three different peers are selected, the harmonic mean of the peers selected is not significantly different under the two valuation inputs. The street harmonic mean EVS is 1.647, while the GAAP harmonic mean is 1.664. Therefore, not only the number of different peers matters but also how different the selected peers are, which we capture by the absolute difference in the harmonic mean of peers selected (0.017 in this case).

\begin{tabular}{lccccccc}
\hline $\begin{array}{l}\text { All industry } \\
\text { peers available }\end{array}$ & FNDC & JRCC & ACI & PEAB & ARLP & ANRI & FLR \\
\hline $\begin{array}{l}\text { I/B/E/S peers } \\
\text { selected }\end{array}$ & $\mathrm{X}$ & & & $\mathrm{X}$ & $\mathrm{X}$ & $\mathrm{X}$ & \\
$\begin{array}{l}\text { GAAP peers } \\
\text { selected }\end{array}$ & & $\mathrm{X}$ & $\mathrm{X}$ & & & $\mathrm{X}$ & $\mathrm{X}$ \\
\hline $\begin{array}{l}\text { Actual EVS of } \\
\text { the peers }\end{array}$ & 1.779 & 1.733 & 2.577 & 2.646 & 1.808 & 1.070 & 1.988 \\
\hline $\begin{array}{l}\text { Harmonic } \\
\text { mean of }\end{array}$ & & & & 1.647 & & & \\
$\begin{array}{l}\text { I/B/E/S peers } \\
\text { Harmonic } \\
\text { mean of GAAP } \\
\text { peers }\end{array}$ & & & & & & & \\
\hline
\end{tabular}






\section{Chapter 3}

Determinants and real effects of "Texas-wide" fairness opinions: Evidence from tender offers 


\begin{abstract}
This study focuses on the properties of fairness opinions (FO), their determinants, and subsequent shareholders' decisions to initiate FO-oriented class action lawsuits. An FO outlines the underlying analyses of the opinion provider used to evaluate the financial fairness of a deal. At the heart of the FO lie the valuation analyses with the corresponding per-share valuation ranges, which represent the spectrum of possible price estimates within which the offer price can fall. I focus on two FO properties that are important to target shareholders: The wideness of FO ranges and the fairness of FOs. Using a hand-collected sample of US tender offers and target FO valuation analyses from 2010 to 2018, I find that firm-specific knowledge and incentives of the board of directors are strong predictors of the wideness of FO ranges. For the fairness of the FO, I find that the higher the boards' equity stakes, the lower the probability that an unfair FO is disclosed. At the same time, the CEO's prospect of remaining employed at the merged company is positively associated with the probability of an unfair FO. Lastly, I find that wide ranges and unfair FOs are more likely to trigger class action lawsuit complaints. Overall, my results show that the role of FOs in tender offers is complex and contingent on various governance factors and incentives.
\end{abstract}




\subsection{Introduction}

An fairness opinion (FO) is obtained in mergers and acquisitions (M\&As) and goingprivate transactions to help the board of the acquiring or target firm determine the appropriateness or "fairness" of the consideration to be paid or received. An FO is meant to serve as an objective assessment of the transaction, as it is delivered by a financial adviser evaluating the target and transaction price. On the basis of various valuation analyses, the financial adviser states whether the price paid or received in the transaction is fair from a financial point of view to shareholders of the client firm (Liu, 2020). These valuation analyses are at the heart of the $\mathrm{FO}$ and serve as an important basis for decisionmaking by the board of directors. Both regulators and courts have therefore called for more detailed disclosures on the underlying valuation analyses used in forming an FO (Liu, 2020). ${ }^{25}$ Yet, despite the central role of the FO valuation analyses, prior studies have mainly focused on the determinants of obtaining an $\mathrm{FO}$ - which is still largely voluntary - and have largely ignored the underlying properties of FOs. However, the informational value of an FO to shareholders depends heavily on its underlying properties and anecdotal evidence suggests a large heterogeneity in the properties of FOs. For instance, one judge presiding over shareholder litigation concluded that the valuation ranges presented in an FO are so wide that "even a Texan would feel at home on [them]". ${ }^{26}$ This paper aims to shed more light on the determinants and consequences of the properties of FOs.

This study focuses on the role of two relevant FO properties: the wideness of FO ranges and fairness of FOs. Both wideness and fairness are central to deal success. When confronted with a takeover bid, the boards' and target shareholders' key consideration is whether the offer price is fair and attractive. Apart from the deal premium, the ranges in an FO can also be used to evaluate the attractiveness of the offer price since they signal the spectrum of possible valuations within which the offer price can fall. Thus, the wideness of the ranges is supposed to provide assurance regarding the offer price and facilitate shareholders' decisions towards accepting the deal. This wideness has further received substantial criticism from media, regulators and courts, as implausibly wide ranges do not aid investors in evaluating the suggested offer price. Duff and Phelps (2017), for instance, note that FOs are mostly criticized for producing valuation ranges that are too wide to provide meaningful information. ${ }^{27}$ The wideness of the ranges therefore

25 In the decision of Pure Resources in 2002, the Court of Chancery stated that "stockholders are entitled to a fair summary of the substantive work performed by the investment bankers upon whose advice the recommendations of their board as to how to vote on a merger or tender rely". The court noted that, "the real informative value of the banker's work is not in its bottom-line conclusion, but in the valuation analysis that buttresses that result" (Liu, 2019).

26 Time's investment banker predicted per-share trading ranges of \$159-\$247 for 1991, \$230-\$332 for 1992, and \$208-\$402 for 1993. See Paramount Communications v. Time, Inc. (CivilActionNo.10866, Del.Ch.LEXIS77).

27 Retrieved from: https://www.duffandphelps.com/insights/publications/transaction-opinions/in-defense-offairness-opinions-an-empirical-review-of-ten-years-of-data 
seems to be a core property used to determine the usefulness of an FO. Another key consideration to target shareholders is whether the offer price is fair according to the FO. Cain and Denis (2013), for instance, find that some target-sought FOs indicate that the offer price is lower than the target's value based on the FO valuations. This is positive news to acquiring firm shareholders, but not for the target shareholders. Therefore, I also investigate the fairness of FOs by examining whether the offer price is at least equal to or above or below the overall price suggested in an FO.

Despite the great visibility of FOs and the prevalent criticism towards their properties, little is known about the determinants and key players shaping these properties. This is the first study to examine the board of directors and their characteristics as the main determinants of the observed FO properties. The board of directors plays an important role in the takeover setting. It is responsible for deciding to obtain an FO, choosing the FO provider, and delivering firm-specific data to be used in valuation analyses. Hence, I expect $\mathrm{FO}$ properties to reflect board's characteristics and incentives.

In a next step, I examine how both FO properties, namely FO wideness and fairness, are perceived by target shareholders. Specifically, I examine the association between wideness and fairness and FO-oriented shareholder class action lawsuits. Despite the high incidence of lawsuits, which are initiated in about $10 \%$ of all M\&A offers, little is known about the role of FOs and their properties as the drivers of these class action lawsuits (Krishnan et al., 2012).

To investigate these questions, I focus on a setting in which fairness opinions are likely to be important, namely tender offers, since their completion and success is highly dependent on target shareholders' tendering decisions. Tender offers often have the so-called minimum conditions, which implies that a deal can only be completed if a certain percentage of target shareholders shares is tendered within a specified time frame. Hence, it is pivotal for shareholders to receive an accurate assessment of the value of their shares and FO valuation analyses can help target shareholders in reaching an informed decision.

I hand-collected all U.S. tender offers and target FO valuation analyses between 2010 and 2018. The average incidence of FO-based lawsuits is 33\%, corroborating the importance of FOs in tender offers. I estimate a simultaneous equation framework modelling the fairness and wideness of FOs, as well as subsequent class action lawsuits. The results show that firm-specific knowledge and incentives of the board are strong predictors of the wideness of FO valuation analyses. Specifically, I find a strong positive association between the independence of the board and the probability of issuing a wide FO. Independent board members may lack firm-specific knowledge and thus provide less precise target valuation estimates or inputs to advisors, which is in line with prior research (e.g., Karamanou and Vafeas, 2005; Faleye, 2015). A long-tenured board, on the other hand, is likely to issue a narrow-ranged FO as it possesses valuable firm- 
specific knowledge to value the target firm more precisely. Lastly, the board's and the CEO's financial incentives to complete the tender offer are positively associated with the probability of issuing wide-ranged FOs. Turning to the fairness of the FO, I find that the higher the boards' equity stake, the lower the probability that an unfair FO is disclosed. The more equity directors own, the more sensitive these directors become to the offer price, as their payout is directly linked to the price. At the same time, if the $\mathrm{CEO}$ is retained at the merged company, the probability of an unfair FO is higher. The analyses further show that class action lawsuits specifically addressing FOs are positively correlated with wide-ranged and unfair FOs. I find that non-sophisticated investors are more likely to initiate a FO-oriented class action lawsuit. These investors might need to rely more on the FO due to a lack of sophistication to conduct their own valuations and fair price assessments. Additional analyses also reveal that wide-ranged and unfair FOs are not only associated with the occurrence but also the amount of class action lawsuits.

Overall, my findings shed light on why differences among FOs are observed and how these are perceived by shareholders. I take on a holistic approach by integrating various characteristics of the parties involved on the supply as well as demand side. On the supply side, the characteristics and incentives of the board of directors are important inputs into the $\mathrm{FO}$ and its underlying properties. On the demand side, it is ultimately the shareholders and their respective characteristics that are related to the perceived usefulness of FOs and their properties. My study shows that, contrary to the criticism of FOs being merely rubber stamps without providing any incremental information, FOs in tender offers represent a relevant information source to target shareholders.

My findings contribute to the fairness opinion, corporate governance as well as litigation literature. First, FOs are still a largely unexplored phenomenon and prior studies provide conflicting evidence on FOs' effect on deal and shareholder wealth. My study aims to explain these contradicting prior studies' findings by focusing on underlying FO properties. I show that while targets issue an FO in all completed tender offers, onethird of them is exposed to FO-related class action lawsuits. This implies that it is not just the occurrence of an FO, but rather their underlying valuation analyses that should be examined. Second, this is the first study to incorporate the board's characteristics and incentives in the context of FOs. Prior research so far has been silent on the role of the target board's characteristics in the context of FO properties and how these can be used strategically to achieve the board's desired objectives. My study also contributes to the research on the role of CEOs' incentives. Lastly, this is the first study to analyze the association between FO properties and target shareholder class actions. Shareholder lawsuits are costly and delay the completion of the deal. Given that acquirers often chose a tender offer over a merger due to faster completion times, it is crucial to understand which FO properties trigger shareholder lawsuits, thereby impeding fast completion of a tender offer. 
The remainder of the paper is organized as follows: Section 3.2 outlines prior literature. Section 3.3 summarizes theoretical predictions. Section 3.4 discusses the research design and sample. Section 3.5 presents the findings, while section 3.6 presents the additional analysis. Section 3.7 concludes.

\subsection{The use of fairness opinions}

\subsubsection{Institutional background}

FOs find their origin in the Smith vs. Van Gorkom case and Delaware law that institutionalized an "outside" opinion within the M\&A context in the U.S. In the Smith vs. Van Gorkom (1985) case, the Delaware Supreme Court declared the board of the Trans Union Corporation guilty because it approved an acquisition without obtaining anything more than a "rough" and unquestioned estimate of a possible value from its CFO. According to the Delaware Supreme Court, a target board, as part of its greater duty of care in a corporate control transaction, is obliged to thoroughly inform itself about its corporation's value by means of a well-prepared financial analysis. Even though FOs are not required by law, over the period 1996 to 2013, over 90 percent of the M\&A transactions have obtained an FO (Liu, 2020). In an M\&A setting, once the merger is publicly announced, the FO is included in the proxy statements and mailed to shareholders for voting approval of the merger. The opinions are publicly disclosed once the proxy statements are mailed and submitted electronically to the SEC.

Whereas FOs are largely voluntary, the information content included in FOs has been regulated - albeit to a limited extent. In 2007, the SEC approved the proposed rules by the National Association of Securities Dealers, Inc. (NASD) to increase disclosure requirements for FOs. As of 2007, firms requesting an FO have to disclose whether the adviser will receive compensation contingent on the successful completion of the underlying transaction, whether the adviser has had a material relationship with the company in the last two years, and what information was provided to the adviser by the board of directors in deriving the opinion. The SEC further monitors the quality of FO disclosures. Liu et al. (2019) examine SEC comment letters for M\&A transactions and find that the most frequent comment letters relate to fairness opinions and their valuations, general compliance, and transaction background. Despite the somewhat increased regulatory scrutiny regarding the disclosure of FOs, board of directors and opinion providers are still left to their own devices in terms of the underlying information content of the FO.

\subsubsection{The role of the board of directors in issuing an FO}

The target board of directors plays a central role in the context of FOs because it is involved in all stages of the FO preparation and issuance. It is the central party charged with receiving, evaluating, and acting on the takeover bid. Upon receiving the offer, the target board needs to assess the value of the target firm to evaluate the fairness and 
attractiveness of the offer price. FOs then are a useful second opinion from a financial adviser, providing an independent valuation of the target firm. The board is the initiator of the decision to obtain an FO, selects and hires an FO provider, provides the FO provider with all relevant firm-specific information and internal forecasts, and ultimately verifies the fairness of the deal. The board is hence heavily involved throughout the FO process.

Since boards vary substantially in their knowledge and expertise, some boards are more likely than others to hire an FO provider to assist in valuation matters and the assessment of the offer price. A survey by Duff and Phelps (2009) reveals that the main motivations for obtaining an $\mathrm{FO}$ indeed include receiving an objective analysis of the proposed offer and fulfilling the board's fiduciary duties. The board perceives the valuation analyses and valuation-related matters to be the most valuable insights received from the FO analysis (Duff and Phelps, 2009). Prior studies provide further evidence that the necessity of an FO is especially great when the board's knowledge and expertise is limited (Kisgen at al., 2009; Frye and Wang, 2010). Besides the board's desire to obtain an objective assessment of the offer price, FOs are also obtained to shield liability and protect the board from potential criticism and shareholder lawsuits. Duff and Phelps (2009) point out that $64 \%$ of senior executives and board members in the US use FOs to protect themselves from potential shareholder lawsuits. The greater scrutiny of the deals has indeed resulted in boards defending their decisions more frequently, and FOs can provide further support for directors' deal recommendations.

One setting in which fairness opinions are likely to be important to target boards of directors are tender offers. A tender offer is a public bid for stockholders to sell their stock, in which the bidder directly approaches target stockholders with an offer to buy their shares without necessarily informing or involving the target board of directors. Tender offers are a common acquisition method-they accounted for $32 \%$ of the deals between 2007 and 2012- since they provide the advantage of a substantially faster completion time compared to mergers (Offenberg and Pirinsky, 2015). Tender offers often have so-called minimum conditions. This implies that the deal can only be completed if a certain percentage of target shareholders' shares is tendered within a specified time frame - otherwise the bidder cannot proceed with the transaction. The completion and success of tender offers is highly dependent on target shareholders' tendering decisions and thus it is crucial for them to receive an accurate assessment of the value of their shares. FO valuation analyses are an important form of information to target shareholders since they can help them in reaching an informed tendering decision.

I argue that FOs are particularly relevant for tender offers for two reasons. First, during negotiated M\&As target shareholders receive a great amount of deal-related information before the disclosure of the final FO and the required shareholder voting. In a tender offer setting, very few relevant details are available to target shareholders prior to the 
disclosure of the FO. ${ }^{28}$ Second, not only the amount and timing of the information differs, but also the time shareholders have to incorporate this information. During negotiated M\&As, target shareholders have a great amount of time to evaluate the attractiveness of the deal and incorporate multiple information sources before their vote is required. For tender offers, once target shareholders receive the FO, they are required to make their tendering decision within a specified time frame, which is typically much shorter than the time given to shareholders of negotiated M\&As. Hence, FOs are of great relevance in tender offers as they bundle relevant information into a single document, allowing investors to make informed decisions regarding the tender offer in a short period of time.

The SEC has recognized the importance of FOs in providing information to shareholders in tender offers. In the case of tender offers, the target company's board of directors is required to disclose whether it has relied on an FO but does not have to disclose the FO (Liu, 2020). The Delaware disclosure requirements however encourage tender offer targets to disclose the FO valuations. In the decision of Pure Resources in 2002, the Court of Chancery further emphasized that " $[\mathrm{A}]$ minority stockholder engaging in the before-the-fact decision whether to tender would find it material to know the basic valuation exercises that the investment banker undertook, the key assumptions that they used in performing them, and the range of values that were thereby generated."

The importance of an FO for target shareholders and the heterogeneity in the properties of disclosed FOs increase the need to understand how the characteristics of the key players shape the properties of FOs. Given the central role of the board, I expect that the observed FO properties largely reflect the board's characteristics and incentives. Moreover, it is important to analyze how the observed FO properties are perceived by target shareholders who are the ultimate users of the FOs.

\subsection{Theoretical predictions}

I argue that a combination of different factors is associated with the properties of an FO. In this study, I focus on two FO properties that are important to shareholders: the wideness of FO ranges and the fairness of the FO. Both properties enable target

28 Offenberg and Pirinsky (2015) find that the completion time of tenders is on average 73 days shorter than the completion time of mergers. In case of a tender offer, a bidder must file a tender offer statement (SC-TO) with the SEC as soon as the tender offer is initiated. Within 10 business days of the commencement of a tender offer, the target company's board of directors must disclose a statement (Schedule 14D-9) to its security holders (Bell, 2016). Under SEC Rule 14d-1, the tender offer can end 20 calendar days after the initial filing. In case of mergers, which require a vote by shareholders to approve the merger, the bidder must first file a preliminary and later a definitive proxy statement to shareholders (Offenberg and Pirinsky, 2015). 
shareholders to evaluate the key dimensions of the offer price in a takeover bid, namely whether it is fair and attractive.

The ranges in an FO represent the spectrum of possible values for the target firm's shares. The wideness of the ranges is meant to provide assurance regarding the offer price and facilitate shareholders' decisions towards accepting the deal. The main criticism from media, regulators and courts towards FOs revolve around FO wideness because it seems to be the core property to evaluate the usefulness of an FO. FOs are often criticized for including valuation ranges that are too wide to provide meaningful information. ${ }^{29}$ Another key consideration to target shareholders is whether the offer price is fair according to the FO. Cain and Denis (2013), for instance, find that some target-sought FOs, which contain the target board's recommendation to tender and FO provider fairness verdict, reveal that the offer price is lower than the target's value based on the FO valuations. Therefore, I investigate the fairness of FOs by examining whether the offer price is above (or at least equal to) or below the overall average price suggested in an FO.

\subsubsection{Determinants of FO properties - wideness of price ranges}

\subsubsection{Knowledge and expertise of the board}

First, I focus on the firm-specific knowledge of the target board. Several studies emphasize the importance of the board's firm-specific knowledge, in both its monitoring and advising functions. For instance, firms with boards that are dominated by outside directors tend to make less precise management forecasts, suggesting that outside directors lack firm-specific knowledge (Karamanou and Vafeas, 2005). Faleye (2015) finds that fully independent boards are associated with a reduction in firm performance because these boards lack regular access to firm-specific information. In a similar vein, Duchin, Matsusaka, and Ozbas (2010) shows that the effectiveness of outside directors is influenced by the cost of acquiring firm-specific information.

In the case of tender offers, the target board's role is to correctly value the target firm and evaluate the fairness and attractiveness of the offer price. The target board is primarily responsible for providing shareholders with information that is useful for their tendering decisions. I posit that there is a negative relation between the board's level of firmspecific knowledge and the width of the ranges in an FO. Boards with greater firmspecific knowledge are likely to provide more precise earnings forecasts to be used in valuing the target. These boards should also be able to provide FO providers with more relevant, precise, and detailed target specific information due to their accumulated internal knowledge. Hence, I hypothesize that:

29 See for example Footnote 25 or a news article by Financial Times in 2017: https://www.ft.com/content/0c20446c$17 \mathrm{eb}-11 \mathrm{e} 7-\mathrm{a} 53 \mathrm{~d}-\mathrm{df} 09 \mathrm{f} 373 \mathrm{be} 87$ 


\section{H1: The board's firm-specific knowledge is negatively associated with the} wideness of the ranges in an FO.

It is not only the firm-specific knowledge of the board that is found to be critical for its performance, but also directors' accumulated experience and knowledge in general. Kroll, Walters and Wright (2008) contends that, in case of acquisitions, director experience in the target industry and in making acquisitions in general facilitates the development of knowledge useful in making profitable acquisitions. Accordingly, a higher number of board members with acquisition experience is positively associated with the acquiring firms' abnormal returns (Kroll et al., 2008). Considering that target firm directors need to value the target firm, I expect that valuation and financial expertise of the target board is negatively related to the width of the ranges in an FO. Boards with financial expertise are likely to be better able to process and synthesize financial information to more precisely value the target firm compared to boards without this knowledge. In addition, financially experienced boards can better monitor the work performed by opinion providers and potentially challenge FO valuations. Based on these arguments, I hypothesize that:

\section{H1a: The board's financial expertise is negatively associated with the wideness of the ranges in an FO.}

\subsubsection{Incentives of the board}

Not only do directors and boards vary in their knowledge and expertise, but also in their incentives to protect and represent shareholders' interests. One of the main objectives of the board is to monitor management on behalf of shareholders to ensure that management acts in the interests of shareholders. Yet, in the case of a takeover bid, target firm directors face a conflict of interest between their fiduciary responsibilities as shareholder representatives and their own potential wealth changes. Directors who believe that a tender offer is in the best interest of their shareholders are still very likely to lose their board seat following a successful tender offer (Harford, 2003). Given that the target firm directors might pursue their personal incentives in the course of a tender offer, they can use the FO as a strategic tool to meet their desired objectives.

The target board can have strong personal incentives to either accept or reject the offer. The board's incentives to complete a takeover bid include equity-related payments, which the board receives upon completion of the tender offer. These equity-related payments often represent substantial amounts, and since they only become available when the tender succeeds, it is in the economic interests of the board to complete the deal. Apart from the tangible financial benefits, there are also intangible rewards such as influence, networking, or prestige that board members derive from their board memberships (Harford, 2003). These nonfinancial rewards, while hard to quantify, can also have substantial value for directors and might incentivize them to reject the takeover bid. Depending on the incentives of the board, the board can use an FO strategically 
to convince target shareholders to follow its recommendation. Therefore, besides firmspecific knowledge and financial expertise, I also examine the incentives of the board when issuing an FO. I first consider equity-related payments that directors enjoy upon a successful completion of the tender offer. Next, I also examine the tender offer related benefits of the CEO.

Board of directors' compensation typically consists of cash and equity compensation, which serves the purpose of aligning the interests of board members with those of shareholders. In the case of tender offers, common equity ownership of the board aligns the interests of the board and its target shareholders, because board members tender their shares at the same price as shareholders. Boards however also enjoy additional benefits upon completion of the tender offer such as accelerated equity vesting benefits. ${ }^{30}$ The boards' total equity benefits represent strong incentives to complete the tender offer.

Du et al. (2011) show that as the ranges of earnings forecasts become wider, they are more likely to contain the actual EPS, thereby increasing the probability that the firm meets its earnings forecast. In a similar vein, I argue that wide ranges might help the target board to complete the tender offer since these ranges are more likely to contain the offer price. Hence, in the case of strong incentives to complete the tender offer, the board is incentivized to issue wide-ranged FOs to justify the offer price more easily. I therefore posit the following hypothesis:

\section{H2: The boards' equity benefits are positively associated with the wideness of the ranges in an FO.}

CEOs face a similar conflict of interest when their company is acquired. Upon a tender offer, CEOs and top executives receive a golden parachute compensation, typically consisting of cash severance payments, accelerated equity awards and some additional cash benefits (e.g., tax gross-up payments). Golden parachutes intend to align top executives' and shareholder incentives by lowering the likelihood that a target firm's management will resist a shareholder-wealth-maximizing takeover bid (Buchholtz and Ribbens, 1994). However, these golden parachute compensations can sometimes represent substantial amounts and might incentivize CEOs to complete unfavorable tender offers. ${ }^{31}$ Similar to the argumentation above, the higher the CEO's golden parachute, the greater the incentives to complete the tender offer, which is facilitated by wide-ranged FOs.

30 Tender offer related disclosures (Schedule 14D-9) typically explicitly refer to these benefits as potential conflict of interest. Schedule 14D-9 disclosures commonly acknowledge that "certain members of management and the board may be deemed to have interests in the offer that are different from and/or in addition to their interests as shareholders generally. Stockholders should be aware of these interests as these may create potential conflicts of interest".

31 For instance, in a tender offer by Pfizer Inc to acquire Anacor Pharmaceuticals in 2016, the CEO of the target was entitled to a golden parachute compensation as high as $\$ 51,5$ million. 
CEOs may also have career incentives to push for an acquisition. Specifically, CEOs often lose their position following a tender offer. If a CEO can bargain for a lower premium, she may hope to retain his function (Bargeron et al., 2009). ${ }^{32}$ A position at the merged company shields the CEO from job loss and represents a secured stream of income, at least in the short run. A potential loss in CEO's wealth due to a lower offer price might then be partially offset by the income secured through retention at the merged company. Even if the offer price is not in the best interest of shareholders, the CEO is then more likely to accept it if she remains employed at the merged company. Hence, if the CEO remains employed at the merged company, she is more inclined to verify any offer price as attractive as opposed to a CEO who loses his job upon the completion of the tender offer. To justify the offer price and convince target shareholders, the CEO is incentivized to issue wide-ranged FOs, which increase the probability that the offer price falls within valuation ranges. In sum, I hypothesize that:

\section{H3: The CEO's golden parachute and a position at the merged company are positively associated with the wideness of the ranges in an FO.}

\subsubsection{The determinants of the FO properties - fairness of the FO}

From the perspective of target shareholders, an FO is fair only if the offer price exceeds, or at least is equal to, the overall average price suggested in an FO. FOs that reveal that the offer price is not fair in combination with the board's recommendation to tender seem to provide little assurance and confidence to target shareholders. Therefore, it is important to analyze what drives the board to disclose an unfair FO. I expect the fairness of an FO to be primarily driven by the board's incentives, being the benefits that directors and the CEO enjoy upon a successful completion of the tender offer, rather than a lack of knowledge or expertise. As discussed above, the higher the boards' equity benefits upon completion of the tender offer, the greater its incentives to complete the tender offer. Yet, the more equity the directors themselves own, the more sensitive they become to the offer price, since their payout is directly linked to the offer price. Therefore, I argue that the incentives to accept an unfair offer price decrease as the amount of equity that directors own increases. I expect the boards' equity benefits upon completion of the tender offer to be negatively associated with the issuance of an unfair FO. In sum, I hypothesize that:

\section{H4: The board' benefits upon completion of the tender are negatively associated with the unfairness of an FO.}

32 The courts and the press have long recognized this conflict of interests faced by CEOs. For instance, one judge concluded that a CEO "had powerful interests to agree to a price and terms suboptimal for public investors so long as the resulting deal" gave him some benefits including "the chance to continue his managerial positions for a reasonable time”. In Re: Lear Corporation Shareholder Litigation, Opinion, Court of Chancery, Delaware, June $15,2007$. 
In contrast, the golden parachute of the $\mathrm{CEO}$ and a position at the merged company provide the CEO with strong incentives to complete the tender offer, regardless of the fairness of the offer price. Hence, I formulate the following hypotheses:

\section{H5: The CEO's golden parachute compensation and a position at the merged company are positively associated with the unfairness of an FO.}

\subsubsection{Shareholder class action lawsuits and the FO properties}

The previous section has focused on the determinants of FO properties. Yet, it is also important to examine the consequences of FOs, and particularly shareholders' reaction to these FO properties. Public announcements of M\&A proposals are associated with a non-trivial number of target shareholder class action lawsuits against boards of directors' decisions. Krishnan et al. (2012) show that about 10\% of all M\&A offers result in shareholder class action lawsuits, most of which revolve around complaints against the board of directors and managers for providing misleading information that results in shareholder losses (Rogers, Van Buskirk and Zechman, 2011). ${ }^{33}$ Prior studies indeed show that the drivers of a class action lawsuit often relate to the firm's failure to disclose material information (e.g., Kellog, 1984; Francis at al., 1994). A clear link with fairness opinions consequently exists. This also holds for tender offers, where shareholders often allege that target firm directors have breached their fiduciary duties by recommending the sale of the target for a too low price (Krishnan et al., 2012). ${ }^{34}$

The estimated ranges of fair prices for target shares are the centerpiece of an FO. These ranges help target shareholders evaluate the offer price, and the amount of uncertainty that exists regarding that price. The wideness of the ranges is supposed to provide assurance regarding the offer price and facilitate shareholders' decisions towards accepting the deal. The class action complaints provide evidence that investors use the provided price ranges to make an informed decision whether to tender their shares. ${ }^{35}$

Prior studies on the earnings forecasts and precision further suggest that investors in general prefer narrow ranges to wide ranges due to the informative advantage of narrow ranges (e.g., Du et al., 2011). On the one hand, wide ranges make it extremely difficult

33 In the case of tender offers in my sample, the percentage of lawsuit initiation increases to $33 \%$.

34 For example, in a complaint against Bronco Drilling Company, Inc, the plaintiffs argue that "The $\$ 11.00$ per share consideration offered in the Proposed Transaction is grossly inadequate. The merger price represents an inadequate $6 \%$ premium - particularly in view of the promising growth. Indeed, at least one analyst has set a price target of $\$ 13.50$ per share. Bronco, if properly exposed to the market for corporate control, would bring a price materially in excess of the amount offered in the Proposed Transaction".

35 For example, the plaintiffs in Khalil v. Santarus, Inc. argue that "Although the Fairness Opinion omits important information, it is nevertheless evident from the Fairness Opinion that the Offer Price undervalues the Company, because ranges derived by Stifel's analysis are above that of the Offer Price of $\$ 32$ per share. For example, the Discounted Cash Flow Analysis in the Fairness Opinion derives a range of values between $\$ 35.54$ and $\$ 49.89$ per share. Selected Companies Analysis produced upper multiple ranges of between $\$ 35.16$ and $\$ 38.49$ per share”. Retrieved from: https://www.sec.gov/Archives/edgar/data/1009356/000119312513474739/d642746dex99a5n. htm 
for investors to assess the attractiveness of the deal and whether the board made the right decision in accepting the deal. On the other hand, wide ranges might simply signal the complexity of the target and reflect the inherent uncertainty of the target's firm value. Hence, narrow-ranged FOs are more useful for target shareholders to assess the deal's attractiveness, especially for complex and difficult-to-value targets. I therefore expect a positive association between the initiation of target shareholder class action lawsuits and the wideness of an FO. I further expect a positive association between the initiation of class action lawsuits and the issuance of an unfair FO. Unfair deals are unfair because the valuation analyses in the FO suggest that the offer price accepted by the board is too low. These deals are likely to trigger shareholders' skepticism towards the board's inconsistent recommendation to tender and its motivation to do so. Hence, I hypothesize that:

\section{H6: The wideness and unfairness of an FO is positively associated with the initiation of a class action lawsuit.}

\subsection{Research design}

\subsubsection{Sample Selection}

I gather data on all tender offers identified in the Thomson Reuters Securities Data Corporation (SDC) database involving deals of publicly traded U.S. firms (acquirers and targets) between 2010 and 2018. Starting from this selection, I exclude deals where the transaction value is lower than $\$ 1$ million, or where deals have a pending or intended status. Both the target and acquirer must be listed on the NYSE, AMEX, or NASDAQ (Kisgen et al., 2009; Cain and Denis, 2013). I exclude buybacks and recapitalizations from the sample, which leads to an initial sample of 214 tender offers. I exclude tender offers that were withdrawn or involved FOs without valuation analyses (17 deals). I exclude tender offers with multiple target FOs (21 deals) and one tender offer where all except one target board's board members are also board members of the acquiring firm, which leads to a final sample of 175 deals. ${ }^{36}$

I manually collect FO data from Schedule 14D-9 filings on the Security and Exchange Commission (SEC) EDGAR Web site. These filings include the target's board recommendation on how shareholders should respond to a tender offer. In addition, they include fairness verdicts, valuation methods and the corresponding valuation ranges, the fees paid to opinion providers as well as their preexisting relationships with client firms. I also obtain board of directors' characteristics from the Schedule 14D-9 filings.

36 The number of tender offers in my sample is in line with prior research. In the time period between 2007 and 2012 , Offenberg and Pirinsky (2015) show that 126 deals were structured as tender offers, which means, on average, 21 tender offers per year. Using this estimation, the expected number of tender offers for my sample is approximately 168 tender offers. Liu at al. (2019) find that about $17 \%$ of the deals are structured as tender offers for the deals announced between 2005 and 2017. Using my sample construction criteria and sample period, a total of 1,087 M\&A deals were completed. My sample of 175 tender offers, thus, represents about $16 \%$ of this M\&A figure. 
If boards' characteristics are missing in the Schedule 14D-9 filling, I either use the proxy statement that is referenced in the filling itself or the most recent proxy statement available prior to the disclosure of the Schedule 14D. Institutional ownership data is obtained from Thomson Reuters Institutional Holdings (13f). I use the most recent institutional ownership figures available immediately prior to the disclosure of the FO. Target and deal related variables are all based on either the SDC database or Schedule 14D-9 fillings, with the exception of Research and Development expenditures, which are obtained from Compustat.

For the class action complaints specifically addressing FOs, I manually examine all target SEC filings found on the EDGAR Web site after the disclosure of the FO. Commonly, these class action complaints are filed in combination with either amended FOs, SC 14D9/A, or amended tender offer statements, SC TO-T/A. In general, firms need to "describe briefly any material pending legal proceedings" to which the company is a party according to Item 103 of Regulation S-K (Krishnan et al., 2012). This rule poses two limitations to my identification of FO related class action complaints. First, only "material" litigation must be disclosed, with materiality being a legal term that different lawyers may interpret in different ways. The rule only requires disclosure of information if "there is a substantial likelihood that a reasonable shareholder would consider it important" (Krishnan et al., 2012). Therefore, it could be the case that not all FO related class action complaints are included in the sample, as legal counsels may deem these immaterial. Nonetheless, given the size of the transactions in my sample, these complaints are likely to be material. Second, the rule mentions a brief description of the legal proceedings. Whereas many firms provide detailed disclosures, some do not disclose any further details regarding the basis of shareholders' complaints. I exclude these complaints from my sample as these legal actions may be the result of shareholders' general dissatisfaction with the board's recommendation, irrespective of the FO.

\subsubsection{Empirical models}

In the first model I focus on notably wide-ranged FOs and their determinants. Since there are multiple valuation methods in an FO, I first calculate the mean scaled wideness of each method and then I calculate the average wideness across all the methods in an FO. The dependent variable WIDE_FO is equal to one if the FO's average wideness is above the sample median average wideness, and zero otherwise. The second model captures unfair FOs and their drivers. Similar to the wideness, I first calculate the average price estimate for each method and then I calculate the overall average price estimate across all the methods in an FO. The dependent variable in the second model UNFAIR_FO is equal to one if an FO suggests a higher overall price estimate than the accepted offer price, and zero otherwise. In the third model, I investigate shareholder class action lawsuit initiation, how this is triggered by the FO wideness and the board's characteristics. The dependent variable in the third model LAWSUIT_FO equals one 
if there is at least one class action lawsuit specifically addressing the FO, and zero otherwise. $^{37}$

I use the average tenure of the board's directors (TENURE) and the percentage of independent directors on the board (IND) to capture the board's firm-specific knowledge. Both long tenured and inside directors are expected to possess substantial internal knowledge about the firm. For the financial expertise of the board members, I manually collect their prior working experience from either Schedule 14D or proxy statements. From all the job positions of the board members, I especially focus on whether they held positions which require valuation skills. First, I use the percentage of board members with investment banking experience (INV_BANK_EXP). Second, I include the percentage of board members who held positions in the finance division such as chief investment officer, or worked as analyst, venture capitalist, manager/partner of investment firms, investment funds or private equity firms (FIN_EXP). Board members with such experience are likely to have been involved in the valuation and assessment of investment opportunities, and should, therefore, possess valuation skills. To capture the incentives of the board, I use the total equity-related payments that target directors enjoy upon a successful completion of the tender offer (DIR_PAYOUT). An indicator variable CEO_RETAIN is used to capture whether the CEO remains employed at the merged company. I expect the magnitude of the cash-based proportion of the golden parachute (CASH_GOLD) to be particularly important. The higher the cash component of the golden parachute, the lower the CEO's sensitivity to the offer price since he is not affected by the offer price to the same extent as shareholders. In line with Fich, Cai and Tran (2011) I argue that the cash component makes the CEO less sensitive to the offer prices since his payoff is fixed, to a large extent, and does not change with the offer price. $^{38}$

In all three models, I control for the target firm's profitability in the fiscal year prior to the takeover bid $(R O A)$ and I include an indicator variable if the target operates in one of the litigious industries (LITIG_IND), which is based on prior going-concern research by DeFond et al. (2002) and Lim and Tan (2008). The CEO who also serves as the chairman of the board has more power and influence over the board as compared to a CEO executive only. Therefore, I control for the combined roles of the CEO (CEO_ $C H A I R)$. Lastly, I control for the existence of any prior relationship with the target. This

37 I recognize that the filing of a class action lawsuit complaint does not necessarily imply that the case is ultimately taken to court and a hearing is scheduled. I use lawsuits as a proxy of how investors perceive the usefulness of a disclosure. Consistent with prior research, I view lawsuits as relevant mechanisms to express shareholder dissatisfaction (e.g., Brochet and Srinivasan, 2014).

38 According to Fich, Cai and Tran (2011), golden parachutes are often based on the regular cash components of the annual salary and bonus paid to the executive. Therefore, they study the differential incentives provided by golden parachutes (assumed to be mainly cash-based and offer price insensitive) and stock options, which increase in value with the takeover offer. The evidence in my sample, however, reveals that cash payments make up, on average, only $38 \%$ of the CEO's golden parachute compensation. 
is captured by an indicator variable PRIOR_REL that is equal to one if the target adviser provided services to the target in the past, and zero otherwise.

Models (1), (2) and (3) are summarized as follows:

WIDE_FO ${ }_{i}=\alpha_{t}+\beta_{1} T E N U R E_{i}+\beta_{2} I N D_{i}+\beta_{3} I N V_{-} B A N K_{-} E X P_{i}+\beta_{4} F I N_{-} E X P_{i}+$

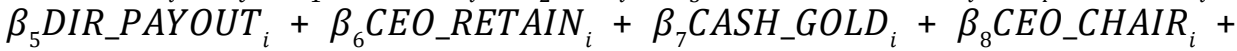
$\beta_{9} P R I O R_{-} R E L_{i}+\beta_{10} R O A_{i}+\beta_{11}$ LITIG_IND $_{i}+\beta_{12}$ TOP_ADV $+\beta_{13} R \& D_{i}+$ $\beta_{14} U N F A I R_{-} F O_{i}+\beta_{15} M E E T_{-} F R E Q_{i}+\varepsilon_{i}$

UNFAIR_FO $O_{i}=\alpha_{t}+\beta_{1} T E N U R E_{i}+\beta_{2} I N D_{i}+\beta_{3} I N V_{-} B A N K_{-} E X P_{i}+\beta_{4} F I N_{-} E X P_{i}+$ $\beta_{5} D_{\text {DIR_PAYOUT }}+\beta_{6}$ CEO_RETAIN $+\beta_{7}$ CASH_GOLD $_{i}+\beta_{8}$ CEO_CHAIR + $\beta_{9} P R I O R_{-} R E L_{i}+\beta_{10} R O A_{i}+\beta_{11} L I T I G_{-} I N D_{i}+\beta_{12} T O P \_A D V_{i}+\beta_{13} I N S T_{-} O W N_{i}+$ $\beta_{14} P A Y_{-} E Q U I T Y_{j}+\varepsilon_{i}$

LAWSUIT_FO $=\alpha_{t}+\beta_{1} T E N U R E_{i}+\beta_{2} I N D_{i}+\beta_{3} I N V_{-} B A N K_{-} E X P_{i}+\beta_{4} F I N_{-} E X P_{i}+$ $\beta_{5}$ DIR_PAYOUT $+\beta_{6}$ CEO_RETAIN $+\beta_{7}$ CASH_GOLD $+\beta_{8} C E O_{-} C H A I R_{i}+$ $\beta_{9} P R I O R_{-} R E L_{i}+\beta_{10} R O A_{i}+\beta_{11} L I T I G_{-} I N D_{i}+\beta_{12} U N F A I R_{-} F O_{i}+\beta_{13} I N S T \_O W N_{i}+$ $\beta_{14} W_{I D E} F_{-} O_{i}+\beta_{15} P A Y_{-} E Q U I T Y_{j}+\beta_{16} D E A L_{-} P R E M_{j}+\beta_{17}$ VOLATILE $_{i}+\varepsilon_{i}$

In addition to the common set of control variables, I also include model-specific controls particularly relevant for each of the models.

In Model (1) I additionally control for the reputation of the FO provider. Similar to Kisgen et al. (2009), I categorize top-tier opinion providers based on the number of deals in my sample in which the adviser provides an FO. An opinion provider is classified as a top-tier adviser (TOP_ADV) if he is among the top five advisers in my sample: Goldman Sachs \& Co, JP Morgan, Centerview Partners, Morgan Stanley and Citi. Moreover, I incorporate the board meeting frequency (MEET_FREQ) to proxy for the level of monitoring activity of the target board (e.g., Vafeas, 1999; Greco, 2011). Lastly, I include the level of $\mathrm{R} \& \mathrm{D}$ expenditures $(R \& D)$ of the target and I control for the fairness of the FO (UNFAIR_FO).

In Model (2), similar to Model (1) I control for the reputation of the FO provider (TOP_ADV). I also include the institutional ownership of the target (INST_OWN) and whether the payment method includes the use of the acquiring firm's stock ( $P A Y_{-}$ EQUITY).

The main variables of interest in Model (3) are, among others, the properties of an FO, namely its wideness (WIDE_FO) and fairness (UNFAIR_FO). I also control for the deal premium (DEAL_PREM) and whether the payment method includes the use of the acquiring firm's stock (PAY_EQUITY). These factors represent important considerations to target shareholders when evaluating not only the deal, but likely also the fairness 
opinion. Similar to Model (2) I include the investor base of the target (INST_OWN) and I control for the volatility of the target firm (VOLATILE) since especially for these firms the need for an FO is expected to be high. Appendix 3A contains more detailed descriptions of the variables used in my empirical tests.

In all models, the denotations $i$ and $j$ capture the unit of analysis, which is either the target firm $(i)$ or in some cases the deal level $(j)$. I include industries fixed effects based on Fama-French 5 factors industry classification. I winsorize VOLATILE at 1 and 99 percent. Since the explanatory variables and residuals may exhibit serial correlation due to the multiple industry observations, I use industry-clustered standard errors (e.g., Krishnan et al., 2012).

Given the nature of my research question, which is the analysis of both the determinants and consequences of wide ranges FOs at the same time, a simultaneous equations framework is used. I focus on a specific type of the simultaneous equation framework, the Seemingly Unrelated Regressions (SUR). The basic intuition behind this framework is that the simultaneous estimation of the models generates additional information above the information available when considering the individual equations separately. The estimation approach also accounts for the interdependencies among the models and the potential correlation between the error terms in all models (Larcker and Rusticus, 2010; Lennox et al., 2012).

\subsection{Results}

\subsubsection{Descriptive statistics}

Table 1 presents summary statistics for all the variables. It is noteworthy to point out that, on average, in approximately one-third (33\%) of all tender offers target shareholders initiate an FO oriented class action lawsuit. This illustrates the importance and relevance of FOs, not only for regulators, as evidenced by the SEC comment letters addressing FOs, but also for target shareholders. Untransformed statistics indicate that the number of lawsuits initiated after the FO disclosure ranges from as low as 1 to as high as 23 . In addition, it is striking that $13 \%$ of all FOs are unfair from the perspective of target shareholders, since these deals have been completed with the FO suggesting a higher offer price than the price accepted by the target board.

Untransformed statistics show that the average tenure of the board members is around seven years and the average percentage of independent directors is $80 \%$. On average, target boards consist of $10 \%$ of the board members with investment banking expertise and of $36 \%$ of financially experienced directors. The average and median equityrelated payment for the board has a log value of 7.70 Untransformed statistics reveal an average total payment of approximately $\$ 163$ million and a median total payout of around $\$ 55$ million. This highlights the importance of equity-related benefits for 
target directors. The average board size in my sample has mean and median values of 7.6 and 7 , respectively. Hence, target board members, on average, receive a payout of approximately $\$ 21$ million per member upon completion of the tender offer. The median payout for individual directors amounts to approximately $\$ 8$ million. ${ }^{39}$ Cash severance payments make up 38\% of the CEO's golden parachute compensation. The CEO remains employed at the merged company in $15 \%$ of the tender offers and $27 \%$ of the targets have a CEO serving as the chairman of the board. Jointly considered, these descriptive statistics suggest an important role of board and CEO incentives. Top advisers are hired in $42 \%$ and advisers with a prior relationship in $57 \%$ of the tender offers. Institutional investors hold, on average, $59 \%$ of the target common stock.

The correlation matrix in Table 2 suggests that there is no significant association between the FO wideness and fairness and the probability of an FO-oriented class action lawsuit. However, these correlations should be treated with caution as they ignore important covariates relevant for the class-action lawsuit initiation. The correlation analysis reveals that the target board's firm-specific knowledge is negatively correlated to FO wideness, while the financial expertise seems to play a less significant role. The decision to approve an unfair fairness opinion is strongly correlated to the equity held by the target board members.

39 Target boards in my sample as a group hold relatively large equity stakes with a mean percentage of $14.6 \%$ and a median of $7.5 \%$ of common stock. 
TABLE 1: Descriptive Statistics

\begin{tabular}{|c|c|c|c|c|c|c|c|c|}
\hline & $\mathbf{N}$ & Mean & Min & Q1 & Median & Q3 & $\operatorname{Max}$ & Std. Dev. \\
\hline$W I D E \_F O$ & 175 & 0.50 & 0.00 & 0.00 & 0.00 & 1.00 & 1.00 & 0.50 \\
\hline UNFAIR_FO & 175 & 0.13 & 0.00 & 0.00 & 0.00 & 0.00 & 1.00 & 0.34 \\
\hline LAWSUIT_FO & 175 & 0.33 & 0.00 & 0.00 & 0.00 & 1.00 & 1.00 & 0.47 \\
\hline N_LAWSUITS & 175 & 0.48 & 0.00 & 0.30 & 0.48 & 0.70 & 1.38 & 0.32 \\
\hline TENURE & 175 & 0.79 & 0.11 & 0.69 & 0.80 & 0.94 & 1.33 & 0.24 \\
\hline$I N D$ & 175 & 0.80 & 0.43 & 0.75 & 0.83 & 0.88 & 1.00 & 0.10 \\
\hline$I N V \_B A N K \_E X P$ & 175 & 0.10 & 0 & 0 & 0 & 0.17 & 0.67 & 0.13 \\
\hline$F I N \_E X P$ & 175 & 0.36 & 0.00 & 0.22 & 0.33 & 0.50 & 1.00 & 0.21 \\
\hline DIR_PAYOUT & 174 & 7.70 & 5.80 & 7.27 & 7.69 & 8.16 & 9.49 & 0.67 \\
\hline CEO_RETAIN & 175 & 0.15 & 0.00 & 0.00 & 0.00 & 0.00 & 1.00 & 0.36 \\
\hline CASH_GOLD & 165 & 0.38 & 0.00 & 0.18 & 0.35 & 0.57 & 1.00 & 0.25 \\
\hline INST_OWN & 170 & 0.59 & 0.00 & 0.40 & 0.67 & 0.83 & 1.24 & 0.32 \\
\hline$T O P \_A D V$ & 175 & 0.42 & 0.00 & 0.00 & 0.00 & 1.00 & 1.00 & 0.50 \\
\hline PRIOR_REL & 175 & 0.57 & 0.00 & 0.00 & 1.00 & 1.00 & 1.00 & 0.50 \\
\hline$R \& D$ & 173 & 0.13 & 0.00 & 0.00 & 0.07 & 0.16 & 1.11 & 0.19 \\
\hline$R O A$ & 173 & -0.07 & -1.49 & -0.13 & 0.01 & 0.09 & 1.55 & 0.32 \\
\hline$D E A L \_P R E M$ & 175 & 0.61 & -0.87 & 0.28 & 0.45 & 0.69 & 4.85 & 0.65 \\
\hline PAY_EQUITY & 175 & 0.09 & 0.00 & 0.00 & 0.00 & 0.00 & 1.00 & 0.28 \\
\hline$L I T I G \_I N D$ & 175 & 0.40 & 0.00 & 0.00 & 0.00 & 1.00 & 1.00 & 0.49 \\
\hline CEO_CHAIR & 175 & 0.27 & 0.00 & 0.00 & 0.00 & 1.00 & 1.00 & 0.44 \\
\hline$M E E T_{-} F R E Q$ & 167 & 0.96 & 0.48 & 0.85 & 0.95 & 1.08 & 1.49 & 0.21 \\
\hline SWEET_TERMS & 175 & 0.09 & 0.00 & 0.00 & 0.00 & 0.00 & 1.00 & 0.28 \\
\hline VOLATILE & 168 & 23.05 & 2.46 & 4.99 & 11.41 & 34.81 & 74.01 & 23.71 \\
\hline
\end{tabular}

This table presents summary statistics of all variables used in empirical models. All variables are defined in Appendix $3 \mathrm{~A}$. 


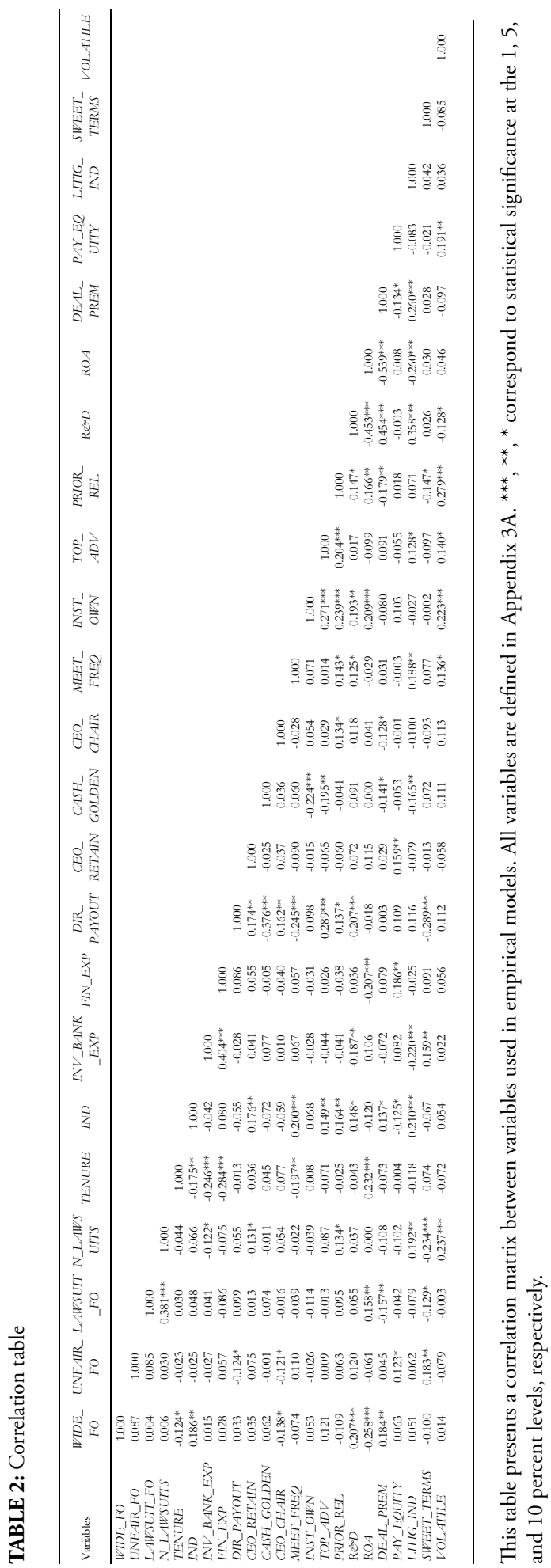




\subsubsection{Wideness and fairness of the FO}

Table 3 reports marginal effects for the three probit regressions. Column 1 presents the determinants of the FO wideness (Model 1) and Column 2 the FO fairness (Model 2), while Column 3 summarizes the results for the determinants of the FO-oriented class action lawsuit initiation (Model 3). The results are reported separately for each model, but remember that these models are estimated simultaneously.

The results in column 1 reveal that firm-specific knowledge is indeed a strong predictor of wide-ranged FOs, which provides support for $\mathrm{H} 1$. The higher the tenure of the board members, and thus the accumulated firm-specific knowledge, the lower the likelihood that a wide-ranged FO is disclosed. The board's independence is the strongest predictor of the FO wideness, with independent board members being more likely to disclose a wide-ranged FO. This supports prior studies that independent board members lack firmspecific knowledge and thus tend to provide less precise information such as earnings forecasts, or in the case of tender offers, target valuation estimates. My results suggest that it is in fact mainly the firm-specific knowledge of the board that is relevant for the wideness of ranges observed in FOs. I find no support for $\mathrm{H} 1$ a since neither financial nor investment banking expertise seems to substantially matter for the FO wideness.

The boards' equity benefits upon completion of the tender offer are positively associated with the wideness of the ranges in an FO, providing support for H2. Similarly, the cash component of the golden parachute represents strong incentives for the CEO to complete the tender offer, resulting in wide-ranged FOs. There is no evidence that the retention of the $\mathrm{CEO}$ is related to $\mathrm{FO}$ wideness, so that there is only partial support for $\mathrm{H} 3$. In addition, FOs tend to have wider valuation ranges in the case of less profitable firms and when FOs are unfair. This suggests that the FO wideness might be used strategically to distract from information such as poor performance of the target in the past or unattractive offer price accepted by the board. R\&D intense target firms also tend to have wide $\mathrm{FO}$ valuation ranges, which simply reflects the valuation difficulty and uncertainty inherent in this type of firms. Lastly, I find that the meeting frequency of the board is negatively related to the FO wideness. This is in line with the target board monitoring activity providing benefits to shareholders. Overall, Model 1 yields evidence that firm-specific knowledge and incentives of the board as well as the CEO are relevant determinants of the $\mathrm{FO}$ wideness.

The results in Model 2 reveal that the higher the boards' equity stake, the lower the probability that an unfair FO is disclosed, which supports $\mathrm{H} 4$. CEO incentives also play an important role for the fairness of an FO. I find that the retention of the CEO is positively associated with the probability of an unfair FO, while the cash component of the golden parachute is unrelated to the FO fairness. Thus, H5 is partially supported. Interestingly, my results also show that the opinion provider's pre-existing relationship with the target is positively associated with the unfairness of an FO, hinging at the potential conflict of interest. Institutional ownership seems to serve as a disciplining 
mechanism for the target board since it is less likely to disclose an unfair FO if its investor base consists primarily of sophisticated investors. Overall, the results in Model 2 suggest that the sensitivity of the board towards the offer price is an important determinant of the fairness of the FO. The more the directors are affected by the offer price themselves, the greater the alignment of the interests with those of target shareholders. I also find that retention at the merged company may lead the CEO to promote unfavorable deals to shareholders, giving rise to important agency costs.

Table 3: Empirical models

\begin{tabular}{|c|c|c|c|}
\hline & $\begin{array}{l}\text { Model 1: } \\
\text { Wideness }\end{array}$ & $\begin{array}{l}\text { Model 2: } \\
\text { Fairness }\end{array}$ & $\begin{array}{c}\text { Model 3: } \\
\text { Lawsuit initiation }\end{array}$ \\
\hline \multirow[t]{2}{*}{$I N D$} & $1.019^{* * *}$ & -0.046 & \\
\hline & $(0.003)$ & $(0.817)$ & \\
\hline \multirow[t]{2}{*}{ TENURE } & $-0.166^{*}$ & 0.055 & -0.058 \\
\hline & $(0.057)$ & $(0.519)$ & $(0.752)$ \\
\hline \multirow[t]{2}{*}{$F I N \_E X P$} & -0.182 & -0.009 & $-0.471^{* *}$ \\
\hline & $(0.588)$ & $(0.967)$ & $(0.013)$ \\
\hline \multirow[t]{2}{*}{$I N V \_B A N K \_E X P$} & 0.161 & -0.107 & $0.426^{* * *}$ \\
\hline & $(0.533)$ & $(0.735)$ & $(0.000)$ \\
\hline \multirow[t]{2}{*}{ DIR_PAYOUT } & $0.098^{*}$ & $-0.095^{* * *}$ & $0.115^{* *}$ \\
\hline & $(0.093)$ & $(0.006)$ & $(0.024)$ \\
\hline \multirow[t]{2}{*}{ CASH_GOLD } & $0.351^{* * *}$ & -0.041 & 0.092 \\
\hline & $(0.004)$ & $(0.728)$ & $(0.338)$ \\
\hline \multirow[t]{2}{*}{ CEO_RETAIN } & 0.036 & $0.101^{* *}$ & 0.046 \\
\hline & $(0.623)$ & $(0.024)$ & $(0.596)$ \\
\hline \multirow[t]{2}{*}{ CEO_CHAIR } & $-0.135^{\dagger}$ & $-0.112^{*}$ & -0.075 \\
\hline & $(0.108)$ & $(0.094)$ & $(0.270)$ \\
\hline \multirow[t]{2}{*}{$R O A$} & $-0.277^{* * *}$ & -0.010 & 0.104 \\
\hline & $(0.000)$ & $(0.801)$ & $(0.368)$ \\
\hline \multirow[t]{2}{*}{ PRIOR_REL } & -0.069 & $0.126^{* * *}$ & $0.135^{\dagger}$ \\
\hline & $(0.443)$ & $(0.000)$ & (0.159) \\
\hline \multirow[t]{2}{*}{$L I T I G \_I N D$} & -0.069 & $0.035^{* *}$ & $-0.098^{\dagger}$ \\
\hline & $(0.506)$ & $(0.047)$ & $(0.147)$ \\
\hline \multirow[t]{2}{*}{$T O P_{-} A D V$} & $0.128^{* *}$ & 0.016 & \\
\hline & $(0.039)$ & $(0.810)$ & \\
\hline \multirow[t]{2}{*}{$R \approx D$} & $0.243^{\dagger}$ & & \\
\hline & $(0.170)$ & & \\
\hline \multirow[t]{2}{*}{ UNFAIR } & $0.192^{*}$ & & $0.128^{* * *}$ \\
\hline & $(0.092)$ & & $(0.010)$ \\
\hline \multirow[t]{2}{*}{$M E E T \_F R E Q$} & $-0.421^{* * *}$ & & \\
\hline & $(0.006)$ & & \\
\hline \multirow[t]{2}{*}{ INST_OWN } & & $-0.075^{* * *}$ & $-0.155^{*}$ \\
\hline & & $(0.009)$ & $(0.069)$ \\
\hline
\end{tabular}


Table 3: empirical models (continued)

\begin{tabular}{|c|c|c|c|}
\hline PAY_EQUITY & & $\begin{array}{c}0.202^{* * *} \\
(0.001)\end{array}$ & $\begin{array}{l}-0.115 \\
(0.330)\end{array}$ \\
\hline WIDE_FO & & & $\begin{array}{c}0.070^{*} \\
(0.075)\end{array}$ \\
\hline DEAL_PREM & & & $\begin{array}{c}-0.166^{* *} \\
(0.013)\end{array}$ \\
\hline VOLATILE & & & $\begin{array}{c}0.001 \\
(0.970) \\
-\end{array}$ \\
\hline Industry $\mathrm{FE}$ & YES & YES & YES \\
\hline Year FE & $\mathrm{NO}$ & $\mathrm{NO}$ & $\mathrm{NO}$ \\
\hline Observations & 155 & 158 & 152 \\
\hline Pseudo $\mathrm{R}^{2}$ & $17.32 \%$ & $14.50 \%$ & $15.45 \%$ \\
\hline
\end{tabular}

This table reports marginal effects of probit regressions of the determinants of the wideness (Model 1), fairness of the FO (Model 2) and the determinants of the FO-oriented class action lawsuit initiation (Model 3). The dependent variable in Model 1, WIDE_FO, is a dummy variable that equals 1 if the average wideness in an FO is higher than the sample median average wideness, and zero otherwise. The dependent variable in Model 2, UNFAIR_FO, is a dummy variable that equals 1 if the average price as suggested by an FO is higher than the accepted offer price, and zero otherwise. The dependent variable in Model 3, LAWSUIT_FO, is a dummy variable that equals 1 if there is at least one class action lawsuit specifically addressing the FO, and zero otherwise. Definitions of all variables are provided in Appendix $3 \mathrm{~A}$. P-values are reported in parentheses $\left({ }^{* * *} \mathrm{p}<0.01,{ }^{* *} \mathrm{p}<0.05,{ }^{*} \mathrm{p}<0.1,{ }^{\dagger}\right.$ one-sided significance) and standard errors are clustered at industry level, using Fama French 5 factors. The SUR estimation technique is applied to control for the correlation of the error terms across models.

\subsubsection{Shareholder class action lawsuit initiation}

The main findings in column 3 are that wide-ranged and unfair FOs are more likely to trigger shareholder class action lawsuits, providing support for H6. These findings clearly indicate that the attributes of FOs matter to investors, despite prior evidence suggesting that FOs are "window-dressing" (e.g., Makhija and Narayanan, 2007; Davidoff, 2006). ${ }^{40}$

Overall, the results suggest that target shareholders consider the valuation and finance expertise of the board as well as its incentives when evaluating the FO and its usefulness. The firm-specific knowledge and the CEO's incentives seem to be less relevant for the FO-oriented class action lawsuit initiation. ${ }^{41}$ It is interesting to note that shareholders' FO lawsuit initiation is different for the different types of the board's expertise. While financial expertise of the board reduces the probability of an FO class action lawsuit, the opposite is true for investment banking. Target shareholders might be more skeptical towards FOs disclosed by the boards with investment banking experience due to the potential conflict of interest arising from directors' affiliation with investment banks in the past. Directors with prior affiliations in the investment banking industry are

40 See, for example, a news article by Financial Times in 2005 "You Can Call It a Fairness Opinion, but That Wouldn't Be Fair”, retrieved from: https://www.nytimes.com/2005/07/10/business/yourmoney/you-can-call-it-a-fairnessopinion-but-that-wouldnt-be.html

41 Since independence of the target board is the strongest predictor of the FO wideness, I exclude it from the model. However, the inferences remain unaffected if I include the boards' independence in the model. 
argued to pursue the interests of those affiliated institutions rather than maximizing shareholder value (Güner, Malmendier \& Tate, 2008). Moreover, target shareholders are more skeptical towards FOs disclosed by target directors with large equity benefits upon completion of the tender offer as these represent strong incentives to complete the deal.

I find that institutional owners are less likely to initiate a FO-oriented class action lawsuit. While both sophisticated and non-sophisticated investors incorporate FOs into their decisions, non-sophisticated investors might need to rely more on the FO due to a lack of sophistication to conduct own valuations and fair price assessments. The existence of prior ties between the target firm and the FO provider seems to trigger shareholders' skepticism towards FOs as it is positively related to the class action lawsuit initiation. Lastly, target shareholders are less likely to initiate a class action lawsuit the higher the deal premium offered by the acquirer. In sum, the evidence shows that the board's characteristics and FO properties trigger target shareholder's skepticism towards FOs.

\subsection{Additional analysis}

Besides examining whether a class action lawsuit is initiated, I also consider the number of class action lawsuits as there is a remarkable variation in the number of class action lawsuits initiated. I analyze whether FO properties exacerbate shareholders' dissatisfaction towards disclosed FOs. Model (4) is summarized as follows:

$$
\begin{aligned}
& N_{-} \text {LAWSUITS }_{i}=\alpha_{t}+\beta_{1} \text { TENURE }_{i}+\beta_{2} I N V_{-} B A N K_{-} E X P_{i}+\beta_{3} F_{I} N_{-} E X P_{i}+ \\
& \beta_{4} \text { DIR_PAYOUT }_{i}+\beta_{5} \text { CEO_RETAIN }+\beta_{6} \text { CASH_GOLD }_{i}+\beta_{7} \text { CEO_CHAIR }+ \\
& \beta_{8} \text { PRIOR_REL } L_{i}+\beta_{9} R O A_{i}+\beta_{10} \text { LITIG IND }_{i}+\beta_{11} \text { UNFAIR_FO } O_{i i}+\beta_{12} I N S T_{-} \\
& O W N i+\beta_{13} W_{I D E} F_{i}+\beta_{14} \text { VOLATILE }{ }_{i}+\beta_{15} S W E E T \_T E R M S_{i}+\varepsilon_{i}
\end{aligned}
$$

The dependent variable in Model (4) is the logarithm of the number of class action lawsuits initiated (N_LAWSUITS). ${ }^{42}$ I additionally include an indicator variable (SWEET_TERMS) to capture deals where the offer price was increased prior to the disclosure of an FO as it is likely to affect shareholders' evaluation of the offer price, and, thus, the FO. All variables are defined in Appendix 3A. The results are reported in Table 4.

The main finding is that both the wideness of the ranges in an FO and its fairness do not only trigger the initiation of class action lawsuits, but also their prevalence. In addition, the investment banking expertise of the board and sweet terms are the strongest predictors of the number of class action lawsuits, both suggesting a negative

42 I consider the total number of lawsuits initiated after the disclosure of an FO. Untransformed statistics indicate that the number of lawsuits initiated after the FO disclosure ranges from as low as 0 to as high as 23 . 
relation. The number of lawsuits seems to be higher when the CEO serves as chairman of the board and when target firms are volatile. Overall, the findings provide support that wide-ranged and unfair FOs trigger significant dissatisfaction among target shareholders with regard to the FO disclosure.

Table 4: Number of class action lawsuits

\begin{tabular}{|c|c|}
\hline & $\begin{array}{c}\text { Model 4: } \\
\text { Number of lawsuit initiations }\end{array}$ \\
\hline \multirow[t]{2}{*}{ TENURE } & -0.115 \\
\hline & $(0.769)$ \\
\hline \multirow[t]{2}{*}{$F I N \_E X P$} & -0.230 \\
\hline & $(0.284)$ \\
\hline \multirow[t]{2}{*}{$I N V \_B A N K \_E X P$} & $-0.420^{\dagger}$ \\
\hline & $(0.125)$ \\
\hline \multirow[t]{2}{*}{ DIR_PAYOUT } & $-0.079^{\dagger}$ \\
\hline & $(0.180)$ \\
\hline \multirow[t]{2}{*}{ CASH_GOLD } & -0.195 \\
\hline & $(0.498)$ \\
\hline \multirow[t]{2}{*}{ CEO_RETAIN } & $-0.180^{*}$ \\
\hline & $(0.089)$ \\
\hline \multirow[t]{2}{*}{ CEO_CHAIR } & $0.083^{* *}$ \\
\hline & $(0.042)$ \\
\hline \multirow[t]{2}{*}{$R O A$} & 0.095 \\
\hline & $(0.628)$ \\
\hline \multirow[t]{2}{*}{ PRIOR_REL } & 0.082 \\
\hline & $(0.408)$ \\
\hline \multirow[t]{2}{*}{$L I T I G \_I N D$} & $0.318^{* * *}$ \\
\hline & $(0.000)$ \\
\hline \multirow[t]{2}{*}{$W I D E \_F O$} & $0.091^{* *}$ \\
\hline & $(0.044)$ \\
\hline \multirow[t]{2}{*}{$U N F A I R \_F O$} & $0.166^{*}$ \\
\hline & $(0.052)$ \\
\hline \multirow[t]{2}{*}{ SWEET_TERMS } & $-0.627^{* * *}$ \\
\hline & $(0.000)$ \\
\hline \multirow[t]{2}{*}{ INST_OWN } & $-0.156^{\dagger}$ \\
\hline & $(0.189)$ \\
\hline \multirow[t]{2}{*}{ VOLATILE } & $0.006^{* * *}$ \\
\hline & $(0.007)$ \\
\hline Industry FE & YES \\
\hline Year FE & NO \\
\hline Observations & 152 \\
\hline Adjusted $\mathrm{R}^{2}$ & $13.56 \%$ \\
\hline
\end{tabular}

This table reports the results for the OLS model capturing the number of class action lawsuits (Model 4). The dependent variable is the logarithm of the number of class action lawsuits initiated ( $\left.N \_L A W S U I T S\right)$. Definitions of all variables are provided in Appendix 3A. P-values are reported in parentheses $\left({ }^{* * *} \mathrm{p}<0.01,{ }^{* *} \mathrm{p}<0.05,{ }^{*} \mathrm{p}<0.1,{ }^{\dagger}\right.$ one-sided significance) and standard errors are clustered at industry level, using Fama French 5 factors. The SUR estimation technique is applied to control for the correlation of the error terms across models. 


\subsection{Conclusion}

This study examines the properties of the obtained FOs, their determinants and how shareholders perceive them. I find that the board's and the CEO's incentives to complete the tender offer shape both the wideness of the FO as well as the decision to accept an unfavorable deal. In addition, the board's firm-specific knowledge is a strong predictor of the FO wideness, which highlights the importance and benefits of accumulated firm-specific knowledge. Both FO properties matter to target shareholders. Target shareholders do not perceive wide-ranged and unfair FOs as useful as these FOs are more likely to trigger class action lawsuits. There is also a difference in the perception among the different types of investors. Non-institutional investors are more likely to initiate a FO-oriented class action lawsuit as compared to sophisticated shareholders. The former might lack sophistication to conduct their own valuations and thus might need to rely more on FOs.

My findings contribute to the fairness opinion, corporate governance as well as litigation literature. First, prior studies mainly focus on the use of FOs in M\&As and outcomes for the acquiring firm shareholders. I investigate the role of FOs in the tender offer setting where I expect FOs to be of greatest importance. Target shareholders are required to make their tendering decisions within a short period of time. Hence, target FO and its underlying valuation analyses help target shareholders in reaching an informed decision. Second, despite the great importance of FO analyses, prior studies mainly focus on the determinants of the use of an FO. My study, however, shows that while all targets issue an FO in tender offers, one-third of them is exposed to class action lawsuits. This implies that it is not the decision to obtain an FO that should be examined for deal outcomes and shareholder implications, but the underling valuation analyses. My study further shows that contrary to the criticism of FOs being merely rubber stamps without providing any incremental information, FOs in tender offers represent a relevant information source to target shareholders. Third, this is the first study to investigate the board's characteristics and incentives in the context of FOs. Given that it is primarily the target board who is responsible for the FO disclosure, it is important to investigate the extent to which the board can use the FOs strategically to achieve its desired objectives. Lastly, this is the first study to analyze the association between the properties of a FO and target shareholder class actions. Shareholder lawsuits are costly and delay the completion rate of the deals. Therefore, it is crucial to understand which FO properties trigger shareholder lawsuits, thereby impeding the fast completion rate of tender offers.

The findings of the study are subject to several limitations. First, in addition to the examined characteristics and incentives of the board, future research can incorporate some additional factors such as age and/or industry experience of the board members. Second, while I capture the investor base of the target firm, I do not explicitly analyze the identity of the lead plaintiff filing the shareholder class action lawsuit. Given that some plaintiff types are more likely to be strategic and interested in pursuing stringent 
case outcomes (Brochet and Srinivasan, 2014), it is interesting to explore it in future research. Third, I examine adviser related characteristics at an aggregate level. Future research can explore the individual level of adviser related characteristics, for example, which reputable advisers issue wide versus narrow ranged FOs. Additionally, the type and the extent of the prior relationship can be examined to get a better understanding of the strength of a potential bond between the adviser and the target firm. Lastly, while I expect FOs to matter more in the case of tender offers as opposed to friendly M\&A deals, this, nevertheless, results in a relatively small sample size. 


\section{Appendix 3A: Variable definitions with the corresponding data-sources}

\begin{tabular}{|c|c|c|}
\hline \multicolumn{2}{|l|}{ Dependent Variables } & \multirow{2}{*}{$\begin{array}{l}\text { Data Source } \\
\text { Schedule 14D-9 }\end{array}$} \\
\hline$W I D E \_F O$ & $\begin{array}{l}\text { I first calculate the mean scaled wideness of each method, } \\
\text { wide }_{1} \text { to wide } \text { as, for instance, wide }_{1}=\left[\mathrm{Upper}_{\mathrm{n}} \text { bound range }{ }_{1}-\right. \\
\left.\text { Lower bound range }_{1}\right] /\left(\left(\mathrm{Upper}_{\text {pound }} \text { range }\right.\right. \\
\end{array}$ & \\
\hline UNFAIR_FO & $\begin{array}{l}\text { Similar to WIDE_FO, I first calculate the average price estimate } \\
\text { for each method, mean } \text { to mean }_{n} \text { as, for instance, mean }{ }_{1}= \\
\left.\left(\text { Upper bound range }_{1}+\text { Lower bound range }_{1}\right) / 2\right) \text {. I then calculate } \\
\text { the overall average price estimate across all the methods in an } \\
\text { FO, as AV_MEAN }=\left(\text { mean }_{1}+\text { mean }_{2}+\ldots \text { mean }_{n}\right) / N \text {, where } N \text { is } \\
\text { the total number of methods with a range in an FO. UNFAIR_ } \\
\text { FO=1 if AV_MEAN is higher than the accepted offer price, and } \\
\text { zero otherwise. }\end{array}$ & Schedule 14D-9 \\
\hline LAWSUIT_FO & $\begin{array}{l}=1 \text { if there is at least one class action lawsuit specifically } \\
\text { addressing the FO, and zero otherwise. }\end{array}$ & $\begin{array}{l}\text { Target SEC filings on the } \\
\text { EDGAR Web site }\end{array}$ \\
\hline N_LAWSUITS & $\begin{array}{l}=\text { Logarithm of }(1+\text { total number of lawsuits initiated after the } \\
\text { disclosure of an FO). }\end{array}$ & $\begin{array}{l}\text { Target SEC filings on the } \\
\text { EDGAR Web site }\end{array}$ \\
\hline Board variables & & Data Source \\
\hline TENURE & $\begin{array}{l}=\text { Logarithm of [total number of years of service of all board } \\
\text { members / total number of board members]. }\end{array}$ & Schedule 14D-9/ DEF 14A \\
\hline$I N D$ & $\begin{array}{l}=\text { Number of independent board members / total number of } \\
\text { board members. }\end{array}$ & Schedule 14D-9/ DEF 14A \\
\hline$I N V \_B A N K \_E X P$ & $\begin{array}{l}=\text { Number of board members with investment banking } \\
\text { experience/ total number of board members. }\end{array}$ & Schedule 14D-9 / DEF 14A \\
\hline$F I N \_E X P$ & $\begin{array}{l}=\text { Number of board members with finance experience } / \text { total } \\
\text { number of board members. }\end{array}$ & Schedule 14D-9/ DEF 14A \\
\hline DIR_PAYOUT & $\begin{array}{l}=\text { Logarithm of the total equity related payments of target } \\
\text { directors. This includes the payments for the common stock held } \\
\text { by the board and the accelerated equity vesting. In case these } \\
\text { accelerated vesting benefits are not explicitly given, I calculate } \\
\text { them manually as (offer price-average option's exercise price) } \\
\text { multiplied by the equity amount to be accelerated. In the case } \\
\text { of restricted stock, I multiply the amount of stock with the offer } \\
\text { price. This is in line with prior research (e.g., Fich, Cai and Tran, } \\
\text { 2011). }\end{array}$ & Schedule 14D-9 \\
\hline CEO_RETAIN & $\begin{array}{l}=1 \text { if } \mathrm{CEO} \text { remains employed at the merged company, and zero } \\
\text { otherwise. }\end{array}$ & Schedule 14D-9 \\
\hline CASH_GOLD & $\begin{array}{l}=\text { Cash component of the golden parachute } / \text { total amount of the } \\
\text { golden parachute. }\end{array}$ & Schedule 14D-9 \\
\hline
\end{tabular}


=Total number of shares owned by institutions / total number of shares outstanding. I use the most recent institutional ownership figure available immediately prior to the disclosure of a FO.

Thomson Reuters

Institutional Holdings (13f)

$=1$ if the target adviser is among Goldman Sachs \& Co, JP

TOP_ADV Morgan, Centerview Partners, Morgan Stanley and Citi, and zero

Schedule 14D-9

otherwise.

PRIOR_REL

$=1$ if the target adviser provided services in the past, and zero otherwise.

Schedule 14D-9

$R \& D$

$=\mathrm{A}$ three-year moving average of $\mathrm{R} \& \mathrm{D}$ expenditures/total assets of the target.

Compustat / SDC

$R O A=$ EBIT of the target firm/total assets of the target.

SDC

$=($ Offer price - target share price 4 weeks prior to the tender

DEAL_PREM offer announcement)/ target share price 4 weeks prior to the tender offer announcement.

SDC

$=1$ if the payment method includes the use of the acquiring firm's stock, and zero otherwise. This variable captures the use of the acquiring firm's equity only and a hybrid payment method, consisting of both cash and equity. (The base level, PAY_EQUITY=0 captures deals where only cash is used as a payment method).

$=1$ if the target operates in one of the litigious industries (SIC

LITIG_IND Codes 2833-2836, 3570-3577, 3600-3674, 5200-5961 and 7370), and zero otherwise.

CEO_CHAIR

$=1$ if the $\mathrm{CEO}$ is also the chairman of the board, and zero otherwise.

Schedule 14D-9

=Logarithm of the total number of target board meetings held

MEET_FREQ in the year prior to the tender offer. I use the most recent figure available prior to the disclosure of the FO.

$=1$ if the offer price was increased prior to the disclosure of an $\mathrm{FO}$, and zero otherwise.

SDC

Schedule 14D-9/

DEF $14 \mathrm{~A}$

Schedule 14D-9/

DEF $14 \mathrm{~A}$

Target SEC filings on the EDGAR Web site

$=$ Standard deviation of net income measured on a rolling basis over a three-year period. This variable is winsorized at 1 and $99 \%$. 




\section{Chapter 4}

As good as it gets? The role of boutique financial advisers in fairness opinions:

Evidence from tender offers ${ }^{43}$ 


\begin{abstract}
This study investigates the role of boutique advisers in the context of the provision of fairness opinions (FO). First, we are interested whether boutique advisers provide more precise FOs as compared to non-boutique investment banks. Second, we investigate the association between the precision of a target-sought $\mathrm{FO}$ and the type of a financial adviser and the probability of a timely tender offer execution. Our findings suggest that boutique advisers provide more precise FOs as compared to their counterparts. The recent popularity of boutique advisers seems to be warranted in terms of the precision of their FOs. In general, we find that target advisers with prior ties with the acquirer provide less precise FOs, potentially to facilitate the success of the acquirer's takeover attempt. Our results, however, reveal that the opposite is true for boutique advisers as they are likely to provide more precise FOs if they have prior ties with the acquirer. This is in line with the "service excellence" idea as the provision of a precise FO increases the likelihood that the acquirer rehires a boutique adviser in the future. We find that less precise FOs tend to delay the completion of the tender offer, suggesting that target shareholders prefer more precise FO disclosures.
\end{abstract}




\subsection{Introduction}

Over the last years, the popularity of boutique financial advisers has been on the rise. Boutique advisers often specialize in certain industries, focus primarily on providing advisory services in mergers and acquisitions (M\&A) and are generally viewed as independent (Chessell, 2015; Song, Wei and Zhou, 2013). These generally small but specialized investment banks are stealing M\&A market share from the larger wellestablished banks at increasing rates. In 2016, boutique financial advisers accounted for 34 percent of total M\&A advisory fees, an increase of $20 \%$ compared to $2007 .{ }^{44}$

The threat of a perceived (or actual) conflict of interest, and a desire to avoid it, have increased the demand by boards of directors for an independent and unbiased advice provided by boutique advisers. Yet, despite their growing popularity, the evidence regarding the benefits of hiring boutique advisers versus their competitors is still scarce (Song et al., 2013). Therefore, this study investigates the role of boutique advisers in the context of the provision of fairness opinions (FO). Specifically, this study attempts to address two research questions. First, we are interested whether boutique advisers provide more precise FOs as compared to non-boutique advisers. Second, we investigate the association between the precision of a target-sought $\mathrm{FO}$ and boutique advisers and the probability of a timely deal completion.

A fairness opinion is obtained in M\&As and going-private transactions to help the board of the acquiring or target firm determine the appropriateness or "fairness" of the consideration to be paid or received. An FO is meant to serve as an objective assessment of the transaction, as it is delivered by a financial adviser evaluating the target and transaction price. On the basis of various valuation analyses, the financial adviser states whether the price received in the transaction is fair from a financial point of view to shareholders of the client firm (Liu, 2019). These valuation analyses are at the heart of the $\mathrm{FO}$ and serve as an important basis for decision-making by the board of directors. Yet, despite the central role of the FO valuation analyses, prior studies have mainly focused on the determinants of obtaining an $\mathrm{FO}$ and have largely ignored the underlying properties of FOs. However, the informational value of an FO to shareholders depends heavily on its underlying properties, and anecdotal evidence suggests a large heterogeneity in the properties of FOs. ${ }^{45}$

We focus on a key FO property, the precision of an FO, which is captured by the wideness of valuation ranges in an FO. When confronted with a takeover bid, the boards' and target shareholders' key consideration is whether the offer price is fair and attractive. The

44 Retrieved from: https://www.reuters.com/article/us-banks-boutiques-strategy-idUSKBN1432WH

45 For instance, one judge presiding over shareholder litigation concluded that the valuation ranges presented in an FO are so wide that "even a Texan would feel at home on them. Per-share prices ranged from \$159-\$247 for 1991, \$230-\$332 for 1992, to \$208-\$402 for 1993. See Paramount Communications v. Time, Inc. (CivilActionNo.10866, Del.Ch.LEXIS77). 
ranges in an FO can be used to evaluate the attractiveness of the offer price since they signal the spectrum of possible valuations within which the offer price can fall. Thus, the wideness of the ranges is supposed to provide assurance regarding the offer price and facilitate shareholders' decisions towards accepting the deal. This wideness has received substantial criticism from media, regulators and courts. Duff and Phelps (2017), for instance, note that FOs are mostly criticized for producing valuation ranges that are too wide to provide meaningful information. ${ }^{46}$ The wideness of the ranges seems to be a core property used to determine the usefulness of an FO. We refer to more precise FOs in case of narrower and less precise FOs in case of wider valuation ranges in an FO.

To investigate our research questions, we focus on a setting in which fairness opinions and their properties are likely to be very important, namely tender offers. The completion and success of tender offers is highly dependent on target shareholders' tendering decisions. Tender offers often have so-called minimum conditions, which implies that a deal can only be completed if a certain percentage of target shareholders' shares is tendered within a specified time frame. Hence, it is pivotal for shareholders to receive an accurate assessment of the value of their shares, and FO valuation analyses can help target shareholders in reaching an informed decision. Considering the central role of FOs and their underlying properties in tender offers, it is important to analyze whether prestigious boutique investment banks provide more precise FO target valuations as suggested by their independence and expertise. Since tender offers are often chosen due to faster completion times, it is crucial to not only understand the relation between the different types of advisers and FO properties but also how these FO properties relate to the timeliness of a deal completion.

Bulge bracket investment banks represent the traditional full-service brokerage houses that offer a wide range of services such as sales, trading, underwriting, research and lending. In contrast, boutique advisers are generally smaller, independent, often industry specialists and focus exclusively on providing M\&A advice. The differential nature and focus of boutique banks make it interesting to investigate whether they provide different FOs as compared to their counterparts. On the one hand, boutique advisers should provide more precise valuation ranges due to their industry specialization and M\&A expertise (Song et al., 2013). On the other hand, except for a few well-known boutique firms, boutique advisers in general tend to be less well known and are much more reliant on fees for advisory services because this is their only line of business. This might provide them with incentives to issue less precise FOs to ensure that the offer price falls within the valuation ranges so that the tender offer is completed, and their compensation is secured. In addition, we also explore whether the existence of prior ties with the acquirer affects the association between boutique advisers and the precision of their FOs. This

46 Retrieved from: https://www.duffandphelps.com/insights/publications/transaction-opinions/in-defense-offairness-opinions-an-empirical-review-of-ten-years-of-data 
might arise due to the potential conflict of interest faced by target boutique advisers. In a takeover setting, the primary concern of target advisers might shift to securing future business with the acquirer, with precise target valuations being of second order importance.

We hand-collected all U.S. tender offers and target FO valuation analyses between 2010 and 2018. The results show that $33 \%$ of target firms in tender offers hire a boutique investment bank, which supports the popularity of and demand for boutique financial advisers. We find that boutique advisers provide more precise FOs as compared to their counterparts, as suggested by their independence and M\&A expertise. The results further show that almost $40 \%$ of financial advisers hired by the target have prior ties with the acquirer. Our results reveal that, in general, target advisers with prior ties with the acquirer tend to provide less precise FOs, yet the opposite is true for boutique advisers. These advisers provide more precise FOs if they have prior ties with the acquirer, likely to increase the likelihood that the acquirer rehires them in the future. This is in line with the "service excellence" idea as the provision of precise FOs is likely to improve boutique advisers' chances of being rehired by the acquirer in the future.

With regard to the second research question, we find that the probability of a timely deal completion is positively associated with the precision of an FO, hinging at target shareholders' preference for more precise FO disclosures. We also find that target shareholders seem to tender their shares faster if the target hires a boutique adviser as compared to other non-boutique investment banks. Overall, our results reveal that target firms benefit from hiring boutique advisers since they provide more precise FOs, which in turn facilitates a timely deal completion.

This paper contributes to the fairness opinion and financial adviser literature in several ways. First, this is the first paper to analyze how the type of a financial adviser is associated with the properties observed in an FO. Boutique financial advisers and FOs both still represent unexplored phenomena despite their remarkable prevalence in the M\&A arena. Prior studies mainly focused on the decision to obtain an FO and therewith associated deal and shareholder wealth implications (Kisgen at al., 2009; Frye and Wang, 2010; Liu, 2018; Liu, 2019). Yet, as prior research suggests it is not the occurrence of an FO, but rather its underlying valuation analyses that should be examined. For instance, the results in chapter 3 reveal that class action lawsuits are more likely to be initiated if less precise FOs are issued. This highlights the importance of FO properties and the need to explore their determinants and consequences in the M\&A setting.

While chapter 3 shows that the target board's characteristics and incentives are important determinants of the observed FO properties, this is the first study to explore the characteristics of an FO provider. Especially the role and superiority of boutique advisers in the context of FO provision has been so far unexplored. So far there are two studies examining the role of boutique advisers and deal outcomes. Song, Wei and Zhou 
(2013) examine the choice and role of boutique advisers for deal outcomes in the US setting, while Loyeung (2019) investigates the performance of boutique advisers in the Australian market. Both studies show that the benefits of hiring a boutique adviser flow to both the acquirers and the target firms, which to some extent validates the increasing popularity of boutique advisers. ${ }^{47}$ This study differs from these studies in at least two aspects. First, we examine the role of boutique advisers in the context of FO provision. Both prior studies focus on the initial stage, being the choice of a boutique adviser, and the final step, namely deal outcomes. While the adviser itself, and thus its choice, is an important determinant of deal outcomes, we argue that it is the intermediate step in the M\&A chain, which is the provision of an FO disclosure, that is equally relevant. In both M\&As and tender offers target shareholders rely on FOs for either their M\&A approval and voting, or tendering decisions in the case of tender offers. Therefore, rather than investigating the type (and choice) of an adviser and deal outcomes directly, we first focus on the type of an adviser and FO properties, and in a second step how these properties relate to certain deal outcomes. Additionally, we integrate characteristics of the target board when examining the decision to hire a boutique adviser and also the precision of an FO. This enables us to have a full picture on the determinants of the FO precision.

Second, this is the first study to analyze how FO properties interact with tender offer extensions, which capture the speed of shareholder's tendering. Similar to class action lawsuits, extensions of a tender offer delay the completion of the deal and diminish the comparative advantage of faster completion times of tender offers over mergers. Thirdly, rather than exploring the target adviser's prior relationship with the target, we focus on prior ties with the acquirer since the latter has been largely unexplored, especially in the context of FOs.

The remainder of the paper is organized as follows: Section 4.2 outlines prior literature. Section 4.3 summarizes theoretical predictions. Section 4.4 discusses the research design and sample. Section 4.5 presents the findings, while section 4.6 concludes.

47 Song et al. (2013) find that deal premiums are lower when acquirers hire boutique advisers and that these advisers lengthen the duration of a deal because they are likely to spend more time on due diligence and negotiation to complete deals. Loyeung (2019) shows that acquiring firms benefit in terms of improved post-merger performance, while target firms benefit in terms of higher completion of value-enhancing deals and positive cumulative abnormal returns when boutique advisers are involved. 


\subsection{The use of fairness opinions}

\subsubsection{Institutional background}

FOs find their origin in the Smith vs. Van Gorkom case and Delaware law that institutionalized an "outside" opinion within the M\&A context in the U.S. In the Smith vs. Van Gorkom (1985) case, the Delaware Supreme Court declared the board of the Trans Union Corporation guilty because it approved an acquisition without obtaining anything more than a "rough" and unquestioned estimate of a possible value from its CFO. According to the Delaware Supreme Court, a target board, as part of its greater duty of care in a corporate control transaction, is obliged to thoroughly inform itself about its corporation's value by means of a well-prepared financial analysis. Even though FOs are not required by law, over the period 1996 to 2013, over 90 percent of the M\&A transactions have obtained an FO (Liu, 2019). In an M\&A setting, once the merger is publicly announced, the FO is included in the proxy statements and mailed to shareholders for voting approval of the merger. The opinions are publicly disclosed once the proxy statements are mailed and submitted electronically to the SEC.

Whereas FOs are largely voluntary, the information content included in FOs has been regulated - albeit to a limited extent. In 2007, the SEC approved the proposed rules by the National Association of Securities Dealers, Inc. (NASD) to increase disclosure requirements for FOs. As of 2007, firms requesting an FO have to disclose whether the adviser will receive compensation contingent on the successful completion of the underlying transaction, whether the adviser has had a material relationship with the company in the last two years, and what information was provided to the adviser by the board of directors in deriving the opinion. The SEC further monitors the quality of FO disclosures. Liu et al. (2019) examine SEC comment letters for M\&A transactions and find that the most frequent comment letters relate to fairness opinions and their valuations, general compliance, and transaction background. Despite the somewhat increased regulatory scrutiny regarding the disclosure of FOs, board of directors and financial advisers are still left to their own devices in terms of the underlying information content of the FO.

\subsubsection{The role of financial advisers in issuing an FO}

Financial advisers play the second most important role in the context of FOs. The target board of directors is responsible for evaluating and acting on the takeover bid. Upon receiving the offer, the target board needs to assess the value of the target firm to evaluate the fairness and attractiveness of the offer price. FOs are a useful second opinion from a financial adviser, providing an independent valuation of the target firm. The board selects and hires an FO provider to deliver target valuations and provides the FO provider with all relevant firm-specific information and internal forecasts. It is then the financial adviser who delivers FO target valuations and verifies the fairness of the offer price and bundles all relevant valuation information into a single document for target shareholders to make informed decisions regarding the tender offer. 
Previous research has primarily focused on two aspects of the advisory relationship: 1) the fee structure and contract terms, and 2) the adviser's reputation and deal outcomes (e.g., Kisgen et al., 2009; Cain and Denis, 2013; Song et al., 2013).

Kisgen et al. (2009) examine the relation between the fee structure and reputation of an adviser and the objectivity and quality of FOs. They find that acquisitions with FO providers who also receive a fee contingent on deal completion have significantly lower announcement-period returns. They also show that the reputation of acquirers' FO advisers positively affects deal quality, namely the use of top-tier FO advisers on the acquirer side reduces the deal premium. At the same time, the use of lower-tier FO advisers is associated with a higher probability of completing the deal, higher premiums paid, and lower announcement returns. This suggests that the incentives of lowertier advisers might not be aligned with those of the acquirer shareholders, which is to complete a high-quality transaction at a reasonable price.

Cain and Denis (2010) analyze target firm valuations disclosed in the FOs by both acquiring and target firms' financial advisers in negotiated mergers. Their findings show that acquirer-side investment banks tend to systematically over-value, while target-side advisers tend to under-value the target firm, although the results for the target side are more mixed. In addition, they show that the reputation of financial advisers is positively related to the valuation accuracy in FOs since top-tier advisers produce more accurate valuations compared to their lower-tier counterparts. Further they show that financial advisers with a pre-established relationship with the target produce more accurate FO valuations than do unaffiliated and independent third-party investment banks. Thus, adviser reputation and relationship-based information appear to play a role in the accuracy of FO valuations. Further, they find no evidence that valuation accuracy is associated with the contingency structure of advisory fees, suggesting that FO valuations might not be driven by conflicts of interest.

In general, the previous literature mainly focuses on the reputation of financial advisers based on their market share. Accordingly, highly reputable and top-tier investment banks represent the large and well-established bulge bracket banks such as Morgan Stanley or Goldman Sachs. Yet, the growing investors' enthusiasm towards independent investment banks, especially since the financial crisis, increased the demand for boutique advisers in the last years. While in 2005 bulge bracket firms accounted for nearly $95 \%$ of the global M\&A volume, by 2016 their share had shrunk to $87.6 \%{ }^{48}$ These developments challenge the traditional definition of reputation and quality of financial advisers. Despite the remarkable prevalence of boutique advisers, to our knowledge, Song et al. (2013) is the only study to examine the role of boutique advisers in the US setting.

48 Retrieved from: https://www.forbes.com/sites/mergermarket/2017/03/29/battling-the-bulge-boutique-banksgaining-ground/?sh=740ce $2 \mathrm{e} 565 \mathrm{e} 5$ 
Loyeung (2019) investigates the performance of boutique advisers in the Australian market.

Song et al. (2013) investigates firms' choice between boutique and full-service advisers and the impact of adviser choice on deal outcomes. They find that boutique advisers are likely to be hired when deals are complex, suggesting that boutique advisers are selected for their skill and expertise. They also show that deal premiums are lower when acquirers hire boutique advisers and that these advisers lengthen the duration of a deal because they are likely to spend more time on due diligence and negotiation to complete deals. The favorable deal outcomes are found to be stronger on the acquirer side than that on the target side. Loyeung (2019) finds that acquiring firms benefit in terms of improved merger performance, while target firms benefit in terms of higher completion of valueenhancing deals and positive cumulative abnormal returns when boutique advisers are involved.

Our study is the first to examine the role of boutique advisers in the context of FOs in tender offers. Considering the central role of FOs and their underlying properties for target shareholders' tendering decisions, we analyze whether boutique investment banks provide more precise FOs as would be expected from their independence and expertise, compared to non-boutique advisers.

\subsubsection{Boutique financial advisers}

The firms engaged in the investment banking industry are commonly classified based on size, types of services provided and therewith associated diversification of revenue streams. Bulge bracket investment banks represent the traditional full-service brokerage that offer a wide range of services and have a full spectrum of diversified business lines such as sales, trading, underwriting, asset management services, research and lending. Recognizable names in this category include Goldman Sachs or J.P. Morgan Chase. Fullservice advisers have great resources and are diversified, but they have been criticized for suffering from potential conflicts of interest (e.g., Allen et al., 2004; Ertugrul and Krishnan, 2014).

Boutique advisers are generally smaller and less well known, independent, often industry specialists and have expertise in M\&A (Song et al., 2013). Boutique advisers are different from their full-service counterparts at least in two important aspects. First, unlike fullservice advisers, boutique advisers are not a brokerage house and not associated with commercial banks. This allows them to operate independently and to focus exclusively on providing advice to their clients rather than trying to cross-sell other products (Loyeung, 2019). As boutique adviser Lazard states on its Web site, one of the main competitive advantages of this type of financial adviser is its independence: "We are an independent firm, free of many of the conflicts that can arise at larger financial institutions as a result of their varied sales, trading, underwriting, research, and lending activities. We believe that recent instances of perceived or actual conflicts of interest... have increased the 
demand by managements and boards of directors for trusted, unbiased advice from professionals whose main product is advice." Thus, one of the main distinctions between bulge bracket and boutique investment banks is that the latter focus solely on advisory services as their main business line and revenue stream. For instance, in 2019, 82\% of Evercore's (boutique bank) total net revenues came from advisory services ${ }^{49}$ while J.P. Morgan's advisory fees accounted for $2 \%$ of their total net revenues. ${ }^{50}$ The second distinction is that boutique advisers often specialize in a certain industry. For example, Torreya Partners mainly serves the life science companies, while Endeavor Financial operates exclusively in the natural resource industry. This enables each advisory firm to better understand the businesses they advise as well as identify opportunities within that industry (Loyeung, 2019). Through repeated transactions, boutique advisers acquire skills and expertise in both M\&As as well as a thorough understanding of the industry within which their clients operate (Kadan et al., 2012). The differential nature and focus of boutique advisers make it interesting to investigate whether they provide different FOs as compared to their counterparts.

\subsection{Theoretical predictions}

\subsubsection{Boutique advisers and fairness opinion precision}

Boutique advisers operate independently and claim to be free of conflicts of interest that are otherwise inherent in full-service investment banks (e.g., Allen et al., 2004; Asker and Ljungqvist, 2010; Ertugrul and Krishnan, 2014; Kolasinski and Kothari, 2008). This enables them to focus exclusively on the provision of advice rather than trying to cross-sell other products. In addition, many boutique advisers are industry specialists, who have developed a thorough understanding of the industry within which their clients operate. This allows them to provide better and more specialized advisory services. Therefore, on the one hand, boutique advisers might provide more precise FOs as compared to non-boutique financial advisers. On the other hand, boutique advisers are greatly reliant on fees for advisory services because this is their only line of business. This may provide them with an incentive to complete deals that might not be in the best interest of their clients and clients' shareholders (Shore, 2013; Song et al., 2013). Rau (2000) shows that valuations of the deals tend to be of secondary importance since investment banks face strong deal completion incentives in their contingent fee structure. This suggests that financial advisers are often primarily concerned with completing deals to receive fees rather than creating value for their clients. Thus, boutique advisers might be incentivized to issue less precise FOs to ensure that the offer price falls within valuation ranges so that the tender offer is completed, and their compensation is secured. Based on these opposing arguments, we formulate the following null hypothesis:

49 Retrieved from: https://investors.evercore.com/static-files/70463eac-3adb-4f50-92ad-f8f0c4e90419

50 Retrieved from: https://www.jpmorganchase.com/content/dam/jpmc/jpmorgan-chase-and-co/investor-relations/ documents/annualreport-2019.pdf 


\section{H1: There is no difference in the precision of an FO provided by a boutique investment bank compared to non-boutique investment banks.}

In addition, we examine whether the existence of prior ties with the acquirer mitigates the association between boutique advisers and the precision of their FOs. Cain and Denis (2013) show that banks with prior relationship with target firms provide more accurate target valuations in FOs. Yet little is known about the role of target advisers' prior ties with the acquirer. In general, hiring merger counterparty's ex-adviser entails two considerations, namely the benefits of information transmission and the costs of a potential conflict of interests. On the target side, the information advantage of hiring acquirers' ex-advisers is rather limited ${ }^{51}$, while the potential conflict of interest is expected to be strong. The potential conflict of interest stems from target advisers' desire to be hired by the acquirer in the future, which is embedded into the asymmetric feature of M\&A transactions. While targets normally cease to exist as standalone companies after a successful takeover, acquiring firms continue to survive and thus represent a lure of future business to target advisers. Considering that $58 \%$ of target's ex-advisers are hired by acquirers in future M\&A transactions, acquirers' ex-advisers hired by targets might be concerned about losing future business from the acquirers if their involvement reduces acquirers' overall gain from the merger (Chang et al., 2016). The conflict of interest also suggests that the target's adviser might even be inclined to cooperate with the bidder at the expense of its client to improve its prospects of procuring future business from the acquiring firm (Bhattacharya et al., 2019). In addition, Francis et al. (2014) shows that acquirers' past relationships with their advisers have a significant impact on their current choice of M\&A advisers. Taken together, this suggests that the potential conflict of interest might be more severe for boutique advisers with a prior relationship with the acquirer. Therefore, on the one hand, boutique advisers with prior ties with the acquirer might issue less precise FOs to facilitate shareholders' tendering and to ensure the success of the acquirer's takeover attempt in the hope to be hired by the acquirer in the future.

Bhattacharya et al. (2019) explore the factors that affect the combined firm's choice to hire the target financial adviser. They find that the likelihood of hiring the target's adviser improves when it provides superior service to the target and if it is a reputable investment bank. Their findings suggest that the "service excellence" demonstrated by investment banks is valuable for securing future business. The industry expertise of a financial adviser has been shown to improve its chances of being hired for a multitude of investment banking transactions (e.g., Graham et al., 2017). Given that boutique

51 Chang et al. (2016) shows that hiring targets' ex-advisers enables acquiring firms to reduce the cost of acquiring information about target firms, achieve better understanding of the true value of targets and more accurate estimation of potential synergies. Thus, the acquirers hiring targets' ex-advisers may enjoy a bargaining advantage in deal negotiations between merging firms due to their better understanding of targets' firm value and outside options. They, however, find that hiring of acquirers' ex-advisers is not associated with superior deal outcomes on the target side. This indicates that the information advantage of acquirers' ex-advisers hired by targets is weaker than that of targets' ex-advisers hired by acquirers. 
advisers are regarded as reputable investment banks and industry as well as M\&A experts, the provision of "excellent" FOs improves their chances of being hired by the combined firm in the future even further. While Bhattacharya et al. (2019) focus on a setting where the acquiring firm has no prior relationship with the target adviser, we expect these incentives to also hold for acquiring firms with such a prior relationship. Thus, on the other hand, boutique advisers with prior ties with the acquirer might issue more precise FOs to increase their chances of a potential rehiring by the acquirer in the future. Hence, we formulate the following null hypothesis:

\section{H2: There is no difference in the precision of an FO provided by a boutique investment bank with or without a prior relationship with the acquirer.}

\subsubsection{Tender offer extensions}

In this study, we focus on tender offer extensions rather than the time-to-completion, which is often analyzed in M\&A studies (e.g., Offenberg and Pirinsky, 2015). The traditional time-to-completion is measured from the day the deal is announced to the day the deal is effective. This measure is often chosen as it reflects, among others, the complexity of the deal, the time target and acquirer advisers spend on due diligence, structuring the transaction and negotiating the deal (Song et al., 2013). To address our second research question however this measure is less appropriate. As opposed to the entire time span of the deal, we are interested in the period after the disclosure of an FO. FOs are not disclosed at the same time as the tender offer is announced, thus the time-to-completion is a rather noisy measure given our setting of tender offers. Our goal is to investigate the extent to which FOs and their properties facilitate target shareholders' tendering decisions. Therefore, we focus on tender offer extensions, which take place after the FO disclosure and represent the time that target shareholders need to make their tendering decisions. The tender offer is extended mainly if not enough of the target's shareholders have tendered their shares, which means the minimum condition is not satisfied, in the originally specified time period..$^{52}$

Our underlying premise is that target shareholders use FOs to decide whether to tender their shares. This premise is supported by the insights from chapter 3 , which show that less precise FOs are more likely to trigger class action lawsuits. Class-action lawsuits reflect how investors perceive the usefulness and credibility of a disclosure and are thus relevant mechanisms to express shareholder dissatisfaction (Brochet and Srinivasan, 2014). Similarly, we argue that tender offer extensions also reflect how target shareholders perceive the usefulness and credibility of an FO. If an FO delivers useful information to target shareholders, they might need less time to evaluate the offer, which implies that they tender their shares relatively fast. This increases the probability that the

52 The second reason why a tender offer might be extended is if the bidder makes a material change in the terms of the tender offer, to ensure that the target's shareholders have the opportunity and time to decide whether to tender shares. 
minimum condition is satisfied within the specified time period. If an FO provides less useful information, target shareholders are likely to need more time to decide whether to tender their shares. This suggests that the minimum condition is unlikely to be satisfied within the specified period and the acquirer needs to extend the expiration time of the offer. In our sample of tender offers, $29 \%$ of the deals have at least one extension. Despite the non-trivial occurrence of tender offer extensions, little is known about their drivers.

Prior studies on earnings forecasts and precision suggest that investors in general prefer more precise information, which means narrow ranges, due to its informative advantage over less precise, that is wide ranges, disclosures (e.g., Du et al., 2011). Imprecise disclosures are viewed as less credible because they signal uncertainty and prior studies find that investors perceive precise forecasts to be more credible than imprecise forecasts (e.g., Hirst et al., 1999).

In the case of tender offers, the precision of FOs is of critical importance as target shareholders only have a defined, often a short, period of time to decide whether to tender their shares. Less precise FOs make it extremely difficult for target shareholders to assess the attractiveness of the deal and whether the board actually made the right decision in accepting the deal. Similar to prior research, we expect more precise FOs to be more useful for target shareholders to assess the deal's attractiveness, especially for complex and difficult-to-value targets. Hence, we formulate the following hypothesis:

\section{H3: Precision of an FO is negatively related to the probability of a tender offer extension.}

Turning to the adviser type, we expect target shareholders to be less skeptical towards FOs disclosed by boutique investment banks. Mercer (2004) identifies factors that investors consider when assessing the credibility of a voluntary disclosure. Apart from the characteristics of the disclosure itself, such as its precision, investors also take into account the credibility of the party responsible for the disclosure. The competence, trustworthiness and reputation of the issuer play thereby an important role. An investment bank's reputation can for example favorably affect the pricing of shares when it serves as underwriter of an IPO (e.g., Michaely and Shaw, 1994). Golubov et al. (2012) show that reputable advisers are associated with higher bidder announcement returns compared with less reputable advisers in public acquisitions. Kale, Kini and Ryan (2003) document that when the client firm (bidder or target) employs a more reputable financial adviser, it enjoys a greater wealth gain. We posit that boutique advisers are viewed as competent and trustworthy due to their M\&A and industry specialization as well as their independence. Thus, target shareholders are likely to perceive the credibility of their FOs issued by a boutique adviser to be higher as compared to non-boutique investment banks. If this is the case, then shareholders are likely to tender their shares 
relatively fast, suggesting a negative relation with the probability of a tender offer extension. We formulate the following hypothesis:

H4: There is a negative association between the probability of a tender offer extension and boutique investment banks as compared to non-boutique investment banks.

\subsection{Research design}

\subsubsection{Sample Selection}

We gather data on all tender offers identified in the Thomson Reuters Securities Data Corporation (SDC) database involving deals of publicly traded U.S. firms (acquirers and targets) between 2010 and 2018. Starting from this selection, we exclude deals where the transaction value is lower than $\$ 1$ million, or where deals have a pending or intended status. Both the target and acquirer must be listed on the NYSE, AMEX or NASDAQ (Kisgen et al., 2009; Cain and Denis, 2013). We exclude buybacks and recapitalizations, which leads to an initial sample of 214 tender offers. We exclude tender offers that were withdrawn or involved FOs without valuation analyses (17 deals) and tender offers with multiple target FOs (21 deals). One tender offer, where all except one target board's board members are also board members of the acquiring firm, is also excluded, which leads to a sample of 175 deals. We remove tender offers that involve multiple advisers that provide one joint FO (7 deals), which leads to a final sample of 168 deals. For these deals, we manually collect FO data from Schedule 14D-9 filings on the Security and Exchange Commission (SEC) EDGAR Web site. These filings include the target's board recommendation on how shareholders should respond to a tender offer. In addition, they include fairness verdicts, valuation methods and the corresponding valuation ranges, the fees paid to opinion providers as well as their preexisting relationships with client firms.

To classify an adviser as boutique, we follow the classification of Song and Wei (2010)..$^{53}$ Hereby, we focus on two aspects. First, we manually inspect the spectrum of the services provided by advisers from their official websites. Second, we analyze the financial reports of advisers (either from websites or SEC) to determine the business line that represents the most substantial revenue stream. Additionally, we examine if there is financing or lending (and also the extent thereof) on the balance sheets of advisers. Boutique advisers represent banks that do not have a full spectrum of services such as trading, underwriting, or lending. These banks have one or two business lines with the most financially significant line representing the M\&A advisory services as evidenced from websites and income statements. Boutique banks also have very small balance

53 We are grateful to Weihong Song and Diana Wei for sharing with us their list of advisers classified as boutiques. Compared to their sample period ending in 2006, there have been changes in the market of boutique investment banks. Our updated list of financial advisers and their classifications as of 2018 is available upon request. 
sheets since they commonly have no financing or lending. We also examine the news and the history of transactions of boutique advisers to ensure that these banks serve primarily in advisory roles. For tender offer extensions, we manually examine all target SEC filings found on the EDGAR Web site after the disclosure of an FO. Commonly, the information on the extensions is filed either under amended FOs, SC 14D9/A, or amended tender offer statements, SC TO-T/A.

We also obtain board of directors' characteristics from the Schedule 14D-9 filings. In case these characteristics are missing in the Schedule 14D-9 filling, we either use the proxy statement that is referenced in the filling itself or the most recent proxy statement available prior to the disclosure of Schedule 14D. Target and deal related variables are all based on either the SDC database or Schedule 14D-9 fillings, with the exception of Research and Development expenditures and net income, which are obtained from Compustat.

\subsubsection{Empirical models}

When examining the association between boutique advisers, the precision of an FO and the probability of a timely deal completion, we recognize that the choice of boutique advisers is itself endogenously determined by the target firms. Prior research finds the use of boutique advisers to be correlated with characteristics of the merging firms and the M\&A transactions (e.g., Song et al., 2013). This endogenous selection process therefore has the potential to bias estimates of the impact of boutique advisers on the merger outcomes that we investigate. Therefore, to control for potential self-selection bias, we employ a two-stage procedure. ${ }^{54}$

Similar to Song et al. (2013), our two-stage model consists of a treatment equation and regression equations on the transaction outcomes (Maddala, 1983). The use of variables in the treatment equation (probit, whether or not a boutique adviser is hired) is motivated by previous research and revolves around deal and merging firms' characteristics. In addition, we proxy for the knowledge of the board since this is likely to be related not only to the decision to obtain an FO, but also to the choice of the adviser. We obtain probit estimates of the treatment equation and compute the hazard rate (denoted by $\lambda h_{i}$ ), which we include in second-stage models. Since the choice of boutique advisers does not represent our core research question, for brevity reasons, we do not extensively discuss these results. The treatment equation with accompanying results is reported in Table 1.

54 Both Kisgen et al. (2009) and Song et al. (2013) use a two-step treatment procedure to control for endogeneity of either the use of fairness opinion or the use of boutique advisers in M\&As, respectively. 
Table 1: The choice of a boutique adviser

\begin{tabular}{|c|c|}
\hline & BOUTIQUE \\
\hline \multirow[t]{2}{*}{ ACQ_BOUTIQUE } & $-0.173^{* *}$ \\
\hline & $(0.012)$ \\
\hline \multirow[t]{2}{*}{$I N D$} & $-0.754^{* *}$ \\
\hline & $(0.033)$ \\
\hline \multirow[t]{2}{*}{$A C C_{-} E X P$} & $-0.384^{\dagger}$ \\
\hline & $(0.194)$ \\
\hline \multirow[t]{2}{*}{$F I N \_E X P$} & $0.234^{\dagger}$ \\
\hline & $(0.139)$ \\
\hline \multirow[t]{2}{*}{$I N V \_B A N K \_E X P$} & $-0.154^{* *}$ \\
\hline & $(0.045)$ \\
\hline \multirow[t]{2}{*}{ CEO_PART } & $-0.427^{* * *}$ \\
\hline & $(0.000)$ \\
\hline \multirow[t]{2}{*}{$R \& D$} & $-0.628^{* * *}$ \\
\hline & $(0.004)$ \\
\hline \multirow[t]{2}{*}{ VOLAT } & $0.005^{* * *}$ \\
\hline & $(0.001)$ \\
\hline \multirow[t]{2}{*}{$S I Z E$} & -0.164 \\
\hline & $(0.262)$ \\
\hline \multirow[t]{2}{*}{$L I T I G \_I N D$} & $-0.116^{* * *}$ \\
\hline & $(0.007)$ \\
\hline \multirow[t]{2}{*}{ DIFF_IND } & 0.082 \\
\hline & $(0.582)$ \\
\hline \multirow[t]{2}{*}{$D E A L \_P R E M$} & $0.254^{* * *}$ \\
\hline & $(0.000)$ \\
\hline \multirow[t]{2}{*}{$S A M E \_I N D$} & 0.057 \\
\hline & $(0.537)$ \\
\hline \multirow[t]{2}{*}{ PAY_EQUITY } & -0.135 \\
\hline & $(0.217)$ \\
\hline Industry FE & YES \\
\hline Year FE & $\mathrm{NO}$ \\
\hline Observations & 160 \\
\hline Pseudo $\mathrm{R}^{2}$ & $19.59 \%$ \\
\hline
\end{tabular}

This table reports marginal effects of the probit regression of the choice of a boutique adviser. The dependent variable, $B O U T I Q U E$, is a dummy variable that equals 1 if the target firm hires a boutique investment bank, and zero otherwise. All variables are defined in Appendix 4A. P-values are reported in parentheses $\left({ }^{* * *} \mathrm{p}<0.01,{ }^{* *} \mathrm{p}<0.05,{ }^{*} \mathrm{p}<0.1,{ }^{\dagger}\right.$ one-sided significance) and standard errors are clustered at industry level, using Fama French 5 factors.

In the first second-stage model we focus on the precision of an FO, which is captured by the wideness of valuation ranges in an FO. Since there are multiple valuation methods in an FO, we first calculate the mean scaled wideness of each method and then we calculate the average wideness across all the methods in an FO. Given that FOs are 
mostly criticized for producing wide valuation ranges, we focus on very wide- versus very narrow-ranged $\mathrm{FO}$ s rather than the average $\mathrm{FO}$ wideness. Thus, our dependent variable PRECISE_FO is equal to one if the FO's average wideness is below the sample median average wideness, and zero otherwise.

In the second model, we investigate the probability that a tender offer is extended. This is captured by a dependent variable EXTEND that is equal to one if there is a tender offer extension, and zero otherwise. Boutique advisers are represented by an indicator variable BOUTIQUE that is equal to one if the target board hires a boutique adviser, and zero otherwise. The existence of a prior relationship with the acquirer is captured by an indicator variable PRIOR_ACQ. To investigate if the existence of prior ties between the acquirer and boutique adviser mitigates $\mathrm{FO}$ precision, we include an interaction term, BOUTIQUE_PRIOR, by interacting BOUTIQUE with PRIOR_ACQ.

In both models, we include several control variables. First, we control for the level of $\mathrm{R} \& \mathrm{D}$ expenditures $(R \& D)$ of the target and whether the acquirer and target operate in the same industry $\left(S A M E_{-} I N D\right)$. Additionally, we include the profitability of the target in the fiscal year prior to the takeover bid, which is represented by $(R O A)$, and the number of FO valuation methods with a valuation range $\left(N \_M E T H\right)$. Lastly, we account for the use of the acquirer's stock as the payment method (PAY_EQUITY). Deal complexity is greater when the medium of payment includes acquirer's stocks, and thus it is in general more difficult to value stock offers. Stock offers also have different tax implications for target shareholders than do cash offers, potentially affecting the timeliness of the tender offer execution (Offenberg and Pirinsky, 2015). ${ }^{55}$

Models (1) and (2) are summarized as follows:

PRECISE_FO ${ }_{i}=\alpha_{t}+\beta_{1}$ BOUTIQUE $_{i}+\beta_{2}$ PRIOR_ACQ $_{i}+$ $\beta_{3}$ BOUTIQUE_PRIOR $_{i}+\beta_{4} R \& D_{i}+\beta_{5} R O A_{i}+\beta_{6} N_{-} M E T H_{i}+\beta_{7} S A M E_{-} I N D_{j}+$ $\beta_{8} P A Y_{-} E Q U I T Y_{j}+\beta_{9} A C Q_{-} B O U T I Q U E_{j}+\beta_{10}$ LITIG_IND $_{i}+\beta_{11}$ FEES +

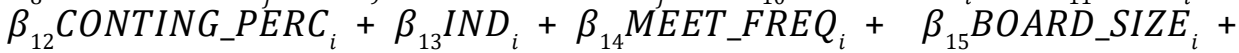
$\beta_{16} C E O_{-} C H A I R_{i}+\lambda h_{i}+\varepsilon_{i}$

$N_{-} E_{\text {EXTEND }}=\alpha_{t}+\beta_{1}$ BOUTIQUE $_{i}+\beta_{2}$ PRECISE_FO ${ }_{i}+\beta_{3} R \& D_{i}+\beta_{4} R O A_{i}+$ $\beta_{5} N_{-} M E T H_{i}+\beta_{6} S A M E_{-} I N D_{j}+\beta_{7} P A Y_{-} E Q U I T Y_{i}+\beta_{8} \%{ }_{-} S O U G H T+\beta_{9} D E A L_{-}$ $P R E M j+\beta_{10} S I Z E_{i}+\beta_{11} D I F F_{-} I N D_{i}+\beta_{12} F O_{-} A M E N D_{i}+\beta_{13} N_{-} M E T H_{-} P A G E_{i}+$ $\beta_{14} B O R D_{-} E Q U I T Y_{i}+\lambda h_{i}+\varepsilon_{i}$

55 When a target shareholder receives cash in exchange for her shares, she could owe taxes on capital gains. However, when the same shareholder receives stock for her shares, there are no taxes due. Huang and Walkling (1987) note that deals with cash payments could require higher premiums to help shareholders offset the taxes due. 
In addition to the common set of control variables in both models, we also include model-specific controls particularly relevant for either FO precision or execution speed of the tender.

In Model (1) we additionally control for the effort and incentives of the FO provider. We include the fees that the adviser receives (FEES), and we also incorporate the percentage of these fees that is contingent upon completion of the offer (CONTING_PERC). This fee structure is often argued to create conflicts of interest between advisers and their clients' shareholders as it provides strong deal completion incentives, which might be reflected in a lower precision of an FO. The use of a boutique investment bank on the acquirer side might have some spill-over effects on the target adviser, potentially affecting the precision of a target-sought FO. Thus, we include an indicator variable (ACQ_BOUTIQUE) that is equal to one if the acquiring firm also hires a boutique investment bank. Duff and Phelps (2009) show that $64 \%$ of senior executives and board members in the US use FOs to protect themselves from potential shareholder lawsuits. Thus, the precision of an FO might reflect the desire of the target board to shield from liability and protect from potential criticism and shareholder lawsuits. We include an indicator variable to capture targets operating in one of the litigious industries (LITIG_IND), based on prior going-concern research (DeFond et al., 2002; Lim and Tan, 2008). Lastly, we include some corporate governance controls. The results in chapter 3 suggest that the knowledge of the board of directors is a strong predictor of the FO precision, with the independence of the board members having the greatest impact. Therefore, to control for the effect of the board's independence, we include the percentage of independent directors on the board (IND). Moreover, we incorporate the board meeting frequency (MEET_FREQ) to proxy for the level of monitoring activity of the target board (e.g., Vafeas, 1999; Greco, 2011). The CEO who also serves as the chairman of the board has more power and influence over the board. Therefore, we control for the combined roles of the CEO and use an indicator variable CEO_CHAIR that is equal to one if the CEO is also the chair of the board, and zero otherwise. While larger boards are likely to possess diversified expertise, they at the same time suffer from communication and coordination problems (Eisenberg, Sundgren \& Wells, 1998). Frye and Wang (2010) find that larger boards are more likely to obtain an FO due to the lack of knowledge dissemination and exchange among board members, which is likely to be also manifested in the precision of an FO. Hence, we control for the size of the target board (BOARD_SIZE).

In Model (2) we control for the percentage of the target's stock that the acquirer intends to acquire (\%_SOUGHT), target firm's size (SIZE) and whether the target belongs to one of the more complex, opaque, and difficult-to-value industries (DIFF_IND). Amendments of an FO represent additional relevant information for target shareholders, and, hence, another reason why a tender offer might be extended. To single out the effect of the $\mathrm{FO}$ precision on tender offer extensions, we include an indicator variable $\left(F O_{-}\right.$ $A M E N D)$ that is equal to one if the $\mathrm{FO}$ is amended after its disclosure. Considering 
that the amount of supporting information is important to shareholders when assessing the credibility of a disclosure, we control for the extent of information and assumptions provided for each method $\left(N_{-} M E T H_{-} P A G E\right)$. We also include the equity held by the target board (BOARD_EQUITY) since the more equity the board owns, the sooner the minimum condition is satisfied, which results in a timelier completion of the deal. Lastly, we account for the deal premium (DEAL_PREM) since its attractiveness is likely to be related to target shareholders' tendering decisions. Appendix $4 \mathrm{~A}$ contains more detailed descriptions of the variables used in empirical tests.

Both models are estimated by means of a probit regression model. In both models, the denotations $i$ and $j$ capture the unit of analysis, which is either the target firm (i) or in some cases the deal level $(j)$. We include industries fixed effects based on Fama-French 5 factors industry classification. ${ }^{56}$ We winsorize the volatility of the target firm (VOLAT) at 1 and $99 \%$.

\subsection{Results}

\subsubsection{Descriptive statistics}

Table 2 presents summary statistics for all the variables. The results show that $33 \%$ of target firms hire a boutique investment bank, which provides support for their growing popularity. Interestingly, the demand for and popularity of boutique advisers are also reflected in their compensation. Song et al. (2013) find that the average fees charged by boutique advisers amounted to $\$ 2.7$ million in the period between 1995 to 2006 . Boutique advisers in our sample charge on average $\$ 14.5$ million and their median compensation is $\$ 7.8$ million. $^{57}$ On average, $80 \%$ of the advisers' compensation is contingent upon the completion of the deal, while the median is $87 \%$. This suggests that advisers have strong incentives to complete the deal, which might cast some doubts on their independence and objectivity. Almost $40 \%$ of target financial advisers have prior ties with the acquirer. It is also interesting to note that $57 \%$ of FOs are amended and $29 \%$ of the deals have at least one extension. This implies that the minimum condition is not satisfied within the originally specified time period in almost one-third of the tender offers.

The correlation matrix in Table 3 suggests that there is no significant association between boutique advisers and the precision of an FO. However, this bivariate relation should be treated with caution as it ignores important covariates relevant for the FO precision. The type of a financial adviser and FO precision should be examined in combination

56 Our results are robust to the inclusion of year fixed effects. However, given our sample size, we report results excluding these fixed effects to increase statistical power of our models.

57 It should be noted that the compensation of full-service advisers in our sample is also higher than the compensation reported by Song et al. (2010), which might hinge at the time trend. Full-service advisers charged on average $\$ 7.22$ million between 1995 and 2006 and an average of \$15.2 million between 2010 and 2018 . 
with other relevant factors, rather than in isolation. We find that the contingent pay percentage of boutique advisers is lower than that of non-boutique counterparts. It should be noted that boutique banks, nevertheless, greatly depend on the successful completion of the deal. ${ }^{58}$ We find that boutique advisers tend to provide more valuation methods containing valuation ranges and also more information and explanations supporting FO valuation analyses. Table 3 further reveals that there is a negative correlation between the precision of an $\mathrm{FO}$ and the probability of a tender offer extension. A timelier completion of the deal is also more likely when the target hires a boutique adviser.

Table 2: Descriptive Statistics

\begin{tabular}{|c|c|c|c|c|c|c|c|c|}
\hline & $\mathbf{N}$ & Mean & Min & Q1 & Median & Q3 & Max & Std. Dev. \\
\hline PRECISE_FO & 168 & 0.49 & 0.00 & 0.00 & 0.00 & 1.00 & 1.00 & 0.50 \\
\hline EXTEND & 168 & 0.29 & 0.00 & 0.00 & 0.00 & 1.00 & 1.00 & 0.45 \\
\hline BOUTIQUE & 168 & 0.33 & 0.00 & 0.00 & 0.00 & 1.00 & 1.00 & 0.47 \\
\hline PRIOR_ACQ & 168 & 0.39 & 0.00 & 0.00 & 0.00 & 1.00 & 1.00 & 0.49 \\
\hline FEES & 164 & 6.88 & 5.00 & 6.62 & 6.92 & 7.27 & 7.77 & 0.53 \\
\hline CONTING_PERC & 152 & 0.80 & 0.00 & 0.78 & 0.87 & 0.92 & 1.00 & 0.22 \\
\hline$N \_M E T H$ & 168 & 0.81 & 0.00 & 0.67 & 1.00 & 1.00 & 1.00 & 0.25 \\
\hline$N \_M E T H \_P A G E$ & 168 & 1.26 & 0.50 & 1.00 & 1.20 & 1.50 & 2.67 & 0.38 \\
\hline$F O \_A M E N D$ & 168 & 0.57 & 0.00 & 0.00 & 1.00 & 1.00 & 1.00 & 0.50 \\
\hline$S I Z E$ & 166 & 2.39 & 0.85 & 1.99 & 2.35 & 2.77 & 4.21 & 0.58 \\
\hline$R \& D$ & 166 & 0.13 & 0.00 & 0.00 & 0.07 & 0.16 & 1.11 & 0.19 \\
\hline$R O A$ & 166 & -0.06 & -1.49 & -0.12 & 0.01 & 0.09 & 1.55 & 0.31 \\
\hline VOLAT & 162 & 22.69 & 2.46 & 4.96 & 11.41 & 30.49 & 73.49 & 23.37 \\
\hline$L I T I G \_I N D$ & 168 & 0.39 & 0.00 & 0.00 & 0.00 & 1.00 & 1.00 & 0.49 \\
\hline DIFF_IND & 168 & 0.69 & 0.00 & 0.00 & 1.00 & 1.00 & 1.00 & 0.46 \\
\hline$D E A L \_P R E M$ & 168 & 0.59 & -0.87 & 0.28 & 0.45 & 0.69 & 3.47 & 0.57 \\
\hline PAY_EQUITY & 168 & 0.09 & 0.00 & 0.00 & 0.00 & 0.00 & 1.00 & 0.29 \\
\hline SAME_IND & 168 & 0.79 & 0.00 & 1.00 & 1.00 & 1.00 & 1.00 & 0.41 \\
\hline$\%$ \%OUGHT & 168 & 98.06 & 14.30 & 100 & 100 & 100 & 100 & 10.56 \\
\hline$A C Q \_B O U T I Q U E$ & 168 & 0.10 & 0.00 & 0.00 & 0.00 & 0.00 & 1.00 & 0.30 \\
\hline$I N D$ & 168 & 0.80 & 0.43 & 0.72 & 0.83 & 0.86 & 1.00 & 0.10 \\
\hline$A C C_{-} E X P$ & 168 & 0.21 & 0.00 & 0.13 & 0.20 & 0.29 & 0.57 & 0.12 \\
\hline$I N V \_B A N K \_E X P$ & 168 & 0.10 & 0.00 & 0.00 & 0.00 & 0.17 & 0.67 & 0.13 \\
\hline$F I N \_E X P$ & 168 & 0.36 & 0.00 & 0.22 & 0.33 & 0.50 & 1.00 & 0.21 \\
\hline CEO_PART & 168 & 0.95 & 0.00 & 1.00 & 1.00 & 1.00 & 1.00 & 0.21 \\
\hline CEO_CHAIR & 168 & 0.27 & 0.00 & 0.00 & 0.00 & 1.00 & 1.00 & 0.45 \\
\hline BOARD_EQUITY & 165 & 7.68 & 5.80 & 7.24 & 7.65 & 8.14 & 9.49 & 0.67 \\
\hline$M E E T \_F R E Q$ & 160 & 0.96 & 0.48 & 0.78 & 0.95 & 1.08 & 1.49 & 0.21 \\
\hline BOARD_SIZE & 168 & 7.50 & 4.00 & 6.50 & 7.00 & 8.00 & 13.00 & 1.62 \\
\hline
\end{tabular}

This table presents summary statistics of all variables used in empirical models. All variables are defined in Appendix 4A.

58 Bulge bracket banks have on average $86 \%$ of their payout being contingent upon the completion of the offer (median is $88 \%$ ). The average (median) contingent pay percentage of boutique investment banks is $73 \%(83 \%)$, respectively. 


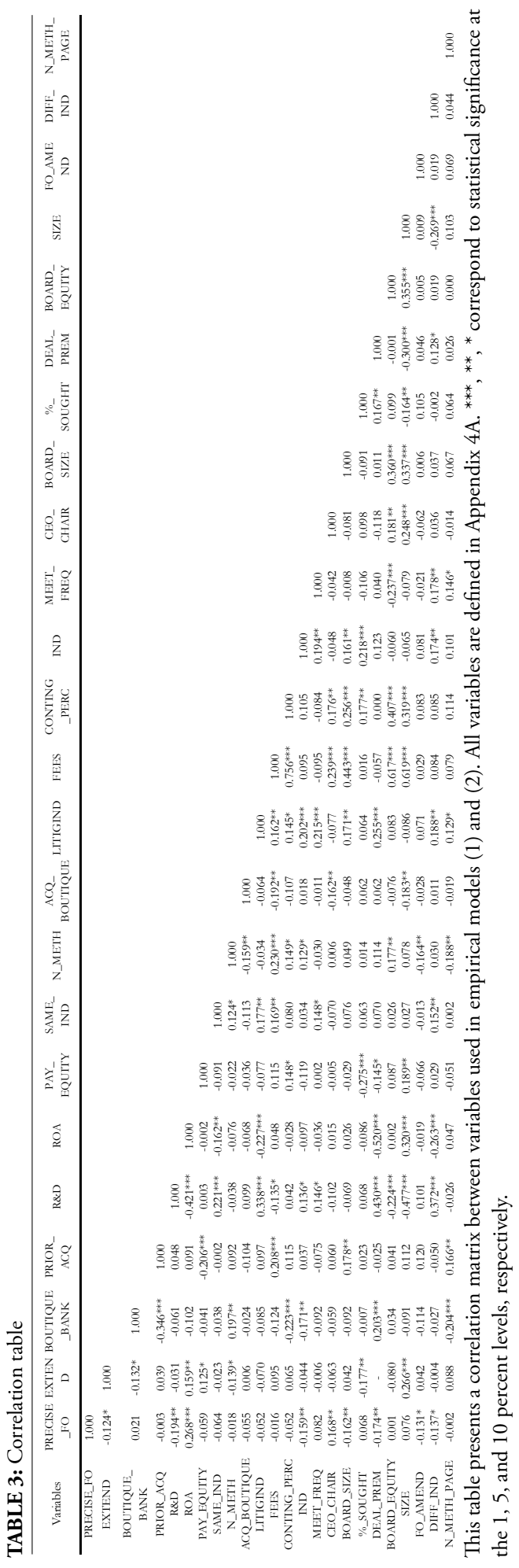




\subsubsection{FO precision}

Column 1 of Table 4 reports marginal effects for the precision of the FO model (Model 1), while Column 2 summarizes the results for the timeliness of the deal execution (Model 2). Note that these models include the hazard variable estimated from a firststage regression to control for potential selection bias.

The results in Column 1 show that boutique investment banks provide more precise FOs relative to non-boutique advisers, which leads us to reject $H 1$. Our results suggest that boutique advisers' superior M\&A expertise seems to outweigh their potential incentives to complete the deal. Therefore, the recent popularity of boutique advisers seems to be warranted with regard to the precision of their FOs. Next, we find that target advisers with prior ties with the acquirer tend to provide less precise FOs, while the opposite is true for boutique advisers. We, thus, reject $H 2$. Boutique advisers with prior ties with the acquirer provide more precise FOs likely to increase the likelihood of their rehiring by the acquirer in the future, in line with the "service excellence" idea. Even though both relations are not significant, it seems that the compensation of an adviser is positively, while the contingent pay percentage is negatively related to the precision of an FO.

Our findings further indicate that target advisers provide more precise FOs when the acquirer hires a boutique investment bank, providing support for the spillover effect among the advisers of merging firms. Not surprisingly, we find that deal and target firm complexity are negatively related to the precision of an FO. R\&D intense target firms are likely to have less precise FOs, which reflects the valuation uncertainty embedded in this type of firms. Similarly, FOs tend to be less precise when the acquirer's equity is used as the payment method, in line with a greater deal and valuation complexity for stock offers. Interestingly, less profitable firms tend to have less precise FOs, suggesting that the target board might use the precision of an FO strategically to conceal the poor performance in the past. Target firms operating in litigious industries are more likely to have precise FOs compared to target firms operating in non-litigious industries, which highlights the role of the scrutiny and litigation risk for target boards. Lastly, in line with the insights from chapter 3 , we find that corporate governance characteristics are strong predictors of the precision of an FO. The coefficient estimate on the inverse mills ratio is insignificant, suggesting that self-selection bias is not an issue. 
Table 4: FO precision and timeliness of the deal completion

\begin{tabular}{|c|c|c|}
\hline & $\begin{array}{c}\text { Model 1: } \\
\text { FO precision }\end{array}$ & $\begin{array}{c}\text { Model 2: } \\
\text { Completion timeliness }\end{array}$ \\
\hline \multirow[t]{2}{*}{ PRECISE_FO } & & $-0.151^{* *}$ \\
\hline & & $(0.006)$ \\
\hline \multirow[t]{2}{*}{ BOUTIQUE } & $0.060^{*}$ & $-0.124^{* *}$ \\
\hline & $(0.056)$ & $(0.034)$ \\
\hline \multirow[t]{2}{*}{ PRIOR_ACQ } & $-0.093^{\dagger}$ & \\
\hline & $(0.120)$ & \\
\hline \multirow[t]{2}{*}{ BOUTIQUE_PRIOR } & $0.194^{*}$ & \\
\hline & $(0.065)$ & \\
\hline \multirow[t]{2}{*}{$R \& D$} & $-0.519^{* *}$ & $0.527^{* *}$ \\
\hline & $(0.023)$ & $(0.003)$ \\
\hline \multirow[t]{2}{*}{$R O A$} & $0.467^{* *}$ & $0.128^{* *}$ \\
\hline & $(0.001)$ & $(0.020)$ \\
\hline \multirow[t]{2}{*}{ PAY_EQUITY } & $-0.166^{* *}$ & $-0.134^{* *}$ \\
\hline & $(0.016)$ & $(0.013)$ \\
\hline \multirow[t]{2}{*}{ SAME_IND } & $-0.130^{\dagger}$ & $-0.096^{* *}$ \\
\hline & $(0.167)$ & $(0.036)$ \\
\hline \multirow[t]{2}{*}{$N \_M E T H$} & -0.097 & $-0.209^{* *}$ \\
\hline & $(0.271)$ & $(0.004)$ \\
\hline \multirow[t]{2}{*}{$A C Q \_B O U T I Q U E$} & $0.180^{\dagger}$ & \\
\hline & $(0.146)$ & \\
\hline \multirow[t]{2}{*}{$L I T I G \_I N D$} & $0.173^{* *}$ & \\
\hline & $(0.028)$ & \\
\hline \multirow[t]{2}{*}{ FEES } & 0.111 & \\
\hline & $(0.635)$ & \\
\hline \multirow[t]{2}{*}{ CONTING_PERC } & -0.163 & \\
\hline & $(0.738)$ & \\
\hline \multirow[t]{2}{*}{$I N D$} & $-0.776^{\dagger}$ & \\
\hline & $(0.163)$ & \\
\hline \multirow[t]{2}{*}{$M E E T \_F R E Q$} & $0.523^{* *}$ & \\
\hline & $(0.005)$ & \\
\hline \multirow[t]{2}{*}{ CEO_CHAIR } & $\mathbf{0 . 1 1 0}^{\dagger}$ & \\
\hline & $(0.129)$ & \\
\hline \multirow[t]{2}{*}{ BOARD_SIZE } & $-1.171^{\dagger}$ & \\
\hline & $(0.107)$ & \\
\hline \multirow[t]{2}{*}{$\% \_S O U G H T$} & & 0.006 \\
\hline & & $(0.482)$ \\
\hline \multirow[t]{2}{*}{ DEAL_PREM } & & $-0.197^{* *}$ \\
\hline & & $(0.001)$ \\
\hline \multirow[t]{2}{*}{ BOARD_EQUITY } & & $-0.139^{*}$ \\
\hline & & $(0.087)$ \\
\hline \multirow[t]{2}{*}{$S I Z E$} & & $0.340^{* * *}$ \\
\hline & & $(0.000)$ \\
\hline \multirow[t]{2}{*}{$F O \_A M E N D$} & & 0.007 \\
\hline & & $(0.576)$ \\
\hline \multirow[t]{2}{*}{$D I F F \_I N D$} & & $0.067^{\dagger}$ \\
\hline & & $(0.189)$ \\
\hline$N \_M E T H \_P A G E$ & & 0.016 \\
\hline & & $(0.853)$ \\
\hline
\end{tabular}


Table 4: FO precision and timeliness of the deal completion (continued)

\begin{tabular}{|c|c|c|}
\hline$\lambda h_{i}$ & $\begin{array}{l}-0.119 \\
(0.241)\end{array}$ & $\begin{array}{l}-0.145^{* *} \\
(0.037)\end{array}$ \\
\hline Year FE & NO & NO \\
\hline Industry FE & YES & YES \\
\hline Observations & 137 & 157 \\
\hline Pseudo $R^{2}$ & $24.39 \%$ & $21.25 \%$ \\
\hline
\end{tabular}

This table reports marginal effects of the probit regressions of the determinants of the precision of an FO (Model 1) and the determinants of a timely tender offer completion (Model 2). The dependent variable in Model 1, PRECISE_FO, is a dummy variable that equals 1 if the average wideness in an FO is lower than the sample median average wideness, and zero otherwise. The dependent variable in Model 2, EXTEND, is an indicator variable that is equal to one if there is a tender offer extension, and zero otherwise. $\lambda h_{i}$ represents the hazard rate obtained using the treatment equation depicted in Table 3. Definitions of all variables are provided in Appendix 4A. P-values are reported in parentheses $\left({ }^{* * *} \mathrm{p}<0.01,{ }^{* *}\right.$ $\mathrm{p}<0.05,{ }^{*} \mathrm{p}<0.1, \dagger$ one-sided significance) and standard errors are clustered at industry level, using Fama French 5 factors.

\subsubsection{Probability of a tender offer extension}

Column 2 in Table 4 reveals that FO precision matters for the execution speed of a tender offer. Specifically, we find that less precise FOs tend to delay the completion of the deal, providing support for $H 3$. Target shareholders seem to take more time to decide whether to tender their shares if less precise FOs are disclosed. In line with our expectations, we find that FOs disclosed by boutique investment banks are perceived as credible. Target shareholders tender their shares faster if FOs are issued by boutique advisers as compared to non-boutique investment banks, which yields support for $\mathrm{H}$.

In line with our expectations, the probability of a tender offer extension is higher for larger and R\&D intense targets and for targets operating in one of the more complex and difficult-to-value industries. This collectively indicates that target shareholders need more time to evaluate the offer for complex and difficult-to-value targets. Additionally, our results indicate that target shareholders tender their shares faster in the case of less profitable targets. We also find that the deal premium and the use of acquirer's stock facilitate the timely execution of the tender offer since both factors increase the attractiveness of the deal. Same industry tender offers tend to be completed faster likely because both sides are familiar with the regulatory nature of the industry and also its common valuation practices and specifics. In addition, we find that target shareholders seem to consider another FO property, namely the number of valuation methods containing valuation ranges. ${ }^{59}$ Valuation analyses with concrete per share-based valuation ranges make the assessment of the offer price more accessible, thereby facilitating the timely execution of the deal.

59 It should be noted that not all valuation analyses yield concrete per-share price estimates. For example, in an FO of Synergetics USA in 2015, there are four valuation methods, yet only one contains a specific per-share valuation range and a reference to the offer price (the discounted cash flow analysis yields ranges from $\$ 5.08$ per share to $\$ 6.73$ per share, while the merger consideration is $\$ 6.50$ per share). The other methods refer to the implied valuation multiples, without concrete per share valuation ranges. The FO can be accessed via: https://www.sec.gov/ Archives/edgar/data/836429/000119312515321177/d42595dsc14d9.htm 
The self-selection bias becomes apparent in Model (2). The negative and significant coefficient on the inverse mills ratio implies that without the correction, the model would produce downwardly biased estimates for boutique investment banks.

\subsection{Conclusion}

This study investigates the role of boutique advisers in the context of FO provision. First, we show that boutique advisers provide more precise FOs as compared to nonboutique advisers. In addition, we also find that boutique advisers with prior ties with the acquirer provide more precise FOs than do boutique banks without such ties. Second, we find evidence that FO precision matters for the probability of a tender offer extension and that target shareholders prefer precise FO disclosures. We also find that target shareholders seem to tender their shares faster if the target hires a boutique adviser as compared to other non-boutique investment banks.

This paper contributes to the fairness opinion and financial adviser literature in several ways. First, this is the first paper to analyze how the type of a financial adviser is associated with the properties observed in an FO, especially the role and superiority of boutique advisers. Fairness opinions and boutique advisers both still represent unexplored phenomena despite their remarkable prevalence in the M\&A arena. Second, this is the first study to analyze how FO properties interact with tender offer extensions, which capture how target shareholders perceive the usefulness and credibility of an FO and diminish the comparative advantage of faster completion times of tender offers over merger.

The findings of the study are subject to several limitations. First, in addition to the examined characteristics of the FO provider, future research can incorporate some additional factors such as industry specialization of the investment bank. Second, future research can examine the different incentives and conflicts of interest of financial advisers in more detail. Lastly, while we expect FOs to matter more in the case of tender offers as opposed to friendly M\&A deals, this, nevertheless, results in a relatively small sample size. 


\section{Appendix 4A: Variable definitions with the corresponding data-sources}

\begin{tabular}{|c|c|c|}
\hline \multicolumn{2}{|c|}{ Dependent Variables } & Data Source \\
\hline PRECISE_FO & 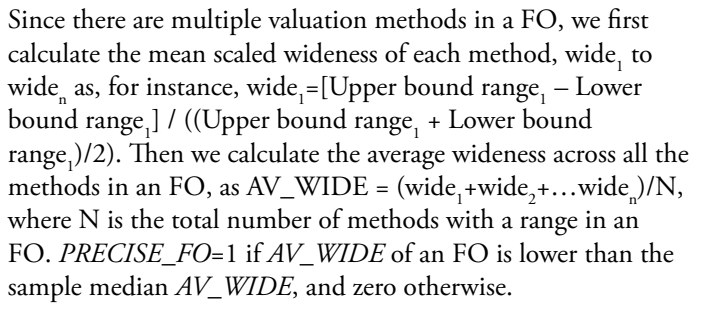 & Schedule 14D-9 \\
\hline EXTEND & $\begin{array}{l}=1 \text { if there is at least one tender offer extension, and zero } \\
\text { otherwise. }\end{array}$ & $\begin{array}{l}\text { Target SEC filings on the } \\
\text { EDGAR Web site }\end{array}$ \\
\hline \multicolumn{2}{|c|}{ Explanatory variable } & Data Source \\
\hline BOUTIQUE & $\begin{array}{l}=1 \text { if the target adviser is classified as a boutique investmen } \\
\text { bank, and zero otherwise. }\end{array}$ & $\begin{array}{l}\text { Official websites / SEC } \\
\text { filings of investment } \\
\text { banks on EDGAR }\end{array}$ \\
\hline PRIOR_ACQ & $\begin{array}{l}=1 \text { if the target adviser provided services to the acquirer in } \\
\text { the past, and zero otherwise. }\end{array}$ & $\begin{array}{l}\text { Schedule 14D-9 / Target } \\
\text { SEC filings on EDGAR }\end{array}$ \\
\hline \multicolumn{2}{|c|}{ Firm and deal complexity control variables } & Data Source \\
\hline$S I Z E$ & $=$ Logarithm of the total assets of the target. & SDC \\
\hline$R \& D$ & $\begin{array}{l}=\text { A three-year moving average of } \mathrm{R} \& \mathrm{D} \text { expenditures } / \\
\text { total assets of the target. }\end{array}$ & $\begin{array}{l}\text { Compustat / } \\
\text { SDC }\end{array}$ \\
\hline VOLAT & $\begin{array}{l}=\text { Standard deviation of net income measured on a rolling } \\
\text { basis over a three-year period. This variable is winsorized } \\
\text { at } 1 \text { and } 99 \% \text {. }\end{array}$ & Compustat \\
\hline$R O A$ & $=\mathrm{EBIT}$ of the target firm / total assets of the target. & SDC \\
\hline$L I T I G \_I N D$ & $\begin{array}{l}=1 \text { if the target operates in one of the litigious industries } \\
\text { (SIC codes 2833-2836, 3570-3577,3600-3674, 5200- } \\
5961 \text { and 7370), and zero otherwise. }\end{array}$ & SDC \\
\hline$D I F F_{-} I N D$ & $\begin{array}{l}=1 \text { if if a firm belongs to one of the more complex and } \\
\text { opaque industries (SIC codes 28, 36, } 38 \text { and 73) zero } \\
\text { otherwise. }\end{array}$ & SDC \\
\hline$D E A L \_P R E M$ & $\begin{array}{l}=(\text { Offer price }- \text { target share price } 4 \text { weeks prior to the } \\
\text { tender offer announcement }) / \text { target share price } 4 \text { weeks } \\
\text { prior to the tender offer announcement. }\end{array}$ & SDC \\
\hline$P A Y \_E Q U I T Y$ & $\begin{array}{l}=1 \text { if the payment method includes the use of the } \\
\text { acquiring firm's stock, and zero otherwise. This variable } \\
\text { captures the use of the acquiring firm's equity only and } \\
\text { a hybrid payment method, consisting of both cash and } \\
\text { equity. (The base level, PAY_EQUTTY=0 captures deals } \\
\text { where only cash is used as a payment method). }\end{array}$ & Schedule 14D-9 \\
\hline
\end{tabular}




\begin{tabular}{|c|c|c|}
\hline$S A M E \_I N D$ & $\begin{array}{l}=1 \text { if the acquirer and target operate in the same industry } \\
\text { (based on } 5 \text { factors Fama French industry classifiation), } \\
\text { and zero otherwise. }\end{array}$ & SDC \\
\hline ACQ_BOUTIQUE & $\begin{array}{l}=1 \text { if the acquiring firm hires a boutique investment bank, } \\
\text { and zero otherwise. }\end{array}$ & SDC / Schedule 14D-9 \\
\hline \%_SOUGHT & $\begin{array}{l}=\text { Percentage of the target's stock that the acquirer intends } \\
\text { to acquire. }\end{array}$ & SDC \\
\hline
\end{tabular}

\begin{tabular}{|c|c|c|}
\hline \multicolumn{2}{|c|}{ Adviser and fairness opinion control variables } & \multirow{2}{*}{$\begin{array}{l}\text { Data Source } \\
\text { Schedule 14D-9/ Targ } \\
\text { filings on EDGAR }\end{array}$} \\
\hline ENG_FEES & $=$ Logarithm of the total fees paid to the adviser. & \\
\hline CONTING_PERC & $\begin{array}{l}=\text { Adviser's fees received upon completion of the offer / } \\
\text { total fees received by the adviser. }\end{array}$ & $\begin{array}{l}\text { Schedule 14D-9 / Tar } \\
\text { filings on EDGAR }\end{array}$ \\
\hline$N \_M E T H$ & $\begin{array}{l}\text { =Number of valuation methods with a range / total } \\
\text { number of valuation methods in an FO. }\end{array}$ & Schedule 14D-9 \\
\hline$N \_M E T H \_P A G E$ & $\begin{array}{l}=\text { Total number of valuation methods / total number of } \\
\text { pages summarizing the valuation methods in an FO. }\end{array}$ & Schedule 14D-9 \\
\hline$F O \_A M E N D$ & $\begin{array}{l}=1 \text { if there are FO amendments after the disclosure of the } \\
\text { FO, and zero otherwise. }\end{array}$ & $\begin{array}{l}\text { Target SEC filings on } \\
\text { EDGAR }\end{array}$ \\
\hline
\end{tabular}

\begin{tabular}{|c|c|c|}
\hline Board controls & & Data Source \\
\hline$I N D$ & $\begin{array}{l}=\text { Number of independent board members / total number } \\
\text { of board members. }\end{array}$ & Schedule 14D-9 / DEF 14A \\
\hline$I N V \_B A N K \_E X P$ & $\begin{array}{l}=\text { Number of board members with investment banking } \\
\text { experience/ total number of board members. }\end{array}$ & Schedule 14D-9 / DEF 14A \\
\hline FIN_EXP & $\begin{array}{l}=\text { Number of board members with finance experience } / \\
\text { total number of board members. }\end{array}$ & Schedule 14D-9/ DEF 14A \\
\hline ACC_EXP & $\begin{array}{l}=\text { Number of board members with accounting expertise/ } \\
\text { total number of board members }\end{array}$ & Schedule 14D-9/ DEF 14A \\
\hline BOARD_EQUITY & $\begin{array}{l}=\text { Logarithm of the total equity related payments of target } \\
\text { directors. This includes the payments for the common } \\
\text { stock held by the board and the accelerated equity vesting. }\end{array}$ & Schedule 14D-9 \\
\hline CEO_PART & $=1$ if $\mathrm{CEO}$ is part of the target board, and zero otherwise. & Schedule 14D-9 / DEF 14A \\
\hline CEO_CHAIR & $\begin{array}{l}=1 \text { if the CEO is also the chairman of the board, and zero } \\
\text { otherwise. }\end{array}$ & $\begin{array}{l}\text { Schedule 14D-9/ } \\
\text { DEF 14A }\end{array}$ \\
\hline$M E E T \_F R E Q$ & $\begin{array}{l}=\text { Logarithm of the total number of target board meetings } \\
\text { held in the year prior to the tender offer. }\end{array}$ & $\begin{array}{l}\text { Schedule 14D-9/ } \\
\text { DEF } 14 \mathrm{~A}\end{array}$ \\
\hline BOARD_SIZE & $=$ Logarithm of the total number of target board members. & Schedule 14D-9 \\
\hline
\end{tabular}



Chapter 5

Conclusion 



\subsection{Summary}

A pre-requisite for a sound investment or a firm acquisition is the accurate estimation of a firm's value so that investors or companies do not overpay (Damodaran, 2008). However, valuation has become more complex over the years. This is partially due to an excessive level of information available to market participants. The vast amount of information sources, which often provide conflicting information, might lead to incorrect choices of valuation inputs, resulting in poor valuation estimates, and ultimately wealth losses for investors. In this dissertation, I explore the relation between several factors, including the nature of valuation inputs, corporate governance and institutional factors, and the precision and accuracy of valuation estimates.

In the first study (chapter two), I examine whether valuation performance improves if street earnings, as opposed to GAAP earnings, are used as a basis for peer selection in a multiple valuation framework. If street earnings represent a better reflection of the true economic performance of a firm, then they should also serve as a better basis for selecting comparable benchmark firms. Thus, I benchmark the use of street earnings versus GAAP numbers and examine whether multiple valuation using peers identified based on street earnings outperforms multiple valuation using peers identified based on GAAP numbers. To compare the performance of these peer valuations, I examine the predictive ability and valuation accuracy of peer-based multiple estimates.

I find that street earnings lead to a different set of selected peers compared to GAAP, which is not surprising given the fundamental differences in the derivation of these two sets of earnings. However, it is interesting to note that this different peer selection does not automatically lead to a superior peer-based valuation. On average, I do not find support for the relative superiority of street peers compared to GAAP peers. It is only when significantly different peers are selected that street-earnings based multiples outperform their GAAP counterparts. In addition, I explore whether the difference between the predicted and actual multiple signals potential mispricing, and hence is correlated with future returns. My findings reveal that while the use of street earnings indeed has the potential for identifying mispricing, no such evidence is found in the case of GAAP earnings. My analyses further show that street earnings are particularly superior in terms of valuation performance and identification of mispricing when target firms are volatile, $R \& D$ intense, or internationally active. Lastly, I find that the peers identified using street earnings are more comparable to the target firm than peers identified using GAAP numbers.

In the second study (chapter three), I focus on target-sought valuations provided in a fairness opinion in the setting of tender offers. Target valuations are not only valuable to the acquiring firm to avoid overpayment, but also to the target firm to ensure that it is not sold at a discount. Therefore, fairness opinions have successfully established themselves in the merger and acquisition arena and are widely used by acquirees and 
acquirers. Despite the prevalence of fairness opinions, prior research so far provides inconclusive evidence on the value of these opinions. I argue that the value of a fairness opinion to shareholders depends on the properties of valuation analyses underlying the opinion. Anecdotal evidence reveals that there is a large heterogeneity in the properties of valuations disclosed. Hence, this study sheds more light on the determinants and consequences of valuation properties. Considering the prominent role of the target board of directors in the takeover setting, I particularly focus on the characteristics and incentives of a target board as the primary determinant.

My findings reveal that firm-specific knowledge and incentives of the board are strong predictors of the precision of fairness opinion valuations. Specifically, it is the firmspecific knowledge of the board that is crucial for the precision of valuations. In addition, I find that it is not only the knowledge of the board that is reflected in the precision of a fairness opinion, but also the board's and CEO's financial incentives to complete the deal. The stronger these incentives, the greater the likelihood that imprecise valuations are disclosed, potentially to facilitate the justification of the fairness of the offer price. I also find that these financial incentives are strong determinants of the fairness of a fairness opinion. Another main finding of this study is that, in line with my expectations, valuation properties in a fairness opinion matter to target shareholders. I find that target shareholders are more likely to initiate class action lawsuits specifically addressing fairness opinions if these are imprecise or unfair. This suggests that target shareholders use fairness opinions to decide on their tendering decisions, and that they consider valuation properties when assessing the usefulness of a fairness opinion.

In the third study (chapter four), I extend our understanding of the determinants and consequences of valuation properties in fairness opinion. The target board of directors and, ultimately, financial advisers are the two key players responsible for the disclosure of a fairness opinion. Therefore, to obtain a more complete picture of the sources of variation in valuation properties, I focus on the role of financial advisers. In particular, I focus on boutique advisers since these have gained in popularity and demand in recent years. Yet, despite their growing popularity, the evidence regarding the benefits of hiring boutique advisers versus their competitors is still scarce, especially in the context of fairness opinions. Boutique advisers have a different nature and focus as compared to large investment banks because they are independent, often industry specialists and focus exclusively on providing M\&A advice. This makes it interesting to investigate whether they provide different fairness opinions as compared to their counterparts.

I find that boutique advisers provide more precise fairness opinion valuations as compared to their counterparts. The recent popularity of boutique advisers seems to be warranted in terms of the precision of their valuation estimates. In general, I find that target advisers with prior ties with the acquirer provide less precise valuations, yet the opposite is true for boutique advisers. They tend to provide more precise valuations if they have prior ties with the acquirer potentially to increase their chances that the acquirer rehires 
them in the future. Another important finding of the study is that valuation properties are not only associated with shareholder class action lawsuits (see Chapter 3), but also with shareholders' general assessment of fairness opinions' credibility. My findings reveal that less precise fairness opinions tend to delay the completion of the tender offer. This suggests that target shareholders need more time to decide whether to tender their shares if a fairness opinion contains less precise valuation estimates. Altogether, my study shows that target firms benefit from hiring boutique advisers since they provide more precise valuations in a fairness opinion, which in turn facilitates a timely deal completion.

\subsection{Contributions and Future Research}

Overall, the three studies in my dissertation enhance our understanding of the role of various explicit and implicit factors that are relevant for the properties of valuation outcomes. My dissertation provides several important contributions to the body of knowledge and research about drivers of valuation performance. The insights from the research questions examined in this dissertation are relevant to market participants of different nature, ranging from individual investors, firms engaged in acquisitions, regulators and standard-setters to the investment community in general.

The results of the first study (chapter two) contribute to the research on the role of alternative performance metrics, in particular street earnings, for forecasting and valuation purposes. Prior research has extensively examined the persistence and informativeness of street earnings in general as well as the individual adjustments made by analysts to arrive at street earnings. Compared to prior studies, I focus explicitly on the valuation angle and examine the performance of street earnings as direct valuation inputs into a multiple-based model. This is motivated by two important observations. First, anecdotal evidence reveals that a substantial portion of investors still relies to a large extent on GAAP earnings. A proprietary survey by Clermont Partners in 2017 reveals that nearly $30 \%$ of active investors rely on GAAP reporting more than nonGAAP when analyzing a company's performance or making a buy or sell decision. ${ }^{60}$ This figure might even be higher for passive investors with a long-term oriented buy-and-hold mentality. Second, multiple sources show that multiple-based valuations are widely used by both sophisticated and non-sophisticated market participants. For instance, almost $85 \%$ of equity research reports rely on multiple-based valuation, and more than $50 \%$ of all acquisition valuation analyses are based on multiples. ${ }^{61}$ Altogether, this emphasizes the relevance of my study on the role of street earnings in the multiple-based valuation framework. My finding that street earnings are not unconditionally superior to GAAP earnings in terms of valuation performance, but predominantly when the firm-to-value is complex and difficult to forecast, should be of interest to all types of investors.

60 Retrieved from: https://www.clermontpartners.com/documents/ActiveInvestorsRelyonNon-GAAPs.pdf

61 Retrieved from: http://people.stern.nyu.edu/adamodar/pdfiles/eqnotes/packet2spr17.pdf 
The second study (chapter three) of this dissertation provides important contributions to the acquisition literature and, more importantly, the role of the target board of directors for valuations obtained in the course of an acquisition. Prior studies examined the relation between various characteristics of the board, such as its financial expertise or acquisition experience and acquisition outcomes, often captured by announcement or post-acquisition returns (e.g., Field and Mkrtchyan, 2017; Güner et al., 2008). Most of these studies, however, focus on acquiring firms and their boards to examine the relation between their characteristics and the value they create for acquiring firm shareholders. Hence, little is known about the target side and the target firms' board of directors, which are equally important in an acquisition. My study is one of the few studies to explore the interplay between characteristics and incentives of the target board and the value they create for target shareholders. Whether a negotiated merger or a hostile tender offer, target shareholders rely on the target board of directors to provide its recommendation towards the offer. Thus, the target board of directors creates value for target shareholders essentially by issuing its recommendation towards the proposed offer, and valuations that support the board's conclusion. Despite the central role of valuations underlying the target board's recommendation, evidence on the factors affecting these valuations is rather scarce. Moreover, while shareholder class action lawsuits are often initiated in the acquisition process to express shareholders' dissatisfaction with disclosures made by the boards of directors, so far little is known on the relation between class action lawsuits and the properties of such disclosures. I fill these research gaps and provide insights on how the target board's characteristics and incentives shape the valuations provided in the board's recommendation and, then in turn, how target shareholders perceive these valuations. The findings in this chapter are not only of interest to firms engaged in acquisitions, but also to regulators as recent studies show that valuations supporting the board' recommendation are closely monitored by regulators. Most of the SEC comment letters for merger and acquisition transactions revolve around fairness opinions and their valuations (Liu et al., 2019).

The third study (chapter four) contributes to the body of research on financial advisers, i.e., investment banks in merger and acquisitions. There is a considerable amount of research on the role of investment banks' attributes, degree and type of involvement, incentives and compensation structure and M\&A outcomes. This study focuses on two angles that so far have been unexplored. First, prior literature mainly uses market share league tables to proxy for financial advisers' reputation. In these league tables, investment banks are ranked based on the value of the target companies in all M\&A deals that they advised during a specified period. The market share league tables are widely publicized by both the media and investment banks themselves and are often used by both academics and practitioners as a measure of expertise (Bao and Edmans, 2011). However, the rise of independent and specialized investment banks, the socalled boutique advisers, has shaken up the M\&A landscape and, thus, challenges the traditional definition of reputation and quality of financial advisers. The acquisition of LinkedIn by Microsoft in 2016 is said to mark the rise of boutique investment banks. 
One the of the largest teach deals in history with a transaction value of $\$ 26$ billion involved boutique investment banks as advisers. Most M\&A transactions close to this transaction value typically involve the well-established giants in the investment banking industry such as J.P. Morgan or Goldman Sachs. Yet LinkedIn decided to hire two much smaller boutique investment banks, Qatalyst and Allen Co., to assist in the acquisition. ${ }^{62}$ Considering the growing importance of and interest in boutique advisers, there is a need for a more detailed understanding on the benefits of hiring a boutique adviser. Second, while prior research examined the relation between boutique advisers and some direct deal outcomes, such as deal premium, my study focuses on a more understudied value creation source of boutique advisers. This is the first study to investigate the role of boutique advisers for valuations underlying a fairness opinion. Since fairness opinion valuations are of great importance to target shareholders, this study provides important insights into the relation between the different types of advisers and the properties of valuations they disclose. This enhances our understanding on when the investment in fairness opinions actually pays off with regard to the precision of the valuation information disclosed by a fairness opinion provider.

The studies in this dissertation are subject to certain limitations, which at the same time can be viewed as possible avenues for future research. The first study uses industry membership based on two-digit SIC codes for the selection of peers. Given the existence and emergence of new alternatives to identify related peer firms, future research could extend the first study and incorporate alternative membership classifications. For instance, Lee, Ma and Wang (2015) propose a new way to identify economically related peers by using a "co-search" algorithm applied to EDGAR's website traffic. Hence, it is interesting to investigate the role of street earnings for alternative groupings and benchmarking of firms. Additionally, future research could examine the role of nonGAAP earnings issued by managers, either in addition to or instead of street earnings, for peer selection in a multiple valuation framework.

In the second study, I focus on the characteristics and incentives of board members in the setting of an acquisition. While I do capture some of the relevant attributes of the board, future research can explore additional factors such as age, industry experience or busyness of the board members. In addition to the financial incentives examined in the study, career concerns can also be examined since mergers represent serious setbacks to target CEOs' and board members' careers. Prior research shows that acquiring firms are more likely to target firms with retirement-age CEOs, likely due to these CEOs' greater willingness to accept a takeover bid (Jenter and Lewellen, 2015). Future research can delve into a potentially disciplining role of career concerns by examining whether young target boards are more likely to provide precise valuations in a fairness opinion as opposed to a board dominated by retirement-age directors. Moreover, while I do

62 Retrieved from: https://www.firmex.com/resources/blog/does-microsofts-acquisition-of-linkedin-mark-the-rise-ofboutique-investment-banks/ 
focus on class action lawsuits explicitly addressing fairness opinions, I do not explicitly examine the content and grounds of these lawsuits and complaints. Hence, future research can provide some additional insights into the specific valuation aspects of a fairness opinion that shareholders most frequently complain about in their class action lawsuit complaints.

In the third study of this dissertation, I examine the role of boutique advisers in the context of fairness opinions. As prior studies provide support for the industry specialization of boutique advisers, I do not explicitly integrate industry specialization in my study. Therefore, future research could more closely inspect the role of industry specialization of boutique advisers for the precision of fairness opinion valuations. In addition, future research could explore the variation within the market of boutique advisers. Considering that boutique banks vary substantially in their size and reputation, it is interesting to analyze if top-tier boutique advisers provide more precise fairness opinions as compared to lower tier boutique banks. Overall, in both studies (study two and three) I focus on a setting where I expect fairness opinions to be of great importance, namely tender offers. The relevance of the setting, however, comes at a cost of a relatively small sample size. Future research could, therefore, investigate the examined research questions in a setting of mergers and acquisitions to increase the statistical power of the tests. 


\section{References}

Abarbanell, J., \& Lehavy, R. (2007). Letting the "tail wag the dog": The debate over GAAP versus street earnings revisited. Contemporary Accounting Research, 24(3), 675-723.

Alford, A. (1992). The effect of the set of comparable firms on the accuracy of the priceearnings valuation. Journal of Accounting Research, 30(1), 94-108.

Alford, A., \& Berger, P. (1999). A simultaneous equations analysis of forecast accuracy, analyst following, and trading volume. Journal of Accounting, Auditing \& Finance, 14(3), 219-240.

Allen, L., Jagtiani, J., Peristiani, S., \& Saunders, A. (2004). The role of bank advisors in mergers and acquisitions. Journal of Money, Credit and Banking, 36, 197-224.

Asker, J., \& Ljungqvist, A. (2010). Competition and the structure of vertical relationships in capital markets. Journal of Political Economy, 118(3), 599-647.

Baik, B., Farber, D., \& Petroni, K. (2009). Analysts' incentives and street earnings. Journal of Accounting Research, 47(1), 45-69.

Baik, B., \& Jiang, G. (2006). The use of management forecasts to dampen analysts' expectations. Journal of Accounting and Public Policy, 25(5), 531-553.

Baker, M., \& Ruback, R. (1999). Estimating Industry Multiples. Working Paper, Harvard University.

Bao, J., \& Edmans, A. (2011). Do investment banks matter for M\&A returns? The Review of Financial Studies, 24(7), 2286-2315.

Barber, B., Lehavy, R., McNichols, M., \& Trueman, B. (2001). Can investors profit from the prophets? Security analyst recommendations and stock returns. The Journal of Finance, 56(2), 531-563.

Barber, B., Lehavy, R., McNichols, M., \& Trueman, B. (2006). Buys, holds, and sells: The distribution of investment banks' stock ratings and the implications for the profitability of analysts' recommendations. Journal of Accounting and Economics, 41(1-2), 87-117.

Bargeron, L., Schlingemann, F., Stulz, R., \& Zutter, C. (2009). Do target CEOs sell out their shareholders to keep their job in a merger? (No. w14724). National Bureau of Economic Research. 
Bell, B. (2016). The acquisition of control of a United States public company. Morrison Foerster. Retrieved from http://media.mofo.com/files/uploads/Images/1302The-Acquisition-of-Control-of-a-United-States-Public-Company.pdf

Bhattacharya, D., Hsu, S., Li, W., \& Liu, C. (2019). A combined firm's decision to hire the target's financial advisor after acquisition: Does "service excellence" pay off? Finance Research Letters, 29, 297-302.

Bhattacharya, N., Black, E., \& Christensen, T. (2003). Assessing the relative informativeness and permanence of pro forma earnings and GAAP operating earnings. Journal of Accounting and Economics, 36(1-3), 285-319.

Bhojraj, S., \& Lee, C. (2002). Who is my peer? A valuation-based approach to the selection of comparable firms. Journal of Accounting Research, 40(2), 407-439.

Bhojraj, S., Lee, C. M., \& Ng, D. T. (2003). International valuation using smart multiples. Journal of Accounting Research, 41, 745-774.

aBlack, D., Christensen, T., Ciesielski, J., \& Whipple, B. (2017). Non-GAAP Earnings: A Consistency and Comparability Crisis? Working Paper.

bBlack, E., Christensen, T., Kiosse, P., \& Steffen, T. (2017). How are Street Earnings Determined? Managers' Influence on Analysts' Exclusions and Agreement. Working Paper.

Bradshaw, M., \& Sloan, R. (2002). GAAP versus the street: An empirical assessment of two alternative definitions of earnings. Journal of Accounting Research, 40(1), 41-66.

Brochet, F., \& Srinivasan, S. (2014). Accountability of independent directors: Evidence from firms subject to securities litigation. Journal of Financial Economics, 111(2), 430-449.

Brown, L., \& Larocque, S. (2013). I/B/E/S reported actual EPS and analysts' inferred actual EPS. The Accounting Review, 88(3), 853-880.

Brown, L., \& Sivakumar, K. (2003). Comparing the value relevance of two operating income. Review of Accounting Studies, 8(4), 561-572.

Brown, L., Call, A., Clement, M., \& Sharp, N. (2015). Inside the "Black Box" of SellSide Financial Analysts. Journal of Accounting Research, 53(1), 1-47. 
Buchholtz, A., \& Ribbens, B. (1994). Role of chief executive officers in takeover resistance: Effects of CEO incentives and individual characteristics. Academy of Management Journal, 37(3), 554-579.

Cain, M., \& Denis, D. (2013). Information production by investment banks: Evidence from fairness opinions. The Journal of Law and Economics, 56(1), 245-280.

Chan, L., Lakonishok, J., \& Sougiannis, T. (2001). The stock market valuation of research and development expenditures. The Journal of Finance, 56(6), 24312456.

Chang, X., Shekhar, C., Tam, L., \& Yao, J. (2016). The information role of advisors in mergers and acquisitions: Evidence from acquirers hiring targets' ex-advisors. Journal of Banking \& Finance, 70, 247-264.

Chen, C., Young, D. \& Zhuang, Z. (2012). Externalities of mandatory IFRS adoption: Evidence from cross-border spillover effects of financial information on investment efficiency. The Accounting Review, 88(3), 881-914.

Chessel, J. (2015). Boutique advisory companies "have edge on big rivals". Retrieved from Australian Financial Review: http://www.afr.com/business/banking-andfinance/investment- banking/ boutique-advisory-companies-have-edge-on-bigrivals-20150307-13y60c

Christensen, T. (2007). Discussion of "Letting the 'Tail' wag the dog': The debate over GAAP versus street earnings revisited. Contemporary Accounting Research, 24(3), 41-762.

Curtis, A., McVay, S., \& Whipple, B. (2014). Non-GAAP earnings: informative or opportunistic? An analysis of transitory gains. The Accounting Review, 89, 933958.

Damodaran, A. (2008). Introduction to Valuation (Third ed.). Handbook of Finance John Wiley \& Sons, Inc.

Davidoff, S. (2006). Fairness Opinions. American University Law Review, 1557-1625.

De Franco, G., Hope, O., \& Larocque, S. (2015). Analysts' choice of peer companies. Review of Accounting Studies, 20(1), 82-109.

De Franco, G., Kothari, S., \& Verdi, R.S. (2011). The benefits of financial statement comparability. Journal of Accounting Research, 49(4), 895-931. 
DeFond, M., Raghunandan, K., \& Subramanyam, K. (2002). Do non-audit service fees impair auditor independence? Evidence from going concern audit opinions. Journal of Accounting Research, 40(4), 1247-1274.

Dichev, I., \& Tang, V. (2009). Earnings volatility and earnings predictability. Journal of Accounting and Economics, 47(1-2), 160-181.

Doukas, J., Kim, C., \& Pantzalis, C. (2010). Arbitrage risk and stock mispricing. Journal of Financial and Quantitative Analysis, 45(4), 907-934.

Doyle, J., Jennings, J., \& Soliman, M. (2013). Do managers define non-GAAP earnings to meet or beat analyst forecasts? Journal of Accounting and Economics, 56(1), 4056.

Du, N., Budescu, D., Shelly, M., \& Omer, T. (2011). The appeal of vague financial forecasts. Organizational Behavior and Human Decision Processes, 114(2), 179189.

Duchin, R., Matsusaka, J., \& Ozbas, O. (2010). When are outside directors effective? Journal of Financial Economics, 96(2), 195-214.

Duff, \& Phelps. (2009). Retrieved from Fairness Opinion Insight: https://www. duffandphelps.com/-/media/assets/pdfs/publications/transaction-opinions/ fairness-opinion-insight.pdf

Duru, A., \& Reeb, D. (2002). International diversification and analysts' forecast accuracy and bias. The Accounting Review, 77(2), 415-433.

Eisenberg, T., Sundgren, S., \& Wells, M. (1998). Larger board size and decreasing firm value in small firms. Journal of Financial Economics, 48(1), 35-54.

Ertugrul, M., \& Krishnan, K. (2014). Investment banks in dual roles: Acquirer M\&A advisors as underwriters. Journal of Financial Research, 37(2), 159-189.

Faleye, O. (2015). The costs of a (nearly) fully independent board. Journal of Empirical Finance, 32, 49-62.

Fich, E., Cai, J., \& Tran, A. (2011). Stock option grants to target CEOs during private merger negotiations. Journal of Financial Economics, 101(2), 413-430.

Field, L. C., \& Mkrtchyan, A. (2017). The effect of director experience on acquisition performance. Journal of Financial Economics, 123(3), 488-511. 
Foster, G. (1986). Financial Statement Analysis (Second ed.). Englewood Cliffs, NJ: Prentice Hall International.

Francis, B., Hasan, I., \& Sun, X. (2014). Does relationship matter? The choice of financial advisors. Journal of Economics and Business, 73, 22-47.

Francis, J., Philbrick, D., \& Schipper, K. (1994). Determinants and outcomes in class action securities litigation. Duke University and Portland State University Working paper.

Frankel, R., \& Lee, C. (1998). Accounting valuation, market expectation, and crosssectional stock returns. Journal of Accounting and Economics, 25(3), 283-319.

Frankel, R., \& Roychowdhury, S. (2005). Testing the clientele effect: An explanation for non-GAAP earnings adjustments used to compute I/B/E/S earnings. Working Paper, MIT.

Frye, M., \& Wang, W. (2010). Boards, uncertainty, and the use of fairness opinions. Corporate Governance: An International Review, 18(1), 48-63.

Golubov, A., Petmezas, D., \& Travlos, N. (2012). When it pays to pay your investment banker: New evidence on the role of financial advisors in M\&As. The Journal of Finance, 67(1), 271-311.

Graham, M., Walter, T., Yawson, A., \& Zhang, H. (2017). The value-added role of industry specialist advisors in M\&As. Journal of Banking \& Finance, 81, 81-104.

Greco, G. (2011). Determinants of board and audit committee meeting frequency. Managerial Auditing Journal, 26(3), 208-229.

Gu, Z., \& Chen, T. (2004). Analysts' treatment of nonrecurring items in street earnings. Journal of Accounting and Economics, 38, 129-170.

Gu, Z., Li, Z., \& Yang, Y. (2013). Monitors or predators: The influence of institutional investors on sell-side analysts. The Accounting Review, 88(1), 137-169.

Güner, A., Malmendier, U., \& Tate, G. (2008). Financial expertise of directors. Journal of Financial Economics, 88(2), 323-354.

Harford, J. (2003). Takeover bids and target directors' incentives: The impact of a bid on directors' wealth and board seats. Journal of Financial Economics, 69(1), 51-83. 
Healy, P., Myers, S., \& Howe, C. (2002). R\&D accounting and the tradeoff between relevance and objectivity. Journal of Accounting Research, 40(3), 677-710.

Hirst, D., Koonce, L., \& Miller, J. (1999). The joint effect of management's prior forecast accuracy and the form of its financial forecasts on investor judgment. Journal of Accounting Research, 37, 101-124.

Huang, Y., \& Walkling, R. (1987). Target abnormal returns associated with acquisition announcements: Payment, acquisition form, and managerial resistance. Journal of Financial Economics, 19(2), 329-349.

Hutton, A., Lee, L., \& Shu, S. (2012). Do managers always know better? The relative accuracy of management and analyst forecasts. Journal of Accounting Research, 50(5), 1217-1244.

Imam, S., Barker, R., \& Clubb, C. (2008). The use of valuation models by UK investment analysts. European Accounting Review, 17(3), 503-535.

Jenter, D., \& Lewellen, K. (2015). CEO preferences and acquisitions. The Journal of Finance, 70(6), 2813-2852.

Kadan, O., Madureira, L., Wang, R., \& Zach, T. (2012). Analysts' industry expertise. Journal of Accounting and Economics, 54(2-3), 95-120.

Kale, J., Kini, O., \& Ryan, H. (2003). Financial advisors and shareholder wealth gains in corporate takeovers. Journal of Financial and Quantitative Analysis, 38(3), 475501.

Karamanou, I., \& Vafeas, N. (2005). The association between corporate boards, audit committees, and management earnings forecasts: An empirical analysis. Journal of Accounting Research, 43(3), 453-486.

Kellog, R. (1984). Accounting activities, security prices, and class action lawsuits. Journal of Accounting and Economics, 6(3), 185-204.

Kim, S., Kraft, P., \& Ryan, S. (2013). Financial statement comparability and credit risk. Review of Accounting Studies, 18(3), 783-823.

Kisgen, D., \& Song, W. (2009). Are fairness opinions fair? The case of mergers and acquisitions. Journal of Financial Economics, 91(2), 179-207. 
Kolasinski, A., \& Kothari, S. (2008). Investment banking and analyst objectivity: Evidence from analysts affiliated with mergers and acquisitions advisors. Journal of Financial and Quantitative Analysis, 817-842.

Krishnan, C., Masulis, R., Thomas, R., \& Thompson, R. (2012). Shareholder litigation in mergers and acquisitions. Journal of Corporate Finance, 18(5), 1248-1268.

Kroll, M., Walters, B., \& Wright, P. (2008). Board vigilance, director experience, and corporate outcomes. Strategic Management Journal, 29(4), 363-382.

Larcker, D., \& Rusticus, T. (2010). On the use of instrumental variables in accounting research. Journal of Accounting and Economics, 49(3), 186-205.

Lee, C., Ma, P., \& Wang, C. (2015). Search-based peer firms: Aggregating investor perceptions through internet co-searches. Journal of Financial Economics, 116(2), 410-431.

Lehavy, R., Li, F., \& Merkley, K. (2011). The effect of annual report readability on analyst following and the properties of their earnings forecasts. The Accounting Review, 86(3), 1087-1115.

Lennox, C., Francis, J., \& Wang, Z. (2012). Selection models in accounting research. The Accounting Review, 87(2), 589-616.

Lim, C., \& Tan, H. (2008). Non-audit service fees and audit quality: The impact of auditor specialization. Journal of Accounting Research, 46(1), 199-246.

Liu, J., \& Gao, Z. (2016). Do Non-GAAP Earnings Adjustments Deliver Comparability? Working Paper.

Liu, J., Nissim, D., \& Thomas, J. (2002). Equity valuation using multiples. Journal of Accounting Research, 40(1), 135-172.

Liu, T. (2020). The information provision in the corporate acquisition process: Why target firms obtain multiple fairness opinions. The Accounting Review, 95(1), 287310.

Liu, T., Tao, S., Erin, T., \& Wang, J. (2019). The Role of External Regulators in Mergers and Acquisitions: Evidence from SEC Comment Letters. Available at SSRN 3464069 .

Loyeung, A. (2019). The role of boutique financial advisors in mergers and acquisitions. Australian Journal of Management, 44(2), 212-247. 
Maddala, G. (1983). Limited-dependent and Qualitative Variables in Econometrics. Cambridge University Press. doi: https://doi.org/10.1017/CBO9780511810176

Makhija, A., \& Narayanan, R. (2007). Fairness opinions in mergers and acquisitions. Working Paper. Fisher College of Business.

Mercer, M. (2004). How do investors assess the credibility of management disclosures? Accounting Horizons, 18(3), 185-196.

Michaely, R., \& Shaw, W. (1994). The pricing of initial public offerings: Tests of adverseselection and signaling theories. Review of Financial Studies, 7(2), 279-319.

Moeller, S., Schlingemann, F., \& Stulz, R. (2004). Firm size and the gains from acquisitions. Journal of Financial Economics, 73(2), 201-228.

Offenberg, D., \& Pirinsky, C. (2015). How do acquirers choose between mergers and tender offers? Journal of Financial Economics, 116(2), 331-348.

Palepu, K., Healy, P., \& Peek, E. (2013). Business Analysis and Valuation: IFRS Edition (Third ed.). Mason, OH: South-Western Cengage Learning Inc.

Papa, V., \& Peters, S. (2016). Investor uses, expectations, and concerns on non-GAAP financial measures. CFA Institute. Retrieved from CFA institute, Advocacy, Policy Positions: https://www.cfainstitute.org/-/media/documents/support/advocacy/ investor-uses-expectations-concerns-on-non-gaap.ashx

Piotroski, J.D., \& So, E.C. (2012). Identifying expectation errors in value/glamour strategies: A fundamental analysis approach. The Review of Financial Studies, 25(9), 2841-2875.

Rau, P. R. (2000). Investment bank market share, contingent fee payments, and the performance of acquiring firms. Journal of Financial Economics, 56(2), 293-324.

Rogers, J., Van Buskirk, A., \& Zechman, S. (2011). Disclosure tone and shareholder litigation. The Accounting Review, 86(6), 2155-2183.

Shore, S. (2013). Battle of investment banks and boutique heats up. Retrieved from Australian Financial Review: http://www.afr.com/it-pro/battle-of-investmentbanks-and-boutiques-heatsup-20130903-j5xdd

Song, W., Wei, J., \& Zhou, L. (2013). The value of "boutique" financial advisors in mergers and acquisitions. Journal of Corporate Finance, 20, 94-114. 
Vafeas, N. (1999). Board meeting frequency and firm performance. Journal of Financial Economics, 53(1), 113-142.

Young, S. (2014). The drivers, consequences and policy implications of non-GAAP earnings reporting. Accounting and Business Research, 40(4), 444-465.

Young, S., \& Zeng, Y. (2015). Accounting comparability and the accuracy of peer-based valuation models. The Accounting Review, 90(6), 2571-2601. 



\section{Impact}





\section{Impact}

Firm valuation is the foundation of numerous decisions, all of which vary in their level of magnitude and impact. Individual investors rely on stock valuations to identify an investment opportunity, firms evaluate their financial health and value-generating sources when deciding on their dividend policies, and acquiring firms value potential targets and estimate their prices to make a value-creating acquisition. At the heart of all these decisions lies the attempt to obtain an estimate of the true value of a firm. Yet, firm valuation is a very complex and challenging task because it is affected by many factors, which often make it difficult to accurately estimate a company's intrinsic value. Information asymmetry, the various sources of information and the incentives and attributes of different parties responsible for the disclosures of relevant information are only a few examples. The accuracy of an estimate of a firm's value, and consequently the quality of an investment decision or acquisition, is not only relevant to various capital market participants, but is also of great importance to the economy as a whole. For instance, the total value of mergers and acquisitions announced by a U.S. acquirer in 2015 reached $\$ 2.5$ trillion, which is $13 \%$ of GDP. ${ }^{63}$ While successful mergers create value for shareholders, misguided acquisitions, which are those that incorrectly determined the offer price or the potential for synergies, can lead to a substantial misallocation of capital and destruction of shareholder value. Hence, it is pivotal to continue expanding our knowledge on what drives the accuracy and precision of valuation, and how it can be improved.

This dissertation has social, economic and scientific relevance as it provides insights on the factors related to the performance of valuation from perspectives that have been so far unexplored. The findings from this dissertation are relevant to investors for their valuations, investments, and ultimately capital allocation decisions, to firms engaged in mergers and acquisitions, and to standard-setters, in terms of the requirements for valuation disclosures.

The insights from Chapter two should be of particular interest to investors, the provider of forecast tracking services $\mathrm{I} / \mathrm{B} / \mathrm{E} / \mathrm{S}$ and investment community in general. The findings reveal that while the use of street earnings impacts the identification of comparable firms, surprisingly, this different peer selection does not, on average, improve the performance of valuation when using the warranted multiple approach. Street earnings' added value seems to materialize mostly for complex and difficult-to-value firms. This suggests that investors might optimize their investment strategies and use the various information sources in a more efficient and less costly way, depending on the complexity of the firm to value. In addition, my dissertation has a scientific impact as it shows that the warranted multiple approach itself is a robust and efficient valuation model, and thus, street earnings do not unconditionally outperform GAAP earnings in terms of

63 Retrieved from: https://evonomics.com/corporate-mergers-strangle-economy-jordan-brennan/ 
valuation performance. Given that the warranted multiple approach is a regressionbased approach that allows to consider the simultaneous effect of various variables, it already by itself yields more accurate valuation estimates than relative valuations using industry or size matches (Bhojraj, Lee and $\mathrm{Ng}$, 2003). Hence, whether for portfolio management purposes or acquisition analyses, this study encourages the use of the warranted multiple approach to increase the accuracy of obtained valuation estimates and ultimately the efficiency of investments and capital allocation decisions.

The insights from Chapter three and four are particularly relevant for the key players in the merger and acquisition industry since they address a relevant and timely phenomenon of fairness opinions. First, the findings of Chapter four should be of interest to the firms obtaining a fairness opinion and their shareholders given that fairness opinion fees are ultimately costs borne by shareholders. Typically, firms pay a substantial fee to obtain a fairness opinion, and as evidenced in the setting of tender offers, these fees have substantially increased over time. For instance, in 2010 firms paid on average approximately $\$ 9$ million for a fairness opinion, while in 2016 they paid approximately $\$ 16$ million. Yet, these substantial investments in fairness opinions are not always value generating since they might contain imprecise valuation information. This is not particularly useful for the board of directors and shareholders when assessing the attractiveness of the offer price. The findings in this dissertation show that while boutique and bulge bracket advisers, on average, charge similar fees for a fairness opinion, the former tend to provide more precise valuations. Therefore, holding fairness opinion expenditures constant, firms can increase their return on investments in fairness opinions by hiring a boutique adviser and obtaining valuations that are more precise. Hence, my dissertation has also a social and economic impact as it provides insights into how to maximize the value created during mergers and acquisitions. This has positive implications for social welfare since the created surplus ultimately circulates back into the community and economy.

Second, the findings of Chapter three might be of special interest to shareholders and standard-setters. One of the main findings of the study is that the incentives of the board and the $\mathrm{CEO}$ are related to the imprecision of valuations in a fairness opinion, which in turn can trigger shareholder class action lawsuits. One explanation for shareholder class action lawsuits is that it is often difficult for shareholders to disentangle valuation uncertainty from strategic motives. It is often not clear to fairness opinion users to what extent the imprecision in valuations reflects the inherent uncertainty of the target (and thus the different sets of projections) as opposed to the incentives of the parties involved in the preparation of the fairness opinion. According to the current state of fairness opinion disclosure requirements, neither Delaware courts nor the SEC perceives the review or receipt of projections by the board or financial advisers to be material 
for purposes of disclosure. ${ }^{64}$ In general, during the course of an acquisition, boards often provide some disclosures of financial forecasts to fulfill their duty of disclosing material information within the board's control. Yet, even if boards disclose financial projections in fairness opinions, the assessment of the materiality of various projections, and thus their disclosure, is highly subjective. Based on the findings in this dissertation, one suggestion to standard-setters is to mandate and harmonize the disclosure of financial projections, which are used as primary inputs in fairness opinion valuations. To increase transparency and credibility of fairness opinion valuations, a more extensive and transparent discussion of the underlying factors responsible for the precision of valuation estimates is needed. Financial advisers and boards of directors should be more transparent about the financial projections underlying valuations and provide more information on the impact of various projections, valuation factors and assumptions on the precision of valuations disclosed in a fairness opinion.

Overall, this dissertation provides interesting and relevant insights into the drivers and consequences of valuation properties. Specifically, the relation between the nature of valuation inputs, corporate governance and institutional attributes, and the precision and accuracy of valuation estimates is examined. This dissertation provides several suggestions on how to improve valuation outcomes, which is of interest not only to capital markets and investment community in general, but also to regulators and standard-setters, who guard the economic wealth of a society.

64 Retrieved from: http://media.straffordpub.com/products/financial-projection-disclosure-requirements-in-mandadeals-preparing-using-and-disclosing-projections-2016-07-20/presentation.pdf 

Summary of the dissertation 



\section{Summary of the dissertation}

Firm valuation is the foundation of numerous decisions, all of which vary in their level of magnitude and impact. At the heart of all these decisions lies the attempt to obtain an accurate estimate of the value of a firm. Yet, firm valuation is a very complex and challenging task because it is affected by many factors, which often make it difficult to accurately estimate a company's intrinsic value. The accuracy of an estimate of a firm's value, and consequently the quality of an investment decision or acquisition, is not only relevant to various capital market participants, but is also of great importance to the economy as a whole. Hence, it is important to continue expanding our knowledge on what drives the accuracy and precision of valuation, and how it can be improved.

In this dissertation, I explore the relation between the nature of valuation inputs, corporate governance and financial adviser attributes, and the precision and accuracy of valuation estimates. In the first study I investigate whether the relative valuation approach improves if financial information provided by the tracking service $\mathrm{I} / \mathrm{B} / \mathrm{E} / \mathrm{S}$ is used as the primary valuation input, as opposed to the financials required by GAAP. Hence, I benchmark the two sets of valuation inputs in the relative valuation framework. In second and third study of this dissertation, the focus is on valuations provided by financial advisers in a fairness opinion as these are relevant not only to the board of directors but also to target shareholders when deciding on the proposed offer. In the second study, I examine to what extent the characteristics and incentives of a target board shape the precision of valuations in a fairness opinion. In addition, I investigate how shareholders perceive the usefulness of fairness opinion valuations, as captured by shareholder class action lawsuits. In the third study, I focus on the role of reputation and expertise of fairness opinion providers, that is financial advisers. I investigate the association between advisers' expertise and valuation precision and timeliness of deal completion.

Concerning the role of valuation inputs (study one), I find that street earnings lead to a different set of selected peers compared to GAAP, which is not surprising given the fundamental differences in the derivation of these two sets of earnings. However, this different peer selection does not automatically lead to a superior peer-based valuation. On average, I do not find support for the relative superiority of street peers compared to GAAP peers. It is only when significantly different peers are selected that street-earnings based multiples outperform their GAAP counterparts. In addition, my findings reveal that while the use of street earnings has the potential for identifying mispricing, no such evidence is found in the case of GAAP earnings. The analyses further show that street earnings are particularly superior in terms of valuation performance and identification of mispricing when target firms are volatile, $R \& D$ intense, or internationally active. Lastly, I find that the peers identified using street earnings are more comparable to the target firm than peers identified using GAAP numbers. 
With regard to the characteristics and incentives of a target board of directors (study two), I find that firm-specific knowledge and incentives of the board are strong predictors of the precision of fairness opinion valuations. Specifically, it is the firm-specific knowledge of the board that is crucial for the precision of valuations. In addition, I find that it is not only the knowledge of the board that is reflected in the precision of a fairness opinion, but also the board's and CEO's financial incentives to complete the deal. I also find that these financial incentives are strong determinants of the fairness of a fairness opinion. Another main finding of this study is that valuation properties in a fairness opinion matter to target shareholders. I find that target shareholders are more likely to initiate class action lawsuits specifically addressing fairness opinions if these are imprecise or unfair. This suggests that target shareholders use fairness opinions to decide on their tendering decisions, and that they consider valuation properties when assessing the usefulness of a fairness opinion.

The results of study three reveal that the reputation and expertise of financial advisers also play an important role for the precision of valuations. I find that boutique advisers provide more precise fairness opinion valuations as compared to their counterparts. The recent popularity of boutique advisers seems to be warranted in terms of the precision of their valuation estimates. In general, I find that target advisers with prior ties with the acquirer provide less precise valuations, yet the opposite is true for boutique advisers. They tend to provide more precise valuations if they have prior ties with the acquirer potentially to increase their chances that the acquirer rehires them in the future. Another important finding of the study is that valuation properties are not only associated with shareholder class action lawsuits, but also with shareholders' general assessment of fairness opinions' usefulness. My findings reveal that less precise fairness opinions tend to delay the completion of the tender offer. This suggests that target shareholders need more time to decide whether to tender their shares if a fairness opinion contains less precise valuation estimates. Altogether, my study shows that target firms benefit from hiring boutique advisers since they provide more precise valuations in a fairness opinion, which in turn facilitates a timely deal completion.

The results of the first study contribute to the research on the role of alternative performance metrics, in particular street earnings, for forecasting and valuation purposes. The study addresses a relevant question since a substantial portion of investors still greatly relies on GAAP earnings and multiple-based valuations are now as before widely used by both sophisticated and non-sophisticated market participants. The insights from study two suggest that investors might optimize their investment strategies and use the various information sources in a more efficient and less costly way, depending on the complexity of the firm to value. In addition, I show that the warranted multiple approach is a robust and efficient valuation model, which by itself yields more accurate valuation estimates than relative valuations using industry or size matches. Hence, whether for portfolio management purposes or acquisition analyses, this study encourages the use of the 
warranted multiple approach to increase the accuracy of obtained valuation estimates and ultimately the efficiency of investments and capital allocation decisions.

The second study of this dissertation provides important contributions to the acquisition literature and, more importantly, the role of the target board of directors for valuations obtained in the course of an acquisition. Despite the central role of valuations underlying the target board's recommendation, evidence on the factors affecting these valuations is rather scarce. The findings in this chapter might be of special interest to shareholders and standard-setters. One of the main findings of the study is that the incentives of the board and the CEO are related to the imprecision of valuations in a fairness opinion, which in turn can trigger shareholder class action lawsuits. Hence, one suggestion to standard-setters might be to mandate and harmonize the disclosure of financial projections, which are used as primary inputs in fairness opinion valuations. To increase transparency and credibility of fairness opinion valuations, a more extensive and transparent discussion of the underlying factors responsible for the precision of valuation estimates is needed. Financial advisers and boards of directors should be more transparent about the financial projections underlying valuations and provide more information on the impact of various projections, valuation factors and assumptions on the precision of valuations disclosed in a fairness opinion.

The third study contributes to the body of research on financial advisers, i.e., investment banks in merger and acquisitions. The rise of independent and specialized investment banks, the so-called boutique advisers, has shaken up the M\&A landscape and, thus, challenges the traditional definition of reputation and quality of financial advisers. Considering the growing importance of and interest in boutique advisers, there is a need to for a more detailed understanding on the benefits of hiring a boutique adviser. The findings of this study should be of interest to the firms obtaining a fairness opinion and their shareholders given that fairness opinion fees are ultimately costs borne by shareholders. The results suggest that while boutique and bulge bracket advisers, on average, charge similar fees for a fairness opinion, the former tend to provide more precise valuations. Therefore, holding fairness opinion expenditures constant, firms can increase their return on investments in fairness opinions by hiring a boutique adviser and obtaining valuations that are more precise. This enhances our understanding on when the investment in fairness opinions actually pays off with regard to the precision of the valuation information disclosed by a fairness opinion provider. 

Samenvatting van het proefschrift 



\section{Samenvatting van het proefschrift}

De waardering van een onderneming ligt aan de basis van talrijke beslissingen, die alle variëren in omvang en impact. Aan de basis van al deze beslissingen ligt de poging om een nauwkeurige schatting van de waarde van een onderneming te verkrijgen. De waardering van een onderneming is echter een zeer complexe en uitdagende taak, omdat zij door vele factoren wordt beïnvloed, die het vaak moeilijk maken de intrinsieke waarde van een onderneming nauwkeurig te schatten. De nauwkeurigheid van een schatting van de waarde van een onderneming, en bijgevolg de kwaliteit van een investeringsbeslissing of overname, is niet alleen van belang voor diverse deelnemers aan de kapitaalmarkt, maar is ook van groot belang voor de economie in haar geheel. Daarom is het belangrijk onze kennis te blijven uitbreiden over wat de nauwkeurigheid en precisie van de waardering bepaalt, en hoe deze kan worden verbeterd.

In dit proefschrift onderzoek ik de relatie tussen de aard van de waarderingsinputs, kenmerken van ondernemingsbestuur en financiële adviseurs, en de precisie en nauwkeurigheid van waarderingsramingen. In de eerste studie onderzoek ik of de relatieve waarderingsbenadering verbetert als de financiële informatie van de tracking service I/B/ $\mathrm{E} / \mathrm{S}$ wordt gebruikt als de primaire waarderingsinput, in tegenstelling tot de door GAAP vereiste financiële gegevens. Daarom vergelijk ik de twee reeksen waarderingsinputs in het kader van de relatieve waardering. In de tweede en derde studie van dit proefschrift ligt de nadruk op waarderingen die worden verstrekt door financiële adviseurs in een fairness opinion, aangezien deze niet alleen relevant zijn voor de raad van bestuur, maar ook voor de doelaandeelhouders wanneer zij beslissen over het voorgestelde bod. In de tweede studie onderzoek ik in welke mate de kenmerken en incentives van het bestuur van een doelvennootschap de nauwkeurigheid van de waarderingen in een fairness opinie bepalen. Daarnaast onderzoek ik hoe aandeelhouders de bruikbaarheid van fairness opinions inschatten, zoals die tot uiting komt in collectieve rechtszaken van aandeelhouders. In de derde studie concentreer ik me op de rol van de reputatie en expertise van de verstrekkers van fairness opinies, namelijk financiële adviseurs. Ik onderzoek het verband tussen de expertise van adviseurs en de nauwkeurigheid van de waardering en de tijdigheid van de afronding van transacties.

Wat de rol van de waarderingsinputs (studie één) betreft, stel ik vast dat de straatwinst leidt tot een andere reeks van geselecteerde "peers" dan de GAAP, hetgeen niet verrassend is gezien de fundamentele verschillen in de afleiding van deze twee reeksen van winstcijfers. Deze verschillende selectie van vergelijkbare ondernemingen leidt echter niet automatisch tot een betere waardering op basis van vergelijkbare ondernemingen. Over het algemeen vind ik geen steun voor de relatieve superioriteit van "street peers" ten opzichte van "GAAP peers". Alleen wanneer er significant andere peers worden geselecteerd, presteren de op straatwinst gebaseerde multiples beter dan hun GAAPtegenhangers. Bovendien blijkt uit mijn bevindingen dat, terwijl het gebruik van straatwinsten het potentieel heeft om mispricing te identificeren, er geen dergelijk 
bewijs wordt gevonden in het geval van GAAP-winsten. De analyses tonen verder aan dat straatwinsten bijzonder superieur zijn in termen van waarderingsprestaties en identificatie van mispricing wanneer de doelondernemingen volatiel, R\&D-intensief of internationaal actief zijn. Ten slotte vind ik dat de peers die aan de hand van straatwinsten worden geïdentificeerd, beter vergelijkbaar zijn met de doelonderneming dan peers die aan de hand van GAAP-getallen worden geïdentificeerd.

Met betrekking tot de kenmerken en motieven van de raad van bestuur van een doelonderneming (studie twee), vind ik dat bedrijfsspecifieke kennis en motieven van de raad van bestuur sterke voorspellers zijn van de nauwkeurigheid van fairness opinion waarderingen. Het is met name de bedrijfsspecifieke kennis van de raad die cruciaal is voor de nauwkeurigheid van de waarderingen. Bovendien vind ik dat niet alleen de kennis van de raad van bestuur de nauwkeurigheid van een fairness opinion beïnvloedt, maar ook de financiële stimulansen van de raad van bestuur en de CEO om de deal te voltooien. Ik vind ook dat deze financiële prikkels sterk bepalend zijn voor de eerlijkheid van een fairness opinie. Een andere belangrijke bevinding van deze studie is dat de waarderingseigenschappen in een fairness opinie van belang zijn voor de aandeelhouders van het doelwit. Ik vind dat aandeelhouders die het doelwit zijn van een transactie eerder geneigd zijn om collectieve rechtszaken aan te spannen die specifiek gericht zijn tegen fairness opinies indien deze onnauwkeurig of oneerlijk zijn. Dit suggereert dat doelaandeelhouders fairness opinions gebruiken om te beslissen over hun biedingsbeslissingen, en dat zij waarderingskenmerken in overweging nemen bij het beoordelen van de bruikbaarheid van een fairness opinion.

De resultaten van studie drie tonen aan dat de reputatie en expertise van financiële adviseurs ook een belangrijke rol spelen voor de nauwkeurigheid van waarderingen. Ik stel vast dat boutique adviseurs nauwkeuriger fairness opinion-waarderingen geven dan hun tegenhangers. De recente populariteit van boutique advisers lijkt gerechtvaardigd te zijn wat de nauwkeurigheid van hun waarderingsramingen betreft. In het algemeen stel ik vast dat adviseurs die reeds banden hebben met de overnemer minder nauwkeurige waarderingen geven, maar dat het omgekeerde waar is voor de boutique advisers. $\mathrm{Zij}$ zijn geneigd preciezere waarderingen te geven als ze al banden hebben met de overnemer, mogelijk om hun kansen te vergroten dat de overnemer hen in de toekomst opnieuw aanwerft. Een andere belangrijke bevinding van de studie is dat waarderingskenmerken niet alleen geassocieerd zijn met collectieve rechtszaken van aandeelhouders, maar ook met de algemene beoordeling door aandeelhouders van de bruikbaarheid van fairness opinions. Mijn bevindingen tonen aan dat minder nauwkeurige fairness opinions de voltooiing van het overnamebod vertragen. Dit suggereert dat aandeelhouders van een doelwit meer tijd nodig hebben om te beslissen of ze hun aandelen willen aanbieden als een fairness opinion minder nauwkeurige waarderamingen bevat. Al bij al toont mijn studie aan dat doelwitondernemingen voordeel halen uit het inhuren van boutique adviseurs, aangezien zij in een fairness opinion nauwkeuriger waarderingen geven, wat op zijn beurt een tijdige afronding van de deal vergemakkelijkt. 
De resultaten van de eerste studie dragen bij tot het onderzoek naar de rol van alternatieve prestatiemaatstaven, met name straatwinsten, voor prognose- en waarderingsdoeleinden. De studie behandelt een relevante vraag aangezien een aanzienlijk deel van de beleggers nog steeds sterk vertrouwt op de GAAP-winst en op multiple gebaseerde waarderingen nu net als vroeger op grote schaal worden gebruikt door zowel geavanceerde als nietgeavanceerde marktdeelnemers. De inzichten uit studie twee suggereren dat investeerders hun investeringsstrategieën zouden kunnen optimaliseren en de verschillende informatiebronnen op een efficiëntere en minder dure manier zouden kunnen gebruiken, afhankelijk van de complexiteit van het te waarderen bedrijf. Bovendien toon ik aan dat de warranted multiple benadering een robuust en efficiënt waarderingsmodel is, dat op zichzelf meer accurate waarderingsschattingen oplevert dan relatieve waarderingen die gebruik maken van industrie- of grootte-matches. Of het nu gaat om portefeuillebeheer of overnameanalyses, deze studie moedigt het gebruik van de warranted multiple benadering aan om de nauwkeurigheid van de verkregen waarderingsramingen te verhogen en uiteindelijk de efficiëntie van investeringen en kapitaalallocatiebeslissingen.

De tweede studie van dit proefschrift levert belangrijke bijdragen tot de overnameliteratuur en, belangrijker nog, tot de rol van de raad van bestuur van het doelwit voor waarderingen die in de loop van een overname worden verkregen. Ondanks de centrale rol van waarderingen die ten grondslag liggen aan de aanbeveling van de raad van bestuur van het doelwit, is bewijsmateriaal over de factoren die deze waarderingen beïnvloeden eerder schaars. De bevindingen in dit hoofdstuk kunnen van bijzonder belang zijn voor aandeelhouders en normbepalers. Een van de belangrijkste bevindingen van de studie is dat de stimulansen van de raad van bestuur en de CEO verband houden met de onnauwkeurigheid van de waarderingen in een fairness opinie, die op haar beurt aanleiding kan geven tot collectieve rechtszaken van aandeelhouders. Daarom zou een suggestie aan de normstellers kunnen zijn om de openbaarmaking van financiële projecties, die als primaire input worden gebruikt in de waarderingen van fairness opinions, verplicht te stellen en te harmoniseren. Om de transparantie en geloofwaardigheid van fairness opinion-waarderingen te vergroten, is een uitgebreidere en transparantere bespreking nodig van de onderliggende factoren die verantwoordelijk zijn voor de nauwkeurigheid van waarderingsramingen. Financiële adviseurs en raden van bestuur zouden transparanter moeten zijn over de financiële projecties die aan de waarderingen ten grondslag liggen en meer informatie moeten verstrekken over de impact van verschillende projecties, waarderingsfactoren en veronderstellingen op de nauwkeurigheid van de in een fairness opinion bekendgemaakte waarderingen.

De derde studie draagt bij tot het corpus van onderzoek over financiële adviseurs, d.w.z. investeringsbanken bij fusies en overnames. De opkomst van onafhankelijke en gespecialiseerde investeringsbanken, de zogenaamde boutique advisers, heeft het fusie- en overnamelandschap door elkaar geschud en stelt bijgevolg de traditionele definitie van reputatie en kwaliteit van financiële adviseurs op de proef. Gezien het groeiende belang van en de groeiende belangstelling voor boutique advisers, is er nood 
aan een meer gedetailleerd inzicht in de voordelen van het inhuren van een boutique adviser. De bevindingen van deze studie zouden van belang moeten zijn voor de ondernemingen die een fairness opinion aanvragen en hun aandeelhouders, aangezien de honoraria voor fairness opinions uiteindelijk kosten zijn die door de aandeelhouders worden gedragen. De resultaten suggereren dat, terwijl boutique en bulge bracket adviseurs gemiddeld vergelijkbare vergoedingen vragen voor een fairness opinion, de eerstgenoemde de neiging hebben om nauwkeuriger waarderingen te geven. Bijgevolg kunnen ondernemingen, wanneer de uitgaven voor fairness opinions constant blijven, hun rendement op investeringen in fairness opinions verhogen door een boutique adviseur in te huren en preciezere waarderingen te verkrijgen. Dit vergroot ons inzicht in wanneer de investering in fairness opinions werkelijk loont met betrekking tot de nauwkeurigheid van de waarderingsinformatie die door een aanbieder van fairness opinions wordt bekendgemaakt. 
Curriculum Vitae 



\section{Curriculum Vitae}

Olga Ihl-Deviv'e was born on April 9, 1991 in Kerch, Ukraine. In 2014, she received her Bachelor of Science degree from Maastricht University, where she studied International Business. During her bachelor studies, she spent a semester abroad at Singapore Management University. After completion of her bachelor studies, Olga did a six months traineeship in the controlling department at Robert Bosch in Munich. Following the traineeship, she completed her Master studies at Maastricht University, where she obtained her Master of Science degree in International Business (specialization accountancy) in 2016.

Subsequently she joined the Department of Accounting and Information Management at Maastricht University as a $\mathrm{PhD}$ student. During her doctoral studies, she was a visiting $\mathrm{PhD}$ student at the Kenan-Flagler Business School, the University of North Carolina at Chapel Hill (U.S.). She presented her research at workshops at Maastricht University, Lancaster University and University of Amsterdam, and at several international conferences, such as the Financial Accounting and Reporting Section (FARS) in Nashville in 2020, the European Accounting Association (EAA) Doctoral Colloquium and conference in Milan in 2018, the XIII International Accounting Symposium in Madrid in 2017, and the Emerging Researchers Consortium in Accounting in Bolzano in 2017.

As of March 2021, Olga holds an assistant professor position at the Department of Accounting and Finance at the Open University in Heerlen. 
